\title{
Gene expression profiling in prepubertal and adult male mice using cDNA and oligonucleotide microarrays
}

Lisa Marie Tomascik-Cheeseman
West Virginia University

Follow this and additional works at: https://researchrepository.wvu.edu/etd

\section{Recommended Citation}

Tomascik-Cheeseman, Lisa Marie, "Gene expression profiling in prepubertal and adult male mice using cDNA and oligonucleotide microarrays" (2003). Graduate Theses, Dissertations, and Problem Reports. 1844.

https://researchrepository.wvu.edu/etd/1844

This Dissertation is protected by copyright and/or related rights. It has been brought to you by the The Research Repository @ WVU with permission from the rights-holder(s). You are free to use this Dissertation in any way that is permitted by the copyright and related rights legislation that applies to your use. For other uses you must obtain permission from the rights-holder(s) directly, unless additional rights are indicated by a Creative Commons license in the record and/ or on the work itself. This Dissertation has been accepted for inclusion in WVU Graduate Theses, Dissertations, and Problem Reports collection by an authorized administrator of The Research Repository @ WVU.

For more information, please contact researchrepository@mail.wvu.edu. 


\title{
GENE EXPRESSION PROFILING IN
}

PREPUBERTAL AND ADULT MALE MICE USING

\section{CDNA AND OLIGONUCLEOTIDE MICROARRAYS}

\author{
Lisa Marie Tomascik-Cheeseman
}
Dissertation submitted to the Genetics and Developmental Biology Program, College of Agriculture, Forestry, and Consumer Sciences, at West Virginia University in partial fulfillment of the requirements
for the degree of

\author{
Doctor of Philosophy \\ in \\ Genetics
}

\author{
Joginder Nath, Ph.D., Co-Chair \\ Andrew J. Wyrobek, Ph.D., Co-Chair \\ Walter Kaczmarczyk, Ph.D. \\ Daniel Panaccione, Ph.D. \\ Sharon Wenger, Ph.D.
}

Morgantown, West Virginia

2003 


\section{Abstract \\ GENE EXPRESSION PROFILING IN PREPUBERTAL AND ADULT MALE MICE USING CDNA AND OLIGONUCLEOTIDE MICROARRAYS}

\section{Lisa Marie Tomascik-Cheeseman}

Variations in gene expression are the basis of differences in cell and tissue function, response to DNA damaging agents, susceptibility to genetic disease, and cellular differentiation. The purpose of this dissertation research was to characterize variation in basal gene expression among adult mouse tissues for selected stress response, DNA repair and damage control genes and to utilize variation in temporal gene expression patterns to identify candidate genes associated with germ cell differentiation from mitosis through meiosis in the prepubertal mouse testis. To accomplish these goals, high throughput analyses of gene expression were performed using custom cDNA and random oligonucleotide microarrays. cDNA microarray technology was optimized by evaluating the effects of multiple hybridization and image analysis methodologies on the magnitude of background-subtracted hybridization signal intensities. The results showed that hybridizing lower probe quantities in a buffer developed at Lawrence Livermore National Laboratory to tryptone-blocked microarrays improved signal intensities. In addition, the error in expression ratio measurements was significantly reduced when microarray images were preprocessed. A custom cDNA microarray comprised of 417 genes and enriched for stress response, DNA repair, and damage control genes was used to investigate basal gene expression differences among adult mouse testis, brain, liver, spleen, and heart. Genes with functions related to stress response exhibited the most variation in expression among tissues whereas DNA repair-associated gene expression varied the least. Random oligonucleotide microarrays comprised of $\sim 10,000$ genes were 
used to profile changes in gene expression during the first wave of spermatogenesis in the prepubertal mouse testis. Approximately 550 genes were differentially expressed as male germ cells differentiated from spermatogonia to primary spermatocytes. These findings suggest that the 313 unannotated sequences and 178 genes with known functions in other biological pathways have spermatogenesis-associated roles. This dissertation research showed that microarrays are a useful tool for quantitating the expression of large numbers of genes in parallel under normal physiological conditions and during differentiation. It has also provided candidate genes for future investigations of the molecular mechanisms underlying (1) tissue-specific DNA damage response and genetic disease susceptibility and (2) cellular differentiation during the onset and progression of spermatogenesis. 
This dissertation is dedicated to my husband, Matthew, for his advice, encouragement, and (most of all) love. Thank you for giving me the courage to dream.

This work is also dedicated to my parents, Thomas and Carol Tomascik, and to my grandmother, Sophie Duzen in honor of their tireless love and support. In memory of my grandfather, Andrew Duzen. 


\section{Table of Contents}

$\begin{array}{lr}\text { Abstract } & \text { ii } \\ \text { Acknowledgements } & \text { vii } \\ \text { List of Tables } & \text { viii } \\ \text { List of Figures } & \text { X } \\ \text { List of Abbreviations } & \text { xii }\end{array}$

Chapter 1. Introduction 1

Dissertation Objectives $\quad 4$

\section{Chapter 2. Expression Microarray Technology}

Chapter Overview 10

Section 2.1 Fluorescent expression microarray technology review

2.1.1 Introduction 11

2.1.2 Types of Expression Microarrays 13

2.1.3 Probe Generation, Hybridization, and Image Captus 14

2.1.4 Microarray Data Acquisition and Analysis 20

2.1.5 Summary 21

2.1.6 References 22

Section 2.2 Optimization of two-color fluorescence cDNA

microarray hybridizations visualized with a white

light imaging system

2.2.1 Abstract 27

2.2.2 Introduction $\quad 27$

2.2.3 Materials and Methods 31

$\begin{array}{lll}2.2 .4 & \text { Results } & 37\end{array}$

2.2.5 Discussion 46

2.2.6 References $\quad 50$

Section 2.3 Accurate quantitation of fluorescence microarrays

2.3.1 Abstract 51

2.3.2 Introduction 51

2.3.3 Materials and Methods 53

2.3.4 Image Processing and Analysis Methods 58

$\begin{array}{lll}2.3 .5 & \text { Results } & 69\end{array}$

$\begin{array}{lll}2.3 .6 & \text { Conclusions } & 73\end{array}$

$\begin{array}{lll}2.3 .7 & \text { Auspices } & 74\end{array}$

$\begin{array}{lll}2.3 .8 & \text { References } & 75\end{array}$ 


\section{Chapter 3. Differential Basal Expression of Genes Associated}

with Stress Response, Damage Control, and DNA Repair Among Mouse Tissues

$\begin{array}{llr}3.1 & \text { Abstract } & 77 \\ 3.2 & \text { Introduction } & 78 \\ 3.3 & \text { Materials and Methods } & 80 \\ 3.4 & \text { Results } & 87 \\ 3.5 & \text { Discussion } & 100 \\ 3.6 & \text { Acknowledgements } & 106 \\ 3.7 & \text { References } & 107\end{array}$

Chapter 4. Mitotic and Meiotic Gene Expression Profiling of Male Germ Cells

4.1 Abstract 114

4.2 Introduction $\quad 115$

4.3 Materials and Methods 117

$\begin{array}{lll}4.4 & \text { Results } & 121\end{array}$

4.5 Discussion 133

$\begin{array}{ll}4.6 & \text { Acknowledgements } \\ & 137\end{array}$

$\begin{array}{lll}4.7 & \text { References } & 138\end{array}$

Chapter 5. Conclusions 152

Appendices

A Symbols, names, biological pathways, I.M.A.G.E. clone IDs, and cDNA microarray data for 152 genes with differential expression among healthy adult mouse tissues

B All annotated genes showing significant differences in expression during the transition from mitosis to meiosis in the prepubertal mouse testis

C Unannotated sequences with significant expression differences during the first wave of spermatogenesis in the prepubertal mouse

D Functional genomics-related websites 173

$\begin{array}{lll}\text { E Curriculum Vitae } & 175\end{array}$

$\begin{array}{ll}\text { F } & 180\end{array}$ 


\section{Acknowledgements}

Dr. Joginder Nath, Academic Advisor and graduate committee Co-chair: Words can't express how thankful I am to have been your student. Your guidance has enabled me to grow both personally and professionally.

Dr. Andrew J. Wyrobek, Research Advisor and graduate committee Co-chair: I am so grateful for the opportunity to be a member of your laboratory. Thank you for constantly challenging me and always finding time for my research.

Dr. Walter Kaczmarczyk, Dr. Daniel Panaccione, and Dr. Sharon Wenger, graduate committee members: Thank you for reviewing the dissertation and providing valuable comments.

Past and present members of the Wyrobek laboratory: Thank you for the spirited scientific conversations and camaraderie. I would especially like to recognize:

Dr. Francesco Marchetti: I could never thank you enough for everything you have taught me. I will always cherish our friendship.

Eddie Sloter: I have enjoyed every discussion (scientific and otherwise). You have been a wonderful friend, and I cannot imagine what this experience would have been like without you.

Dr. Matthew A. Coleman: Thanks for always keeping me on task by asking, "Is that dissertation finished yet???" I admire your scientific insight and appreciate your friendship.

Francesca Hill: Thanks for sharing your cytogenetic expertise and friendship.

Nancy Wrigley: Thank you for the administrative assistance and motherly advice.

Dr. David O. Nelson and Shea Gardner: I am truly thankful for all of your assistance with the microarray statistical analyses.

Laura Mascio Kegelmeyer: Thanks for patiently teaching me everything I ever needed to know about UNIX systems. Perhaps more importantly, thank you for the afternoon tea.

The Tomascik and Cheeseman families: Your love and unwavering support has made this dream possible. I promise to get a REAL job...someday.

Dr. Sara Frias, Ana Claudia Velazquez-Wong, Doug and Linda Hamilton, and the Jackson family: I will never forget the laughter, smiles, and many words of encouragement. Thank you for your friendship. 


\section{List of Tables}

Chapter 2.

Page

\section{Expression Microarray Technology}

Section 2.2 Optimization of cDNA microarray hybridizations visualized with a Xenon light source

2.2.1 Primers used to amplify cDNA clones for the gene-specific hybridization experiments

2.2.2 Experimental design for the gene-specific and tissue sample hybridizations

2.2.3 Comparison of background-subtracted signal intensities obtained from gene-specific hybridizations

2.2.4 Characterization of the signal intensities obtained for each Alex Fluor following different tissue sample hybridization protocols

2.2.5 Relationship between tissue sample hybridization protocol and number of genes with signal intensity ratios, $\square 1.5$

Section 2.3 Accurate quantitation of fluorescence microarrays

2.3.1 Six genes were used to build a groundtruth series over ten microarray slides

2.3.2 Error measurements obtained for the groundtruth series

following different image analysis methods

\section{Chapter 3.}

Differential Basal Expression of Genes Associated with Stress Response, Damage Control, and DNA Repair Among Mouse Tissues

3.1 Differences in the gene expression ratios from replicate independent hybridization:

3.2 Distribution of $F$ ratios for differentially expressed genes with respect to biological pathway

3.3 Differentially expressed stress response, DNA repair, and damage control genes 


\section{Chapter 4.}

Mitotic and Meiotic Gene Expression Profiling of Male Germ Cells

4.1 Examples of genes with differential expression between mitosis and the onset of meiosis

4.2 Genes with significant differential expression between the onset and middle of meiosis I

4.3 Genes with complex patterns of differential expression from mitosis to mid-meiosis I 


\section{List of Figures}

Chapter 2.

Page

\section{Expression Microarray Technology}

Section 2.1 Fluorescent expression microarray technology review

2.1.1 Experimental outline for cDNA microarray hybridizations

15

2.1.2 Experimental outline for Affymetrix microarray hybridizations

Section 2.2 Optimization of cDNA microarray hybridizations visualized with a Xenon light source

2.2.1 Effect of hybridization buffer and slide blocking protocol on background-subtracted microarray signal intensities

2.2.2 Distribution of background-subtracted median signal intensities obtained for tissue sample hybridizations

Section 2.3 Accurate quantitation of fluorescence microarrays

2.3.1 A contrast-enhanced fluorescence microarray image with very high background

2.3.2 Removal of underlying autofluorescence and subsequent lowering of target spot intensities

2.3.3 Contours of hybridized target spots delineated by one of four segmentation methods

2.3.4 The groundtruth (ratio of known probe amounts) for Rad52 was tracked among 10 slides

\section{Chapter 3.}

Differential Basal Expression of Genes Associated with Stress Response, Damage Control, and DNA Repair Among Mouse Tissues

3.1 Intensity-based normalization of cDNA microarray data

3.2 Distribution of normalized expression ratios for testes vs. testes hybridizations

3.3 Distribution of gene expression results among tissues 93

3.4 Cluster analysis of genes using CLUSFAVOR

3.5 Comparison of northern blot and cDNA microarray results for selected genes 


\section{Chapter 4.}

Mitotic and Meiotic Gene Expression Profiling of Male Germ Cells

4.1 Germ cell progression through mouse spermatogenesis

122

4.2 Genes that were differentially expressed between mitosis and the onset of meiosis

124

4.3 Genes that were differentially expressed between the onset of meiosis and mid-meiosis I

4.4 Genes with complex patterns of differential expression from mitosis to mid-meiosis I

4.5 Examples of gene sub-clusters obtained using CLUSFAVOR 


\section{List of Abbreviations}

\begin{tabular}{ll} 
Abbreviation & Full name \\
AP & Apoptosis \\
BER & Base excision repair \\
bp & Base pair \\
CC & Cell cycle \\
cDNA & Complementary deoxyribonucleic acid \\
Cy3 & Cyanine 3 \\
Cy5 & Cyanine 5 \\
DAPI & 4 ',6-diamidino-2-phenylindole \\
DDR & Direct damage reversal \\
dNTP & Deoxyribose nucleoside triphosphate \\
d.p.c. & Days post-coitum \\
DSBR & Double strand break repair \\
EST & Expressed sequence tag \\
FITC & Kilobase pair \\
GS & Fawrescein isothiocyanate \\
HS & Generalized stress response \\
IVT & Heat shock response \\
MI & In vitro transcription \\
\hline &
\end{tabular}


MII

NER

p.n.

RT

OS

PC

SAGE

SDS

SSC
Meiosis II

Nucleotide excision repair

Postnatal

Reverse transcription

Oxidative stress response

Personal computer

Serial analysis of gene expression

Sodium dodecyl sulfate

Saline sodium citrate 


\section{Introduction}

Every cell contains the complete genetic code for an organism, yet cell morphologies and functions are biologically diverse. The morphological, biochemical, and physiological diversity of cells within an organism is attributable to differences in their history of gene expression during differentiation (Strachan and Read, 1999). The profile of genes transcribed in a differentiated cell includes (a) genes whose expression is

specific and required for a given cell type, (b) genes that are essential for general cell functions and are expressed in all cell types, and (c) genes that have tissue-specific functions but low levels of transcription are observed in all cell types (referred to as illegitimate expression; Strachan and Read, 1999). Understanding the variation in gene expression patterns among cells and tissues under normal physiological conditions and abnormal conditions (e.g., in response to genotoxic agents) is important for understanding cellular differentiation and function.

In 1961 Jacob and Monod reported that the expression of groups of genes in the bacterial operon is strictly coordinated. Expression studies up to the 1990s were typically limited to analyzing one or a small number of genes using techniques such as cell or tissue in situ hybridization, northern blot, RNA dot blot, etc. These low throughput investigations provided only limited insight on the molecular events underlying 
individual biological processes (e.g., cellular differentiation, cell cycle, DNA repair, etc.). However, these techniques are not able to simultaneously analyze the expression of the many genes involved in any complex biological process. The advent of new molecular capabilities, such as automated PCR, together with the exponential increase of publicly accessible genome sequence information has facilitated the development of high throughput methods for gene expression analysis (i.e., serial analysis of gene expression or SAGE, expression microarrays, and mRNA differential display). Through the use of these genome-scale techniques, it is possible to analyze the expression of several thousand genes in parallel.

SAGE and mRNA differential display are used to determine which sequences are differentially represented between two samples. This information is then used to determine gene identities using other molecular techniques (i.e., DNA sequencing) and bioinformatics approaches (e.g., pairwise comparisons of each newly determined sequence with the non-redundant sequence database available through the National Center for Biotechnology Information). Microarrays, on the other hand, analyze the differential expression of a set of known genes and/or unannotated sequences that are selected a priori. Expression microarrays can be customized to include only specific genes of interest. It is feasible to build custom microarrays to simultaneously study the expression of all genes involved in a given biological process (e.g., cell cycle, apoptosis, DNA repair, etc.). Alternatively, expression microarrays may contain random sets of genes that represent a variety of biological pathways. These random microarrays are useful for discovering new genes associated with a biological process or tissue pathology. 
A particularly promising application of both types of expression microarrays is the high throughput investigation of a broad range of biological questions in model organisms, such as the mouse. Microarray-based studies of tissues from model organisms promise to provide valuable insight on differential gene expression (a) under normal physiological conditions, (b) during development, (c) following exposure to genotoxic agents, and (d) during carcinogenesis. Although a genome-wide characterization of basal gene expression levels is necessary for a thorough understanding of the molecular mechanisms underlying tissue-specific differences in differentiation, response to DNA damaging conditions, and genetic disease susceptibility, the high throughput analysis of tissue-specific differences in basal gene expression has not been reported. Several laboratories, however, have started to examine global changes in gene expression in the mouse following exposure to genotoxic agents such as ionizing radiation (Amundson et al., 2001) and phencyclidine (Toyooka et al., 2002). Expression microarrays are also being utilized to profile transcriptional changes associated with various types of cancer (e.g., prostate cancer: Ho and Lau, 2002; breast cancer: Jiang et al., 2002; colon cancer: Zou et al., 2002; etc.).

Using expression microarrays, it is possible to obtain a more comprehensive evaluation of the sequential molecular changes that are correlated with cellular differentiation during development. The prepubertal mouse is an excellent model for studying the modulations in expression profiles that are associated with germ cell differentiation through the mitotic and meiotic phases of spermatogenesis. A characterization of gene expression across critical timepoints during spermatogenesis is essential for understanding the molecular mechanisms of meiosis (e.g., transition from 
spermatogonial mitosis to meiosis: Wolfes et al., 1989; synaptonemal complex assembly: Allen et al., 1996; meiotic cell division: Koji et al., 1992; etc.). Furthermore, a detailed characterization of the normal baseline events may help us understand the genetic causes of male infertility (e.g., meiotic arrest of primary spermatocytes: Bailis et al., 2000; genetic causes for infertility previously characterized as idiopathic), and the induction and transmission of mutations to offspring following paternal exposure to genotoxic agents (e.g., ethylnitrosourea: Russell et al., 1979; cyclophosphamide; Schimenti et al., 1997; ionizing radiation: Matsuda et al., 1985; etc.).

\section{Dissertation objectives}

The objectives of this dissertation research were to characterize the differential basal expression of stress response, damage control, and DNA repair genes among healthy mouse tissues and investigate differential gene expression during the differentiation of spermatogonia into meiotic cells. Our approach utilized both custom cDNA microarrays and random oligonucleotide microarrays that contain known genes with diverse biological functions (including stress response, DNA repair, apoptosis, cell cycle, cellular differentiation, etc.) as well as unannotated sequences that may represent novel genes.

The custom cDNA microarray technology used in the basal gene expression studies (Chapter 3) was first optimized for the accurate quantitation of expression ratios by evaluating different hybridization and image analysis techniques. Various microarray hybridization strategies were investigated to increase signal intensity and reduce 
background while maintaining hybridization specificity, including studies of the effects of (a) fluorescent probe quantity, (b) hybridization buffer composition, and (c) selection of slide blocking reagent. To provide accurate quantitation of hybridization signals, the microarray image capture system was calibrated by hybridizing a dilution series to the microarray and evaluating the following methods: (a) target spot segmentation, (b) quantitation, (c) background subtraction, (d) preprocessing, and (e) normalization. This work helped determine the optimal experimental conditions for accurately evaluating differential gene expression in subsequent biological studies.

The first biological objective of this dissertation research was to investigate the differential expression of stress response, damage control, and DNA repair genes among healthy adult mouse tissues using the optimized custom cDNA microarrays (Chapter 3). After assessing its reproducibility and precision, the cDNA microarray technology was used to (a) compare and contrast gene expression profiles among testis, brain, liver, spleen, and heart and (b) evaluate the differential tissue expression of genes with respect to their functions in different biological pathways. Microarray expression ratio measurements were compared with northern blot expression ratio measurements for selected genes in order to validate the microarray data. By characterizing in vivo differences in the baseline expression of stress response, damage control, and/or DNA repair-associated genes, this research provides insight on tissue-specific differences in the basal levels of cellular resources immediately available for responding to and processing DNA damage.

The second biological objective of this dissertation research was to investigate the temporal changes in gene expression that are associated with progressive stages of 
cellular differentiation in the seminiferous tubules as germ cells proceed from mitotic spermatogonia to meiotic pachytene spermatocytes (Chapter 4). Random expression microarrays, which contain a diverse representation of known (annotated) genes and unannotated sequences, were used to establish gene expression profiles at specific times in this differentiation pathway (during spermatogonial mitosis, at the onset of meiosis, during mid-prophase of meiosis I (MI), and in the adult mouse to compare the first wave of spermatogenesis with full spermatogenesis). These profiles were compared in order to identify both annotated and novel genes whose expression was coordinately up- or downregulated as germ cells differentiated through spermatogenesis. This specific research provides insight on the molecular mechanisms responsible for the onset and progression of meiosis and may also contribute to our understanding of the genetic causes of male infertility and the paternal transmission of mutations to offspring.

\section{References}

Allen, J.W., Dix, D.J., Collins, B.W., Merrick, B.A., He, C., Selkirk, J.K., PoormanAllen, P., Dresser, M.E., and Eddy, E.M. (1996). HSP70-2 is part of the synaptonemal complex in mouse and hamster spermatocytes. Chromosoma 104, 414-21.

Amundson, S.A., Bittner, M., Meltzer, P., Trent, J., and Fornace, A.J. (2001). Induction of gene expression as a monitor of exposure to ionizing radiation. Radiat. Res. 156, 657661. 
Bailis, J.M., Smith, A.V., and Roeder, G.S. (2000). Bypass of a meiotic checkpoint by overproduction of meiotic chromosomal proteins. Mol. Cell. Biol. 20, 4838-48.

Ho, S.M. and Lau, K.M. (2002). DNA microarrays in prostate cancer. Curr. Urol. Rep. 3, 53-60.

Jacob, F. and Monod, J. (1961). Genetic regulatory mechanisms in the synthesis of proteins. J. Mol. Biol. 3, 318-56.

Jiang, Y., Harlocker, S.L., Molesh, D.A., Dillon, D.C., Stolk, J.A., Houghton, R.L., Repasky, E.A., Badaro, R., Reed, S.G., and Xu, J. (2002). Discovery of differentially expressed genes in human breast cancer using subtracted cDNA libraries and cDNA microarrays. Oncogene 21, 2270-82.

Koji, T., Jinno, A., Matsushime, H., Shibuya, M., and Nakane, P.K. (1992). In situ localization of male germ cell-associated kinase (mak) mRNA in adult mouse testis: specific expression in germ cells at stages around meiotic cell division. Cell. Biochem. Funct. 10, 273-9.

Matsuda, Y., Tobari, I., and Yamada, T. (1985). Studies on chromosome aberrations in the eggs of mice fertilized after irradiation. II. Chromosome aberrations induced in mature oocytes and fertilized eggs at the pronuclear stage following X-irradiation. Mutat. Res. 151, 275-80. 
Niehrs, C. and Pollet, N. (1999). Synexpression groups in eukaryotes. Nature 204, 4837.

Russell, W.L., Kelly, E.M., Hunsicker, P.R., Bangham, J.W., Maddux, S.C., and Phipps, E.L. (1979). Specific-locus test shows ethylnitrosourea to be the most potent mutagen in the mouse. Proc. Natl. Acad. Sci. USA 76, 5818-9.

Schimenti, K.J., Hanneman, W.H., and Schimenti, J.C. (1997). Evidence for cyclophosphamide-induced gene conversion and mutation in mouse germ cells. Toxicol. Appl. Pharmacol. 147, 343-50.

Strachan, T. and Read, A.P. (1999). RNA transcription and gene expression. Human Molecular Genetics. 2nd Ed. New York: Wiley-Liss. pp. 9-14.

Toyooka, K., Usui, M., Washiyama, K., Kumanishi, T., and Takahashi, Y. (2002). Gene expression profiles in the brain from phencyclidine-treated mouse by using DNA microarray. Ann. N.Y. Acad. Sci. 965, 10-20.

Wolfes, H., Kogawa, K., Millette, C.F., and Cooper, G.M. (1989). Specific expression of nuclear proto-oncogenes before entry into meiotic prophase of spermatogenesis. Science 245, 740-3. 
Zou, T.T., Selaru, F.M., Xu, Y., Shustova, V., Yin, J., Mori, Y., Shibata, D., Sato, F., Wang, S., Olaru, A., Deacu, E., Liu, T.C., Abraham, J.M., and Meltzer, S.J. (2002). Application of cDNA microarrays to generate a molecular taxonomy capable of distinguishing between colon cancer and normal colon. Oncogene 21, 4855-62. 


\section{Expression Microarray Technology}

\section{Chapter Overview}

This chapter reviews the development and application of expression microarray technology (Section 2.1), discusses the optimization of cDNA microarray hybridizations for improved background-subtracted signal intensities (Section 2.2), and examines the effects of image acquisition and analysis on expression ratio measurements (Section 2.3). After determining the best methods for accurately quantitating expression ratios from fluorescent cDNA microarrays visualized using a white light image capture system, this research will be applied to the study of differential basal gene expression levels among healthy adult mouse tissues (Chapter 3). 


\subsection{Fluorescent expression microarray technology review}

\subsubsection{Introduction}

Historically, gene expression studies have involved analyzing the expression of one gene, or a small number of genes, at a time. Over the past decade, the rapid incorporation of genome sequence information into publicly available databases, such as the National Center for Biotechnology Information's (NCBI) Entrez Nucleotide Query (http://www.ncbi.nlm.nih.gov/Entrez/nucleotide.html) has facilitated the development of a new generation of high throughput methods for studying gene expression on a genomewide scale, including serial analysis of gene expression (SAGE), PCR-based technologies (e.g., mRNA differential display), and expression microarrays. SAGE and the PCR-based technologies first identify transcripts that are differentially represented between experimental groups (i.e., cell or tissue samples) and then rely on downstream methods for gene identification and expression ratio quantitation. Microarrays quantitate the expression for up to tens of thousands of annotated genes or unannotated sequences that have been selected a priori for representation on the array.

To analyze gene expression using microarrays (transcript profiling), RNA is extracted from cells or tissue samples, fluorescently or radioactively labeled, and hybridized to a solid support that has been spotted with DNA (complementary DNA or oligonucleotide sequences) representing the genes of interest. Images of the hybridized array are captured, by either a white light system or a laser scanner, and the spot intensities are measured and then compared between samples in order to obtain gene expression ratios. Detailed descriptions of (a) the types of expression microarrays, (b) 
probe generation, hybridization, and visualization, and (c) microarray data acquisition and analysis are contained in sections 2.1.2, 2.1.3, and 2.1.4, respectively.

The first microarray-based experiments were described by Schena et al. (1995) who applied complementary DNA (cDNA) microarray technology to the study of differential expression among 45 Arabidopsis genes. Using a dual color fluorescence in situ hybridization scheme, Arabidopsis mRNA was reverse transcribed in the presence of either fluorescein or lissamine and was hybridized to a microarray comprised of 96 targets (replicate spotting of 45 Arabidopsis cDNAs and 3 negative control cDNAs). This study showed that (1) fluorescently labeled probes could be hybridized to immobilized target cDNA with high specificity and (2) the differential expression of multiple genes could be quantitated in parallel, even for genes with low abundance transcripts.

Since their development in the mid-1990s, microarrays have become an increasingly popular tool for the analysis of differential gene expression. From January 2001 to January 2002 alone, over 900 microarray-related articles were indexed in PubMed, the database for biomedical literature sponsored by NCBI (http://www.ncbi.nlm.nih.gov/ entrez/query.fcgi?db=PubMed). This technology has been used to address a broad range of research questions, including those related to (a) cancer (Khan et al., 1999) and other genetic diseases (e.g., Fragile X syndrome: Brown et al., 2001; Type 1 diabetes: Eaves et al., 2002); (b) host-pathogen interactions (e.g., comparative analysis of respiratory pathogens: Diehn and Relman, 2001; Yersinia enterocolitica infection: Sauvonnet et al., 2002); (c) environmental and/or occupational exposures (Bartosiewicz et al., 2001); (d) development (Tanaka et al., 2000); (e) aging 
(Weindruch et al., 2001); (f) behavior (Dent et al., 2001); (g) reproduction (e.g., Liu et al., 2001); and (h) pharmacology (e.g., therapeutic response: Chang et al., 2002; drug metabolism: Gerhold et al., 2001; drug discovery: Debouck and Goodfellow, 1999). Because this technology is easily adapted for studying any organism for which genome sequence information is available, it has been used to profile expression in diverse organisms including prokaryotes such as Escherichia coli (Oh and Liao, 2000), Pseudomonas aeruginosa (Ichikawa et al., 2000), and Staphylococcus aureus (Dunman et al., 2001) as well as lower eukaryotic organisms (e.g., Saccharomyces cerevisiae: Spellman et al., 1998). Expression microarrays have also been widely applied to the study of higher eukaryotes, including plants (e.g., Arabidopsis: Seki et al., 2001; loblolly pine: Whetten et al., 2001) and animals (e.g., mouse: Rockett et al., 2001; rat: Guo et al., 2000; and human: Schena et al., 1996).

\subsubsection{Types of expression microarrays}

Based on the type of "target" nucleotide sequence that is immobilized on the solid support (i.e., glass microscope slide or onto a nylon filter supported by a glass slide), there are two broad classifications of expression microarrays: cDNA or oligonucleotide. cDNA microarrays are generated by immobilizing expressed sequence tag (EST)-derived cDNA clones that are usually $\sim 100 \mathrm{bp}$ to $2 \mathrm{~kb}$ in size. Oligonucleotide microarrays are generated by immobilizing or synthesizing identified nucleotide sequences of approximately $25-100 \mathrm{bp}$ in length that are unique to the transcript for the gene of interest. 
cDNA and oligonucleotide microarrays are both generated by robotically arraying DNA sequences that represent the genes of interest directly onto the solid support. However, oligonucleotide microarrays have also been constructed by synthesizing DNA sequences directly on the solid support through processes such as photolithography (e.g., Affymetrix Expression Microarrays, Affymetrix, Inc., Santa Clara, CA).

\subsubsection{Probe generation, hybridization, and image capture}

Although specific protocols differ among laboratories, the overall experimental approaches for probe generation, hybridization, and visualization are generally very similar and include isolation of total RNA or mRNA, cDNA synthesis with fluorescent dye or radioactive label incorporation, hybridization (including pre-hybridization slide blocking, probe binding, and post-hybridization washes), and image capture. Figures 1 and 2 are schematic representations of the probe generation, hybridization, and visualization protocols used in our laboratory for the cDNA microarray study in Chapter 3 and the Affymetrix oligonucleotide microarray study in Chapter 4, respectively.

\section{Probe generation}

To generate probes for hybridization to the microarray, either total RNA or mRNA is isolated from cells or tissues and subsequently labeled with fluorophoreconjugated or radioactively-labeled dNTPs. Commonly, total RNA is isolated using guanidine isothiocyanate and phenol, and mRNA is isolated using an oligo-dT cellulose column [the polyA(+) tails of the mRNA bind to the oligo-dTs]. Microarray probes are 
A. Isolation of reference sample total RNA or mRNA

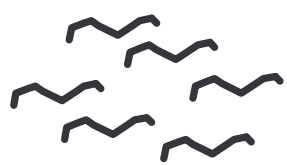

1

B.
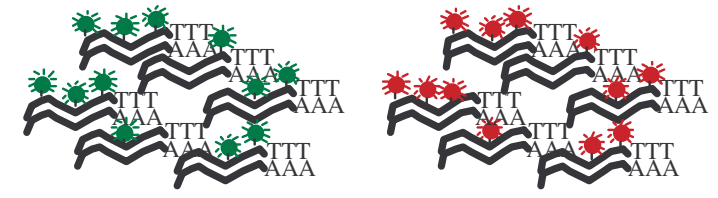

C.<smiles>[CH]1[CH]C1</smiles>

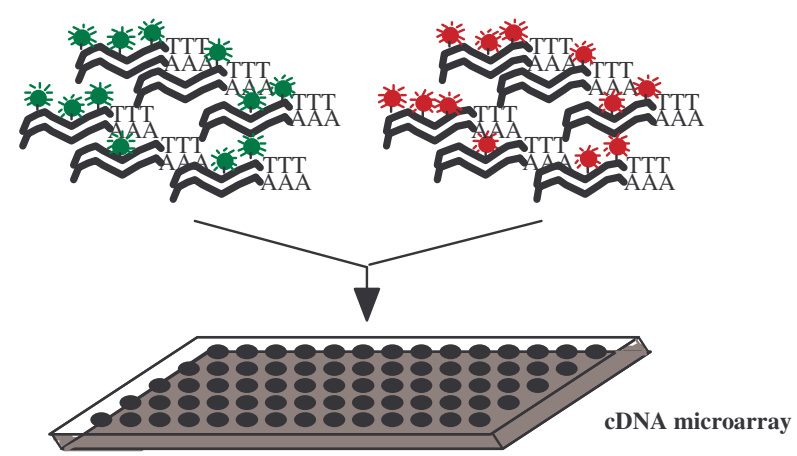

1

D.

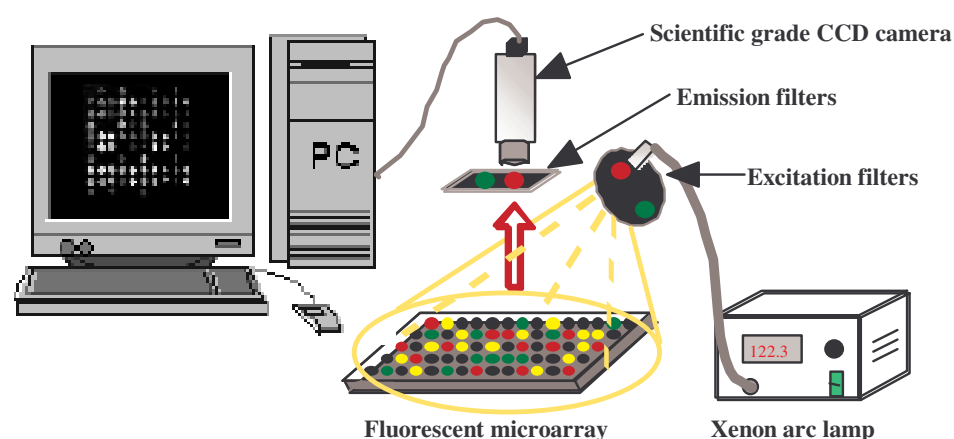

Figure 2.1.1. Experimental outline for cDNA microarray hybridizations. (A) Total RNA or mRNA is isolated from the cell or tissue source of interest. (B) Oligo-(dT) and an RNase $\mathrm{H}^{-}$reverse transcriptase are used to incorporate fluorophoreconjugated dUTPs into $1^{\text {st }}$ strand cDNA. (C) The two pools of labeled cDNA are cohybridized onto the microarray. (D) Images of the hybridized array are captured using a white light imaging system. 
A. Isolation of total RNA or mRNA

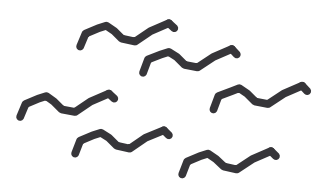

F. Image capture by laser scanner

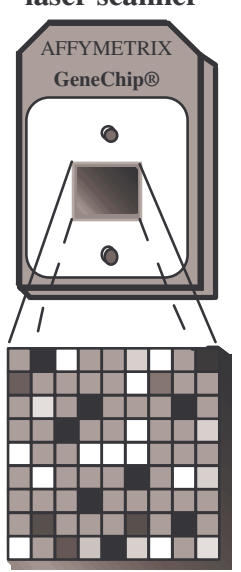

B. $\quad$ 1st \& 2nd strand cDNA synthesis

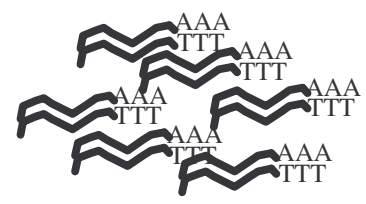

E. Hybridization \& staining with streptavidin-phycoerythrin conjugate

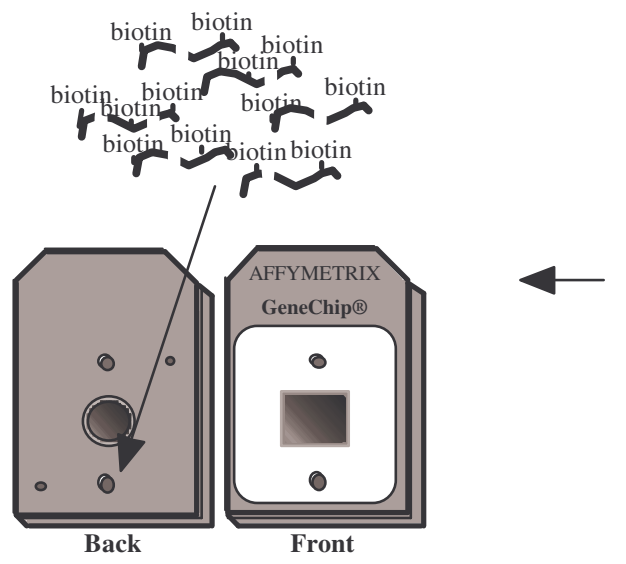

C. In vitro transcription (IVT) and incorporation of biotin-UTP \& biotin-CTP

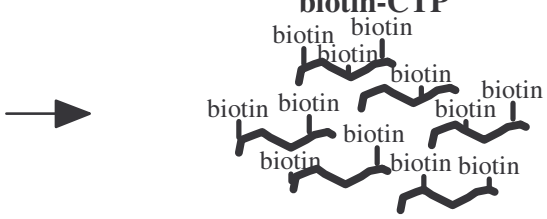

1

D.

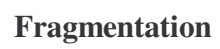

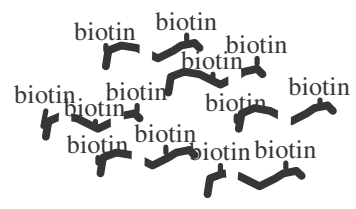

Figure 2.1.2. Experimental outline for Affymetrix oligonucleotide microarray hybridizations. (A) Total RNA or mRNA is isolated from the cell or tissue source of interest. (B) T7- $(\mathrm{dT})_{24}$ oligomer and an Rnase $\mathrm{H}^{-}$reverse transcriptase are used to generate $1^{\text {st }}$ strand cDNA. DNA polymerase I and DNA ligase are used in the presence of RNase $\mathrm{H}$ for $2^{\text {nd }}$ strand cDNA synthesis. (C) T7 RNA polymerase is used to transcribe RNA in vitro while simultaneously incorporating biotin labeled UTPs and CTPs. (D) Transcribed RNA is fragmented in a magnesium acetate/ potassium acetate buffer. (E) Fragmented sequences are hybridized to the Affymetrix oligonucleotide expression arrays, and the hybridized sequences are stained with a streptavidin-phycoerythrin conjugate. (F) Images of the hybridized array are captured using a laser scanner. 
labeled by incorporating fluorophore-conjugated dUTPs or dCTPs during either reverse transcription or nick translation. (Although radioactive labels have been used for nylonbased microarrays, most commercial and non-commercial microarray systems involve the hybridization of fluorescently labeled probes to glass slides. Therefore, this review focuses primarily on fluorescent microarray hybridizations.)

Probe generation techniques vary depending on the cell- or tissue-type or size of the tissue sample. Total RNA is usually isolated from smaller samples in order to prevent the loss of mRNA. In addition the isolated RNA may need to be linearly amplified through in vitro transcription in order to obtain enough RNA for hybridization to the microarray. The type of array being hybridized (cDNA or oligonucleotide) also contributes to variation in probe generation techniques between laboratories. For oligonucleotide microarrays, the probes must be fragmented prior to hybridization, but this step is not necessary for cDNA microarray hybridizations. Also, the characteristics of the microarray imaging system (e.g., wavelengths of the excitation and emission filters) must be matched to the type of fluorophore to be incorporated into the probe.

\section{Hybridization}

Typically, all microarray probe hybridization protocols include: a slide blocking procedure (which reduces non-specific binding of the fluorescently labeled probe mixture to areas outside of the arrayed spots); use of a special hybridization buffer; and posthybridization washing techniques to further reduce non-specific probe binding.

Several reagents have been found to prevent the non-specific binding of the probes to the glass slide during in situ hybridizations (e.g., ammonium hydroxide, bovine 
serum albumin, tryptone, acetic anhydride, etc.). In our experience, selection of the appropriate blocking reagent for microarray experiments depends upon the system used for image capture because the magnitude of the background intensity is directly affected by the combination of blocking reagent, excitation source (i.e., white light or laser), and excitation/emission filters.

Microarray hybridization stringency is determined by the combination of hybridization buffer, the length of time for hybridization, and hybridization temperature. More specifically, the composition of the hybridization buffer directly affects the length of time and temperature of the hybridization. The presence of large polymers (e.g., dextran sulfate) in the buffer increases the rate of reassociation and therefore decreases the length of time necessary for hybridization. The environmental temperature required for hybridization is also affected by whether or not the buffer contains formamide. The presence of formamide increases the effective hybridization temperature, (calculated as the environmental temperature $+0.4-0.6$ times the $\%$ formamide), and, therefore, is usually determined prior to hybridization in order to maintain the correct level of hybridization stringency (i.e., allows the probe to hybridize, but prevents non-specific probe hybridization). Additional information on the optimization of fluorescent cDNA microarray hybridizations is contained in Section 2.2.

Post-hybridization washes usually involve using sodium phosphate buffers (i.e., $\mathrm{PN}$ ), saline sodium citrate (SSC), and/or DNase-free water to remove excess probe and non-specific probe hybridization. In general, we have found it preferable to have high stringency hybridizations so that less rigorous washing procedures (which may affect the intensity of the fluorescently-labeled probe and, therefore, also lower the dynamic range 
and ultimately affect expression ratio quantitation) are required. The concentrations of the wash solutions as well as the temperature of the washes are inversely dependent upon the stringency of the hybridization (i.e., the higher the hybridization stringency, the lower the wash stringency and vice versa).

\section{Image capture}

Following hybridization, the fluorescent microarray images are visualized using either a white light system or a laser scanner. White light systems are easily adapted for imaging a broad range of fluorophores, including those detected in the UV bandwidth. However, laser scanners are most commonly used for image capture because they avoid data analysis problems associated with non-uniform illumination. In addition, laser scanners are able to provide better resolution than the white light systems ( $\sim \mu \mathrm{m}$ vs. $\sim 15 \mu \mathrm{m})$.

Our white light image capture system (Figure 1D; Kegelmeyer et al., 2001) utilizes light $(400 \mathrm{~nm}-600 \mathrm{~nm})$ from a source such as a Xenon arc lamp. The light is usually scrambled through a fiber optic cable and passed through excitation and emission filters appropriate for the fluorophore used to label the probe. The emitted light is captured by a scientific grade CCD camera connected to a personal computer (PC). The PC controls the camera and collects the microarray images for analysis. Integration time and gain can be adjusted by the user during image capture in order to maximize the signal without pixel saturation.

Laser image capture systems sequentially scan hybridized arrays with focused gas

lasers (Application note from Packard Bioscience Company, Meriden, CT; 
http://www.packardbioscience.com/reference_matl/827.asp). Briefly, the laser is reflected from a beamsplitter through an objective lens and onto the microarray. The resulting fluorescence is converted into parallel beams that travel back through the beamsplitter and through an emission filter to a detector lens. The detector lens focuses the beam onto the detector for image capture.

\subsubsection{Microarray data acquisition and analysis}

After capturing the microarray images, data acquisition and analysis software is used to extract signal intensity data from the images and generate expression ratios. A large number of microarray data acquisition and analysis software packages are currently available (e.g., ImaGene from Biodiscovery, Inc., Marina del Ray, CA and QuantArray from Packard Bioscience Company). Most acquisition and analysis software allows the user to select from a variety of parameters including methods for quantitation, color correction (for dual color hybridizations), background subtraction, normalization, and sample-to-sample or slide-to-slide comparisons. The selection of specific software varies depending upon the type of microarray (cDNA or oligonucleotide), imaging system, and computer platforms (i.e., PC, Macintosh, or UNIX) utilized. Consideration must also be given to the type of downstream analysis to be performed so that the formatted microarray data can be easily uploaded into bioinformatics databases, such as those for hierarchial clustering (e.g., CLUSFAVOR: Peterson, 2002), promoter analysis (e.g., PromoterInspector by Genomatix: Scherf et al., 2000), and biological pathway analysis (e.g., GenMAPP: Dahlquist et al., 2002). Furthermore, the design of microarray 
experiments is critical (i.e., number of experimental groups; number of replicates per group; type of data analysis; selection of data to be reported in the literature and/or in public databases; and the type of downstream analysis). There are useful recommendations given by the Microarray Gene Expression Data Group (http://www.mged.org/ or http://industry.ebi.ac.uk/ alan/MicroArray/), which continues to revise its guidelines based on input from the scientific community.

\subsubsection{Summary}

Although they have undeniably become a prominent tool in biological research since their first description in 1995, expression microarray technology varies greatly among laboratories (different: types of microarrays, probe generation and hybridization techniques, image capture systems, and data analysis methods) and the field continues to mature. Standards for conducting microarray experiments, as well as analyzing and reporting the voluminous data, are constantly being debated and revised. However, because this technology is maturing in concordance with a rapid increase in the amount of publicly accessible genome sequence information for both prokaryotic and eukaryotic organisms, it is expected that microarray (and related genome-scale technologies) usage will be even more prevalent in the future. 


\subsubsection{References}

Bartosiewicz, M., Penn, S., and Buckpitt, A. (2001). Applications of gene arrays in environmental toxicology: fingerprints of gene regulation associated with cadmium chloride, benzo(a)pyrene, and trichloroethylene. Environ. Health Perspect. 109, 71-4.

Brown, V., Jin, P., Ceman, S., Darnell, J.C., O’Donnell, W.T., Tenenbaum, S.A., Jin, X., Feng, Y., Wilkinson, K.D., Keene, J.D., Darnell, R.B., and Warren, S.T. (2001). Microarray identification of FMRP-associated brain mRNAs and altered mRNA translational profiles in fragile X syndrome. Cell 107, 477-87.

Chang, B.D., Swift, M.E., Shen, M., Fang, J., Broude, E.V., and Roninson, I.B. (2002). Molecular determinants of terminal growth arrest induced in tumor cells by a chemotherapeutic agent. Proc. Natl. Acad. Sci. USA 99, 389-94.

Dahlquist, K.D., Salomonis, N., Vranizan, K., Lawlor, S.C., and Conklin, B.R. (2002). GenMAPP, a new tool for viewing and analyzing microarray data on biological pathways. Nat. Genet. 31, 19-20.

Debouck, C. and Goodfellow, P.N. (1999). DNA microarrays in drug discovery and development. Nat. Genet. 21(1 Suppl), 38-41. 
Dent, G.W., O’Dell, D.M., and Eberwine, J.H. (2001). Gene expression profiling in the amygdala: an approach to examine the molecular substrates of mammalian behavior. Physiol. Behav. 73, 841-7.

Diehn, M. and Relman, D.A. (2001). Comparing functional genomic datasets: lessons from DNA microarray analyses of host-pathogen interactions. Curr. Opin. Microbiol. 4, 95-101.

Dunman, P.M., Murphy, E., Haney, S., Palacios, D., Tucker-Kellogg, G., Wu, S., Brown, E.L., Zagursky, R.J., Shlaes, D., and Projan, S.J. (2001). Transcription profiling-based identification of Staphylococcus aureus genes regulated by the agr and/or sarA loci. J. Bacteriol. 183, 7341-53.

Eaves, I.A., Wicker, L.S., Ghandour, G., Lyons, P.A., Peterson, L.B., Todd, J.A., and Glynne, R.J. (2002). Combining mouse congenic strains and microarray gene expression analyses to study a complex trait: the NOD model of type 1 diabetes. Genome Res. 12, $232-43$.

Gerhold, D., Lu, M., Xu, J., Austin, C., Caskey, C.T., and Rushmore, T. (2001). Monitoring expression of genes involved in drug metabolism and toxicology using DNA microarrays. Physiol. Genomics 5, 161-70. 
Guo, Q.M., Malek, R.L., Kim, S., Chiao, C., He, M., Ruffy, M., Sanka, K., Lee, N.H., Dang, C.V., and Liu, E.T. (2000). Identification of c-myc responsive genes using rat cDNA microarray. Cancer Res. 60, 5922-8.

Ichikawa, J.K., Norris, A., Bangera, M.G., Geiss, G.K., van't Wout, A.B., Bumgarner, R.E., and Lory, S. (2000). Interaction of Pseudomonas aeruginosa with epithelial cells: identification of differentially regulated genes by expression microarray analysis of human cDNAs. Proc. Natl. Acad. Sci. USA 97, 9659-64.

Kegelmeyer, L.M., Tomascik-Cheeseman, L., Burnett, M.S., van Hummelen, P., and Wyrobek, A.J. (2001). A groundtruth approach to accurate quantitation of fluorescence microarrays. SPIE Proceed. 4266, 35-45.

Khan, J., Saal, L.H., Bittner, M.L., Chen, Y., Trent, J.M., and Meltzer, P.S. (1999). Expression profiling in cancer using cDNA microarrays. Electrophoresis 20, 223-9.

Liu, H.C., He, Z., and Rosenwaks, Z. (2001). Application of complementary DNA microarray (DNA chip) technology in the study of gene expression profiles during folliculogenesis. Fertil. Steril. 75, 947-55.

Oh, M.K. and Liao, J.C. (2000). Gene expression profiling by DNA microarrays and metabolic fluxes in Escherichia coli. Biotechnol. Prog. 16, 278-86. 
Peterson, L.E. (2002). Factor analysis of cluster-specific gene expression levels from cDNA microarrays. Comput. Methods Programs Biomed. In press.

Rockett, J.C., Luft, C.J., Garges, B.J., Krawetz, S.A., Hughes, M.R., Kirn, H.K., Oudes, A.J., and Dix, D.J. (2001). Development of a 950-gene DNA array for examining gene expression patterns in mouse testis. Genome Biol. 2, 0014.1-0014.9.

Sauvonnet, N., Pradet-Balade, B., Garcia-Sanz, J.A., and Cornelis, G.R. (2002). Regulation of mRNA expression in macrophages following Yersinia enterocolitica infection: role of different Yop effectors. J. Biol. Chem. In press.

Schena, M., Shalon, D., Davis, R.W., and Brown, P.O. (1995). Quantitative monitoring of gene expression patterns with a complementary DNA microarray. Science 270, 46770.

Schena, M., Shalon, D., Heller, R., Chai, A., Brown, P.O., and Davis, R.W. (1996). Parallel human genome analysis: microarray-based expression monitoring of 1000 genes. Proc. Natl. Acad. Sci. USA 93, 10614-9.

Scherf, M., Klingenhoff, A., and Werner, T. (2000). Highly specific localization of promoter regions in large genomic sequences by PromoterInspector: a novel context analysis approach. J. Mol. Biol. 297, 599-606. 
Seki, M., Narusaka, M., Abe, H., Kasuga, M., Yamaguchi-Shinozaki, K., Carninci, P., Hayashizaki, Y., and Shinozaki, K. (2001). Monitoring the expression pattern of 1300 Arabidopsis genes under drought and cold stresses by using a full-length cDNA microarray. Plant Cell 13, 61-72.

Spellman, P.T., Sherlock, G., Zhang, M.Q., Iyer, V.R., Anders, K., Eisen, M.B., Brown, P.O., Botstein, D., and Futcher, B. (1998). Comprehensive identification of cell cycleregulated genes of the yeast Saccharomyces cerevisiae by microarray hybridization. Mol. Biol. Cell 9, 3273-97.

Tanaka, T.S., Jaradat, S.A., Lim, M.K., Kargul, G.J., Wang, X., Grahovac, M.J., Pantano, S., Sano, Y., Piao, Y., Nagaraja, R., Doi, H., Wood, W.H., Becker, K.G., and Ko, M.S. (2000). Genome-wide expression profiling of mid-gestation placenta and embryo using a 15,000 mouse developmental cDNA microarray. Proc. Natl. Acad. Sci. USA 97, 912732.

Weindruch, R., Kayo, T., Lee, C.K., and Prolla, T.A. (2001). Microarray profiling of gene expression in aging and its alteration by caloric restriction in mice. J. Nutr. 131, 918S-23.

Whetten, R., Sun, Y.H., Zhang, Y., and Sederoff, R. (2001). Functional genomics and cell wall biosynthesis in loblolly pine. Plant Mol. Biol. 47, 275-91. 


\subsection{Optimization of two-color fluorescence cDNA microarray hybridizations visualized with a white light imaging system}

\subsubsection{Abstract}

The major parameters that affect the quantitation and interpretation of gene expression from cDNA microarrays are microarray quality, probe preparation, hybridization conditions, image capture, and methods of analysis. This research focused on the technological development of microarray hybridization strategies to increase signal intensity while decreasing background. Specifically, gene-specific and tissue sample probes were hybridized to cDNA microarrays to evaluate the effects of probe quantity ( $25 \mu \mathrm{g}$ vs. $50 \mu \mathrm{g}$ ), hybridization buffer (commercial vs. LLNL formulas), and slide blocking procedure (ammonium hydroxide vs. tryptone) on hybridization signal intensities. The results show that improved signal intensities were obtained when lower probe amounts were hybridized in a buffer comprised of $42 \%$ formamide / 2 x SSC / 10\% dextran sulfate to microarrays blocked with $0.25 \%$ tryptone in water. These conditions were applied to the study of differential basal expression levels among mouse tissues which is described in Chapter 3.

\subsubsection{Introduction}

Maximizing signal to background ratios is critical for obtaining accurate measurements of gene expression from cDNA microarrays. The magnitude of the signal 
remaining after background subtraction is dependent upon several factors, including the quality of (a) the microarray (e.g., no inherent defects in the solid support and no degradation of target DNA spots), (b) the probe (e.g., efficient fluorophore incorporation and prevention of photobleaching), (c) the hybridization (e.g., correct hybridization stringency and blocking of non-specific probe binding), (d) the image capture system (e.g., use of fluorophore-appropriate, narrow bandpass excitation and emission filters and the ability to measure differences in exposure time between samples), and (e) the data acquisition software (e.g., ability to account for: the measured exposure differences, nonuniform illumination, spectral crosstalk, etc.).

Two major aspects of microarray fabrication, preparation of the solid support and preparation of the target spot cDNA, can affect background and must be controlled to obtain accurate gene expression measurements. To accomplish this in our experiments, the glass microscope slides used as the solid supports (a) were rigorously cleaned using concentrated acids such as HCL and $\mathrm{H}_{2} \mathrm{SO}_{4}$; (b) had a uniform distribution of the chemical used for cDNA attachment to the solid support (e.g., poly-L-lysine or aminopropyltrimethoxysilane); and (c) were inspected immediately prior to spotting to ensure that the area to be arrayed is free of chips or cracks. Additionally, the cDNA to be spotted onto the array was placed in buffers that facilitated cDNA attachment without compromising cDNA integrity (e.g., sodium carbonate/bicarbonate) and arrayed under environmental conditions (i.e., temperature and humidity) that allowed the spots to dry quickly without spreading into neighboring spots.

Probe quality has a large impact on signal to background ratios and, therefore, also on the accurate quantitation of expression. In our experiments, fluorescently labeled 
probes were generated by incorporating both unlabeled dNTPs and fluorophoreconjugated dUTPs or dCTPs during a reverse transcription reaction. The appropriate balance of labeled and unlabeled dNTPs had to be determined, because if too many fluorophore-conjugated dNTPs were incorporated in succession, the reverse transcriptase could stall and fall off of the transcript. Irrespective of the dNTP that was selected, the fluorophores have a substantial effect on the signal to background ratios. The most common fluorescent dyes currently used for microarray experiments are the Cyanine dyes (Cy3 and Cy5) and the Alexa Fluor dyes (Alexa Fluors 488 and 546). Initially, the Cy dyes were used for microarray experiments due to the limited wavelengths available for laser scanners. However, white light imaging systems (and a few recently developed laser scanners) are capable of detecting a broad range of fluorophores, including the Alexa Fluor dyes. We found that the Alexa Fluor 488 and 546 dyes (which have excitation and emission spectra similar to FITC and $\mathrm{Cy} 3$, respectively) were preferable to the Cy dyes because they are brighter, more photostable, and less sensitive to alterations in $\mathrm{pH}$. Also, when used for dual color hybridizations, these Alexa Fluor dyes have less spectral overlap with each other compared to Cy3 and Cy5. Regardless of the fluorophore selected, the use of antifades typically provided better signal to background ratios because they preserve signal intensity by preventing photobleaching during the image capture procedure. Unfortunately, antifades can only be used when images are captured by white light imaging system because laser scanners require dry slides.

Hybridization strategies (e.g., increasing probe concentration and the rate of DNA reassociation by the addition of large polymers such as dextran sulfate and polyethylene glycol; Wetmur, 1971) also have a significant impact on signal to background ratios. 
Stringent hybridization conditions are critical for accurate expression ratio measurements because they increase probe binding while reducing non-specific probe hybridization. In our experiments, stringency was optimized by matching the probe hybridization buffer with hybridization temperature and time conditions. This required the use of the proper combinations of formamide (which increases the effective hybridization temperature; Miesfeld, 1999) and salt concentration (which stabilizes the hybridized probe; Strachan and Read, 1999) for a given hybridization temperature and time.

To obtain accurate gene expression information from microarray images using a white light image capture system, we ensured that the excitation and emission filters had narrow, non-overlapping bandpasses (to circumvent/reduce spectral cross-talk) with wavelengths that were suitable for the excitation and emission spectra of the fluorophore used in probe labeling. For additional information, see Section 2.3 "Accurate quantitation of fluorescence microarrays". Improvements to background-subtracted signal intensities were also made in our experiments by correcting for camera dark noise, non-uniform illumination, spectral cross-talk, and integration time differences. In addition, the selection of segmentation and quantitation methods was dependent upon the target spot shapes and the array grid layout (i.e., horizontal $\mathrm{x}$ vertical number of spots and their position within each row and column) as well as the area hybridized on individual spots (e.g., accurate measurements for irregularly shaped spots or spots that only hybridize along the edges). The selection of data acquisition software that included flexible background subtraction methods for hybridizations with either high or low background was also important for accurately measuring expression ratios. (See Section 2.3.). 
As described above, there are many parameters (and combinations of these parameters) that may affect the magnitude of background-subtracted microarray signal intensities. The purpose of this research was to develop cDNA microarray hybridization protocols that increased signal to background ratios by concurrently improving signal intensity and reducing background intensity. Probe quantity, hybridization buffer, and microarray slide blocking procedures were evaluated for hybridizations of gene-specific (simple) and/or tissue sample (complex) probes.

\subsubsection{Materials and Methods}

cDNA microarray preparation

Two custom cDNA microarrays were spotted: the microarray used for genespecific hybridizations was comprised of 72 genes (322 target spots) and the microarray used for the tissue sample hybridizations was comprised of 53 genes (252 target spots). For each gene, one to four cDNA clones were obtained from the I.M.A.G.E. Consortium at LLNL. Up to five lambda phage and bacterial sequences served as controls. Clones were PCR-amplified with 5'-C6 amino-modified vector-specific primers, purified on Qiagen purification columns (Qiagen Inc., Valencia, CA), ethanol precipitated, and resuspended in $0.1 \mathrm{M}$ sodium carbonate/bicarbonate $(\mathrm{pH}=10.2)$ for spotting onto the microarray slides.

The glass slides used for arraying were cleaned for $30 \mathrm{~min}$. in 1:1 concentrated hydrochloric acid:methanol, soaked overnight in concentrated sulfuric acid, and washed $10 \times 10 \mathrm{~min}$. in room temperature water and $1 \times 10 \mathrm{~min}$. in boiling water. Slides were 
then submerged in 1\% 3-aminopropyltrimethoxysilane (Sigma, St. Louis, MO) / 95\% acetone/ water for $2 \mathrm{~min}$., washed 10 x $5 \mathrm{~min}$. in acetone, and heated at $110^{\circ} \mathrm{C}$ for $45 \mathrm{~min}$. (Guo et al., 1994). Silane-coated slides were submerged in $0.2 \%$ 1,4-phenylene diisothiocyanate (Sigma), 10\% pyridine (Sigma) and dimethylformamide (Aldrich, Milwaukee, WI) for 2 hours, washed in methanol (2 x 10 min.) and acetone (2 x 10 min.), and air-dried. Target spots for both the gene-specific (simple) and tissue sample (complex) hybridizations were robotically arrayed (Norgren Systems, Palo Alto, CA) in duplicate with a $250 \mu \mathrm{m}$ center-to-center distance.

\section{Probe generation}

Gene-specific (simple) probes were generated for each of the following genes: Cdc2, Eif-4c, Lig1, Tp53, and Xrcc1. A cDNA clone representing each gene was obtained from the I.M.A.G.E. Consortium at LLNL and was PCR-amplified with genespecific primers designed using the Oligo v4.0 primer design software (National Biosciences, Inc., Plymouth, MN; Table 2.2.1). The expected amplicon sizes (range: $150-470 \mathrm{bp}$ ) were verified by electrophoresis on a $2 \%$ agarose gel. The quantity of each PCR-product was determined using the GeneQuant spectrophotometer (Amersham Pharmacia Biotech, Piscataway, NJ). To incorporate the fluorescent label (Alexa Fluor 488-dUTP for Cdc2 and Tp53; Alexa Fluor 546-dUTP for Eif-4c, Lig1, and Xrcc1; Molecular Probes Inc., Eugene, OR), $0.5 \mu \mathrm{g}$ of each product was nick translated using the Nick Translation System from Life Technologies (Rockville, MD). A master mixture containing all of the fluorescently labeled genes was prepared and then divided equally, 
Table 2.2.1. Primers used to amplify cDNA clones for the gene-specific hybridization experiments.

\begin{tabular}{|c|c|c|c|c|c|}
\hline Gene & Gene name & I.M.A.G.E. clone & Primers $\left(5^{\prime} \quad 3^{\prime}\right) \rightarrow$ & Estimated aı & n size (bp) \\
\hline & & & & Expected & Actual \\
\hline$C d c 2$ & Cell division cycle 2 & 763260 & $\begin{array}{l}\text { TTTGGAATACCGATACGAGT } \\
\text { CGACCAGCAGACAGGGACAT }\end{array}$ & 470 & 450 \\
\hline Eif-4c & Elongation initiation factor $4 \mathrm{C}$ & 959700 & $\begin{array}{l}\text { AAGAAGTCTGAAGGCCTATG } \\
\text { CAGAGAACTTGGAATGTAGC }\end{array}$ & 150 & 150 \\
\hline Lig1 & Ligase I & 605700 & $\begin{array}{l}\text { ATGCAAGCTGGGAACTGGATT } \\
\text { TGAACCGAGGAAAACGAAGAG }\end{array}$ & 250 & 230 \\
\hline Tp53 & Tumor suppressor protein 53 & 464741 & $\begin{array}{l}\text { AAGTGAAGCCCTCCGAGTGT } \\
\text { CCATAGTTGCCCTGGTAAGT }\end{array}$ & 150 & 150 \\
\hline Xrcc1 & X-ray repair complementing defective repair & 1022963 & $\begin{array}{l}\text { GACTGTCACCACATGCGGCG } \\
\text { GGCTGCCTTTGTTCCCTCTG }\end{array}$ & 350 & 300 \\
\hline
\end{tabular}


such that each slide was hybridized with $\sim 10$ ng of labeled DNA per gene. The labeled probes were co-purified on Qiagen columns (Qiagen, Inc.) and ethanol precipitated.

Tissue sample (complex) probes were generated by synthesizing first strand cDNA from 25-50 $\mu \mathrm{g}$ of adult mouse testis or brain total RNA (Clontech, Inc., Palo Alto, CA). Specifically, testis and brain total RNA were reverse transcribed at $42^{\circ} \mathrm{C}$ using an oligo-dT primer in the presence of Superscript II reverse transcriptase (Life Technologies). Testis and brain cDNA were labeled during the reverse transcription reaction by incorporation of Alexa Fluor 488-dUTPs and Alexa Fluor 546-dUTPs (Molecular Probes, Inc.), respectively. The labeled probes were co-purified on Qiagen columns (Qiagen, Inc.) and ethanol precipitated.

\section{Hybridization}

To prevent non-specific probe binding (and thereby reduce background intensity), slides were blocked prior to hybridization with ammonium hydroxide (Sigma, St. Louis, MO) or tryptone (Difco Laboratories, Detroit, MI). Slides blocked with ammonium hydroxide were incubated at room temperature in $1 \% \mathrm{NH}_{4} \mathrm{OH}$ in water for $10 \mathrm{~min}$., washed 3 x 10 min. in double distilled water, and air-dried. To block with $0.25 \%$ or $0.50 \%$ tryptone in water, the slides were submerged in the solution and agitated at 100 rpm for 1 hour and then immediately denatured. Regardless of the blocking procedure used, slides were denatured for 6 minutes in $70 \%$ formamide / $2 x S S C /$ water at $78^{\circ} \mathrm{C}$, passed through a 70\% / 85\% / 100\% ethanol series, and air-dried. An in situ frame (Eppendorf, Westbury, NY) was affixed to the slide in order to confine the probe mixture over the arrayed area. 
Table 2.2.2. Experimental design for the gene-specific and tissue sample hybridizations.

\begin{tabular}{|c|c|c|c|}
\hline $\begin{array}{c}\text { Hybridization } \\
\text { probe }\end{array}$ & Probe quantity $^{\mathrm{a}}$ & Hybridization buffer & Slide blocking reageı \\
\hline \multicolumn{4}{|l|}{ Gene-specific } \\
\hline & $50 \mathrm{ng}$ & Commercial $^{\mathrm{b}}$ & $1 \% \mathrm{NH}_{4} \mathrm{OH}^{\mathrm{b}}$ \\
\hline & $50 \mathrm{ng}$ & LLNL & $1 \% \mathrm{NH}_{4} \mathrm{OH}$ \\
\hline & $50 \mathrm{ng}$ & LLNL & $0.50 \%$ Tryptone \\
\hline & $50 \mathrm{ng}$ & LLNL & $0.25 \%$ Tryptone \\
\hline \multicolumn{4}{|l|}{ Tissue sample } \\
\hline & $50 \mu g^{b}$ & Commercial $^{\mathrm{b}}$ & $1 \% \mathrm{NH}_{4} \mathrm{OH}^{\mathrm{b}}$ \\
\hline & $25 \mu \mathrm{g}$ & Commercial $^{\mathrm{b}}$ & $1 \% \mathrm{NH}_{4} \mathrm{OH}$ \\
\hline & $50 \mu \mathrm{g}$ & LLNL & $0.50 \%$ Tryptone \\
\hline & $25 \mu \mathrm{g}$ & LLNL & $0.25 \%$ Tryptone \\
\hline
\end{tabular}

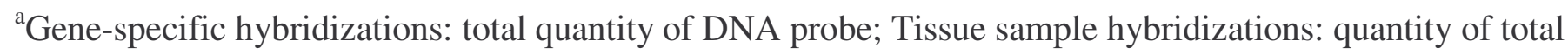
RNA used for probe generation

${ }^{\mathrm{b}}$ Probe quantity, hybridization buffer, and slide blocking reagent traditionally used in our laboratory for microarray hybridizations 
The specific combination of probe quantity, hybridization buffer, and slide blocking procedure used for each hybridization is shown in Table 2.2.2. For the genespecific hybridizations, each slide was hybridized with $15 \mu$ l of probe mixture $(10 \mu 1$ hybridization buffer $+1 \mu 1$ herring sperm DNA $+4 \mu$ l labeled probe resuspended in double distilled water). For the tissue-specific hybridizations, each slide was also hybridized with $15 \mu \mathrm{l}$ of probe mixture; however, the detergent SDS was added to promote probe movement across the array, and poly (A)+ (Amersham Pharmacia Biotech) as well as cot-1 mouse DNA (Life Technologies) were added to increase hybridization specificity. Both hybridization buffers contained formamide and were either commercially obtained (Vysis, Inc., Downers Grove, IL) or made at LLNL. The LLNL hybridization buffer was prepared by incubating $4.2 \mathrm{ml}$ of formamide, $1.05 \mathrm{ml}$ of $20 \mathrm{x} \mathrm{SSC}$, and $1 \mathrm{~g}$ of dextran sulfate overnight at $65^{\circ} \mathrm{C}$. Following incubation, water was added to bring the hybridization buffer volume to $7 \mathrm{ml}$. Probes prepared with the LLNL hybridization buffer had a $\mathrm{pH}=7.0$ and a final concentration of $42 \%$ formamide, $2 \mathrm{x}$ SSC, and $10 \%$ dextran sulfate.

All hybridization mixtures were denatured at $78^{\circ} \mathrm{C}$ for $6 \mathrm{~min}$. and snap-cooled on ice. Slides were hybridized for 12 hours in a gently rocking moist chamber at $37^{\circ} \mathrm{C}$ and washed 2 x $2 \mathrm{~min}$. in $42^{\circ} \mathrm{C}$ water. Prior to image capture, Vectashield mounting media (Vector Laboratories, Inc., Burlingame, CA) was placed over the arrayed area to prevent photobleaching. 
Image capture and analysis

Image capture and processing was performed as described by Kegelmeyer et al. (2001). Briefly, images were acquired with a full-field white light imaging system. Arrays were exposed to bandpass-filtered excitation light from a Xenon arc lamp. The resulting emitted light was bandpass-filtered and collected by a scientific-grade CCD camera. All images used for the gene-specific experiments were captured using comparable integration time and gain settings. This was also true for the set of tissue sample experiments. Custom algorithms, built within SCIL-Image (Delft, The Netherlands), corrected for CCD dark noise, spectral cross-talk, misaligned images and integration time variation. Additional processing algorithms determined the "segmentation mask" for each cDNA spot. The red and green intensities for all spots were computed by taking the median of all pixels within the segmentation mask that were greater than zero after background subtraction. Spots covered by debris were eliminated from all subsequent processing.

\subsubsection{Results}

Effects of hybridization buffer and slide blocking procedure on signal intensity for genespecific (simple probe) hybridizations

Five genes, labeled with either Alexa Fluor 488 or Alexa Fluor 546, were cohybridized to the 72 gene microarray to evaluate the effects of hybridization buffer and slide blocking on the background-subtracted median signal intensities. Figure 2.2.1 shows the median background-subtracted signal intensities ( \pm standard error for all target 


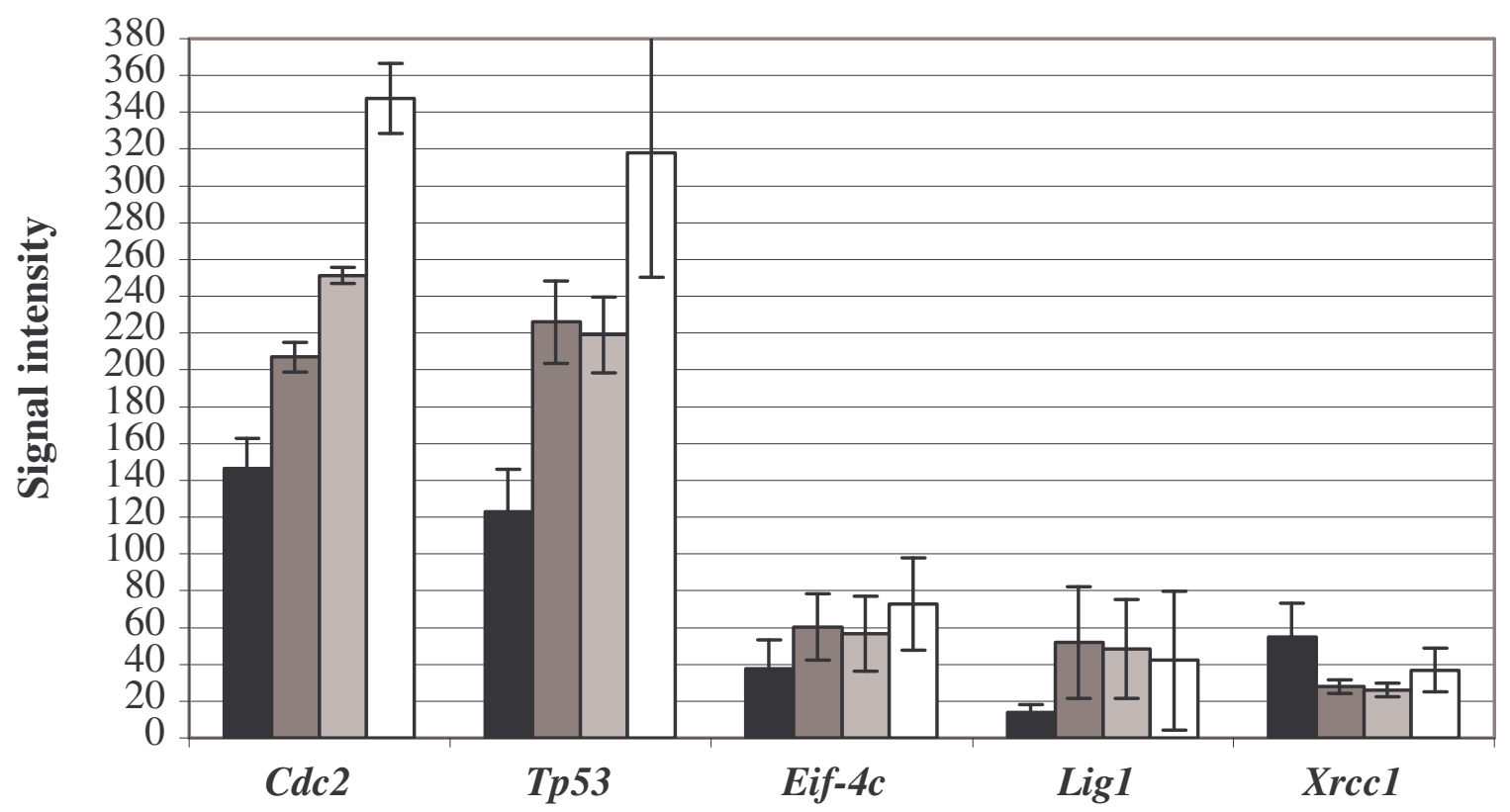

Figure 2.2.1. Effect of hybridization buffer and slide blocking protocol on background-subtracted microarray signal intensities obtained for the gene-specific probes. The $\mathrm{x}$-axis represents the genes selected for co-hybridization to the cDNA microarray. Cdc2 and Tp53 were labeled with Alexa Fluor 488. Eif-4c, Lig1, and Xrcc1 were labeled with Alexa Fluor 546. The y-axis represents the median background subtracted signal intensity. Each column represents a different combination of hybridization buffer and slide blocking protocol: black - commercial fluorescent probe hybridization buffer and $1 \%$ ammonium hydroxide blocking reagent; dark gray - LLNL hybridization buffer and 1\% ammonium hydroxide blocking reagent; light gray - LLNL hybridization buffer and $0.50 \%$ tryptone blocking reagent; and white - LLNL hybridization buffer and $0.25 \%$ tryptone blocking reagent. Bars represent the standard error among the replicate spots used to represent each gene. 
spots representing the gene of interest) obtained from each hybridization buffer and slide blocking combination listed in Table 2.2.2. The sum of the median intensities (calculated as all Alexa Fluor 488 probe intensities + all Alexa Fluor 546 probe intensities per hybridization condition) for the commercial buffer / 1\% $\mathrm{NH}_{4} \mathrm{OH}$, LLNL buffer / $1 \%$ $\mathrm{NH}_{4} \mathrm{OH}$, LLNL buffer / $0.50 \%$ tryptone, and LLNL buffer / $0.25 \%$ tryptone hybridization conditions were approximately $375,572,601$, and 817 , respectively. Based on the average intensity values (average Alexa Fluor 488 vs. average Alexa Fluor 546) within each set of hybridization conditions, probes labeled with Alex Fluor 488 had 3.8 to 6.6fold higher intensities than those labeled with Alexa Fluor 546.

To further compare the effects of hybridization buffer and slide blocking protocol on signal intensity, the percent increases in signal intensities, obtained after using different hybridization methods, were calculated (Table 2.2.3). The results showed that, irrespective of the blocking reagent utilized, the LLNL hybridization buffer yielded signal intensities that were $\sim 41$ to $275 \%$ higher than those obtained using the commercial hybridization buffer. Next, the effect of slide blocking reagent on signal intensity was determined for all slides hybridized using the LLNL buffer. From these comparisons, it was determined that the $0.50 \%$ tryptone and $1 \% \mathrm{NH}_{4} \mathrm{OH}$ reagents gave similar results and that use of the $0.25 \%$ tryptone blocking reagent resulted in signal intensities that were up to $\sim 45 \%$ higher than those from $0.50 \%$ tryptone-blocked slides and up to $\sim 68 \%$ higher than those from $1 \% \mathrm{NH}_{4} \mathrm{OH}$-blocked slides. Furthermore, signal intensities for both of the LLNL buffer/tryptone combinations ranged from $~ 51$ to $250 \%$ higher than those obtained using the commercial buffer / $1 \% \mathrm{NH}_{4} \mathrm{OH}$ hybridization procedure, with the exception of $\mathrm{Xrccl}$. 
Table 2.2.3. Comparison of background-subtracted signal intensities obtained from gene-specific hybridizations using different combinations of hybridization buffer and slide blocking reagent.

\begin{tabular}{|c|c|c|c|c|c|c|}
\hline \multirow[t]{3}{*}{ Genes } & \multicolumn{6}{|c|}{ Relative percent increase in signal intensity ${ }^{a}$} \\
\hline & \multirow{2}{*}{$\begin{array}{c}\text { Effect of hybridization } \text { buffer }^{\mathbf{b}} \\
\text { LLNL vs. Commercial }\end{array}$} & \multicolumn{3}{|c|}{ Effect of slide blocking reagent ${ }^{c}$} & \multicolumn{2}{|c|}{$\begin{array}{c}\text { Combined effect of hybridization buffer and slide } \\
\text { blocking reagent }\end{array}$} \\
\hline & & $\begin{array}{l}0.50 \% \text { tryptone } \\
\text { vs. } 1 \% \mathrm{NH}_{4} \mathrm{OH}\end{array}$ & $\begin{array}{l}0.25 \% \text { tryptone } \\
\text { vs. } 1 \% \mathrm{NH}_{4} \mathrm{OH}\end{array}$ & $\begin{array}{l}0.25 \% \text { tryptone vs. } \\
0.50 \% \text { tryptone }\end{array}$ & $\begin{array}{c}\text { (LLNL \& } 0.50 \% \text { tryptone) vs. } \\
\left(\text { Commercial \& } 1 \% \mathrm{NH}_{4} \mathrm{OH}\right)\end{array}$ & $\begin{array}{l}\text { (LLNL \& } 0.25 \% \text { tryptone) vs. } \\
\left(\text { Commercial \& } 1 \% \mathrm{NH}_{4} \mathrm{OH}\right)\end{array}$ \\
\hline$C d c 2$ & 41.3 & 21.4 & 67.9 & 38.3 & 71.5 & 137.2 \\
\hline Eif-4c & 60.8 & $\mathrm{NI}^{\mathrm{d}}$ & 20.7 & 28.8 & 50.7 & 94.1 \\
\hline Ligl & 275.4 & $\mathrm{NI}^{\mathrm{d}}$ & $\mathrm{NI}^{\mathrm{d}}$ & $\mathrm{NI}^{\mathrm{d}}$ & 250.0 & 204.3 \\
\hline$T p 53$ & 84.0 & $\mathrm{NI}^{\mathrm{d}}$ & 40.7 & 45.2 & 78.3 & 159.0 \\
\hline Xrccl & $\mathrm{NI}^{\mathrm{d}}$ & $\mathrm{NI}^{\mathrm{d}}$ & 32.4 & 41.5 & $\mathrm{NI}^{\mathrm{d}}$ & $\mathrm{NI}^{\mathrm{d}}$ \\
\hline
\end{tabular}

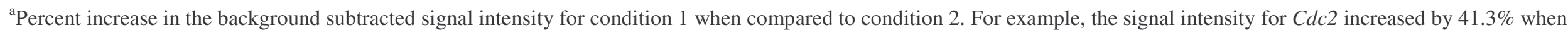
the LLNL hybridization buffer was used instead of the commercial hybridization buffer.

${ }^{\mathrm{b}}$ Slide blocking reagent: $1 \% \mathrm{NH}_{4} \mathrm{OH}$

${ }^{c}$ LLNL hybridization buffer. See Materials and Methods for details.

${ }^{\mathrm{d}} \mathrm{NI}=$ no increase in signal intensity was observed 
Effects of probe quantity, hybridization buffer, and slide blocking procedure on signal intensity for tissue sample (complex probe) hybridizations

Mouse tissue samples were labeled with either Alexa Fluor 488 (testis) or Alexa Fluor 546 (brain) and co-hybridized to the 53 gene microarray in order to evaluate the combined effects of probe quantity, hybridization buffer, and slide blocking protocol on the background-subtracted median signal intensities for complex probe hybridizations. As shown in Panel A of Figure 2.2.2, probe quantities of $25 \mu \mathrm{g}$ tended to yield higher Alexa Fluor 488 intensities, regardless of the hybridization buffer and slide blocking reagent utilized. However, the same trend was not observed for the Alexa Fluor 546 labeled probes (Panel B) which generally had the highest intensities when $25 \mu \mathrm{g}$ of probe was hybridized using the LLNL buffer to microarray slides blocked with $0.25 \%$ tryptone. The remaining three probe quantity / hybridization buffer / slide blocking reagent combinations had similar (lower) signal intensities.

As shown in Table 2.2.4, the maximum signal intensities obtained for Alexa Fluor 488 probes ranged from 50.3 for the $50 \mu \mathrm{g} /$ commercial buffer / $1 \% \mathrm{NH}_{4} \mathrm{OH}$ hybridization to 237.0 for the $25 \mu \mathrm{g}$ / LLNL buffer / $0.25 \%$ tryptone hybridization. Minimum signal intensities, however, were similar across all procedures (range: 9.0 to 15.5). In general, hybridizations using $25 \mu \mathrm{g}$ of probe had higher intensities than the 50 $\mu \mathrm{g}$ probe hybridizations. The highest and lowest average signal intensities were observed for the $25 \mu \mathrm{g} /$ commercial buffer / $1 \% \mathrm{NH}_{4} \mathrm{OH}$ hybridization (40.9) and the $50 \mu \mathrm{g} /$ LLNL buffer / $0.50 \%$ tryptone hybridization (14.2), respectively. In fact, the $25 \mu \mathrm{g} /$ commercial buffer / $1 \% \mathrm{NH}_{4} \mathrm{OH}$ protocol had even the highest signal intensity at the $75^{\text {th }}$ percentile. The maximum signal intensities for probes labeled with Alexa Fluor 546 
A.

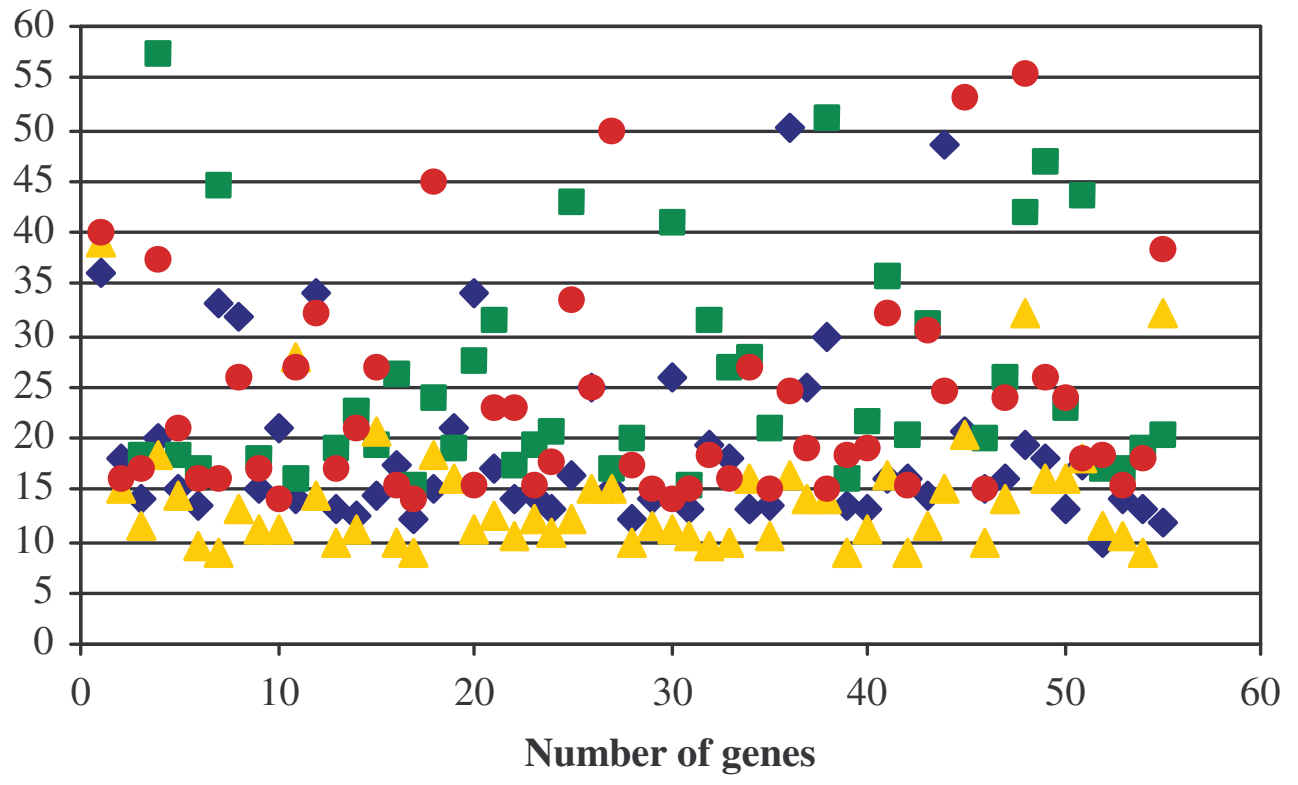

B.

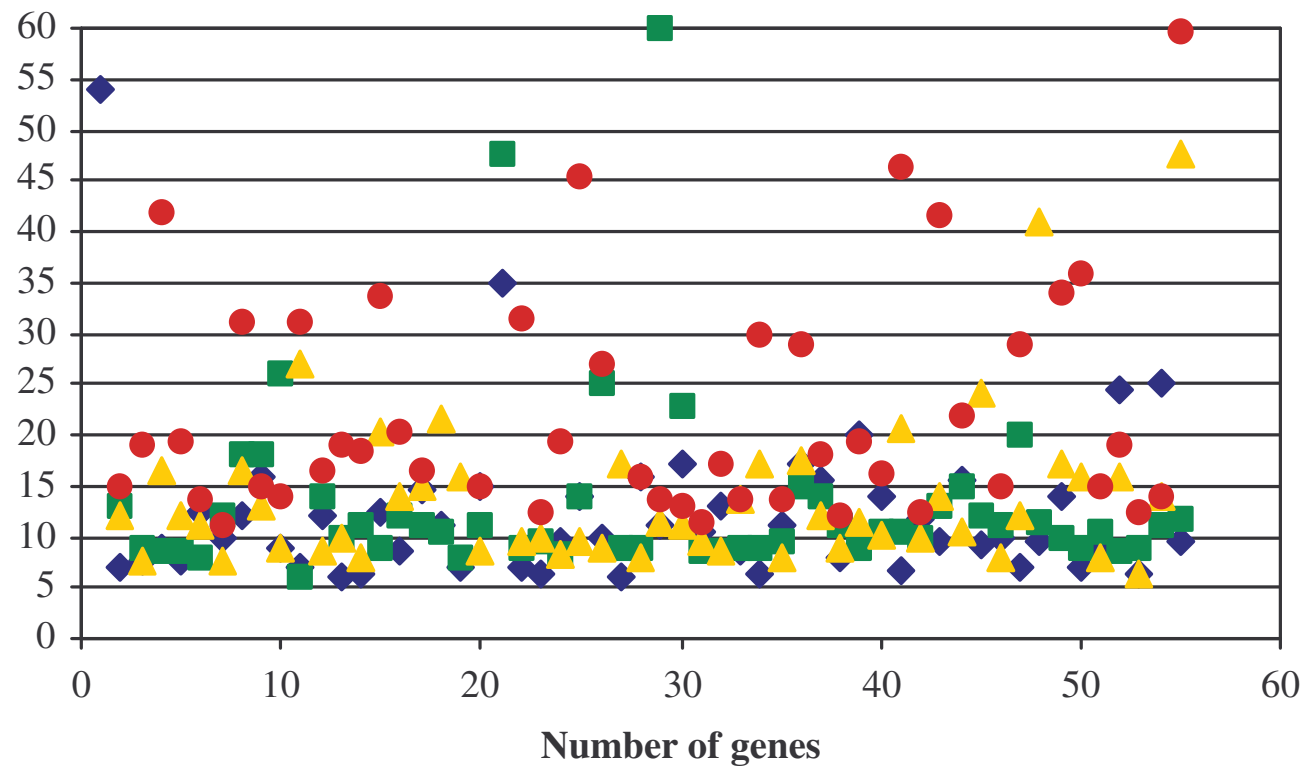

Figure 2.2.2. Distribution of backgroundsubtracted median signal intensities obtained for tissue sample hybridizations performed under different conditions. The $\mathrm{x}$-axis represents the number of genes evaluated. The y-axis represents the median background subtracted signal intensity. The combinations of probe quantity, hybridization buffer, and slide blocking protocol are represented as follows: blue diamond - $50 \mu \mathrm{g}$ probe / commercial buffer / $1 \% \mathrm{NH}_{4} \mathrm{OH}$ blocking reagent; green square $-25 \mu \mathrm{g}$ probe / commercial buffer / $1 \%$ $\mathrm{NH}_{4} \mathrm{OH}$ blocking reagent; yellow triangle -50 $\mu \mathrm{g}$ probe / LLNL buffer / $0.25 \%$ tryptone blocking reagent; and red circle $-25 \mu \mathrm{g}$ probe / LLNL buffer / $0.25 \%$ tryptone blocking reagent. A.) Distribution of Alexa Fluor 488 intensities. B.) Distribution of Alexa Fluor 546 intensities. 
Table 2.2.4. Characterization of the signal intensities obtained for each Alexa Fluor following different tissue sample hybridization protocols.

Signal intensity distributions

\begin{tabular}{|c|c|c|c|}
\hline $\begin{array}{c}50 \mu \mathrm{g} / \\
\text { commercial / } \\
\mathrm{NH}_{4} \mathrm{OH}^{\mathrm{a}}\end{array}$ & $\begin{array}{c}25 \mu \mathrm{g} / \\
\text { commercial / }_{\mathrm{NH}^{2} \mathrm{OH}^{\mathrm{a}}}\end{array}$ & $\begin{array}{c}50 \mu \mathrm{g} / \\
\text { LLNL / } \\
0.50 \% \\
\text { tryptone }^{\mathrm{a}}\end{array}$ & $\begin{array}{c}25 \mu \mathrm{g} / \\
\text { LLNL / } \\
0.25 \% \\
\text { tryptone }^{\mathrm{a}}\end{array}$ \\
\hline
\end{tabular}

\section{Alexa Fluor 488}

Percentile

Minimum

25 th

50 th

75 th

Maximum

10.0

13.5

15.5

19.0

9.0

14.0

15.0

26.0

10.5

16.0

20.4

45.8

12.0

19.0

50.3

162.5

16.0

27.0

39.0

237.0

Average

19.0

40.9

14.2

27.3

\section{Alexa Fluor 546}

Percentile

Minimum

25th

50 th

75 th

Maximum

6.0

6.0

6.5

11.0

7.5

9.0

9.0

15.0

10.0

10.5

12.0

19.0

14.0

13.5

16.5

33.9

54.0

72.0

136.0

418.0

Average

12.3

14.3

17.6

36.9

${ }^{\text {a}}$ Probe quantity / hybridization buffer / slide blocking procedure 
ranged from 54.0 for the $50 \mu \mathrm{g} /$ commercial buffer / $1 \% \mathrm{NH}_{4} \mathrm{OH}$ hybridization to 418.0 for the $25 \mu \mathrm{g} /$ LLNL buffer / $0.25 \%$ tryptone hybridization. The minimum signal intensity for the $25 \mu \mathrm{g}$ / LLNL buffer / $0.25 \%$ tryptone hybridization was slightly higher (11.0) than the other procedures which resulted in minimum intensities of $\sim 6.0$. The highest and lowest average signal intensities were observed for the $25 \mu \mathrm{g}$ / LLNL buffer / $0.25 \%$ tryptone hybridization (36.9) and the $50 \mu \mathrm{g} /$ commercial buffer / $1 \% \mathrm{NH}_{4} \mathrm{OH}$ hybridization (12.3), respectively. At the $75^{\text {th }}$ percentile, the $25 \mu \mathrm{g} /$ LLNL buffer / $0.25 \%$ tryptone hybridization had 2.1 to 2.5 -fold higher signal intensities compared to the other three hybridization protocols.

Median background-subtracted signal intensities obtained from the different hybridization protocols were also evaluated by determining the number of genes with signal intensities $\geq 1.5$ times the average negative control intensity (Table 2.2.5). The negative control intensities obtained for the Alexa Fluor 546 probes ranged from a low of 9.5 to a high of 14.1 (data not shown). The negative control intensities obtained for the Alexa Fluor 488 probes were slightly higher and ranged from 10.1 to 18.5 (data not shown). Among the probes labeled with Alexa Fluor 488, the hybridization of $25 \mu \mathrm{g}$ of probe with the commercial buffer to $1 \% \mathrm{NH}_{4} \mathrm{OH}$-blocked slides resulted in the largest number of genes with intensities at least 1.5 times the average negative control intensity ( 25 genes $\geq 1.5 ; 12$ genes $\geq 3.0$ ). Increasing the probe quantity for this procedure to 50 $\mu \mathrm{g}$, however, resulted in the lowest number of genes with signal intensity ratios that were at least 1.5 ( 14 genes $\geq 1.5 ; 2$ genes $\geq 3.0$ ). Among the Alexa Fluor 546 labeled probes, microarrays blocked with $0.25 \%$ tryptone and hybridized using $25 \mu \mathrm{g}$ of probe in the LLNL buffer had the highest number of genes with intensities $\geq 1.5$ 
Table 2.2.5. Relationship between the tissue sample hybridization protocol utilized and the number of genes with signal intensity ratios $\geq 1.5$. $^{\mathrm{a}}$

Number of genes

\begin{tabular}{|c|c|c|c|}
\hline Signal Intensity Ratio & $\begin{array}{c}50 \mu \mathrm{g} / \\
\text { Commercial / } \\
\mathrm{NH}_{4} \mathrm{OH}^{\mathrm{b}}\end{array}$ & $\begin{array}{c}25 \mu \mathrm{g} / \\
\text { Commercial / } \\
\mathrm{NH}_{4} \mathrm{OH}\end{array}$ & $\begin{array}{cc}50 \mu \mathrm{g} / \text { LLNL } & 25 \mu \mathrm{\mu g} / \mathrm{LLNL} \\
\text { / Tryptone } & \text { / Tryptone }\end{array}$ \\
\hline
\end{tabular}

\section{Alexa Fluor 488}

$\begin{array}{lcccc}\geq 1.5 & 14 & 25 & 16 & 16 \\ \geq 2.0 & 9 & 20 & 6 & 9 \\ \geq 2.5 & 3 & 14 & 4 & 5 \\ \geq 3.0 & 2 & 12 & 3 & 3\end{array}$

Alexa Fluor 546

$\begin{array}{lcccc}\geq 1.5 & 13 & 11 & 19 & 23 \\ \geq 2.0 & 5 & 7 & 9 & 21 \\ \geq 2.5 & 4 & 5 & 5 & 13 \\ \geq 3.0 & 2 & 3 & 4 & 11\end{array}$

Alexa Fluor 488 \&

Alexa Fluor 546

$\begin{array}{lcccc}\geq 1.5 & 21 & 27 & 21 & 25 \\ \geq 2.0 & 13 & 22 & 10 & 22 \\ \geq 2.5 & 6 & 15 & 5 & 13 \\ \geq 3.0 & 3 & 13 & 4 & 11\end{array}$

${ }^{a}$ Calculated for each gene as: (average gene intensity)/(average negative control intensity)

${ }^{\mathrm{b}}$ Probe quantity / hybridization buffer / slide blocking procedure 
times the average negative control intensity ( 23 genes $\geq 1.5 ; 11$ genes $\geq 3.0$ ), while probes hybridized using the commercial buffer and $1 \% \mathrm{NH}_{4} \mathrm{OH}$ blocking reagent had the lowest number of genes (11-13 genes $\geq 1.5$ and $2-3$ genes $\geq 3.0)$. When both Alexa Fluors were considered together, the number of genes with signal intensity ratios $\geq 1.5$ but less than 2.0 was similar across all procedures (21-27 genes). However, slides hybridized with $25 \mu \mathrm{g}$ of probe, irrespective of the hybridization buffer and blocking procedure, had a 2.8 to 4.3 -fold increase (over slides hybridized with $50 \mu \mathrm{g}$ of probe) in the number of genes with signal intensity ratios $\geq 3.0$.

\subsubsection{Discussion}

The results of the gene-specific and tissue sample hybridizations show that probe quantity, hybridization buffer, and slide blocking procedures all affect backgroundsubtracted signal intensities, and therefore may also affect accurate microarray expression ratio quantitation, especially for genes with low hybridization signal intensities.

\section{Gene-specific probe hybridizations}

Gene-specific hybridizations were performed to determine the effects of hybridization buffer and microarray slide blocking procedure on background-subtracted signal intensities. These simple probes were ideal for comparing the intensities obtained for specific genes following different hybridization procedures because the amplicons (which do not degrade as readily as the tissue RNA used as the starting material for tissue 
sample hybridizations) can be simultaneously labeled, combined, and then aliquoted from a single master mix for each hybridization.

Irrespective of the set of hybridization conditions utilized, Alexa Fluor 546 intensities were always lower than the Alexa Fluor 488 intensities. Therefore, these differences are most likely the result of intrinsic differences between the fluorophores and/or differences between the filter sets used for image capture. When considering total intensities, however, the LLNL buffer / $0.25 \%$ tryptone procedure yielded $\sim 2.2$-fold higher intensity than the method that had been traditionally used in our laboratory (commercial buffer/ammonium hydroxide). In fact, microarray slides hybridized using the LLNL hybridization buffer and blocked with $0.25 \%$ tryptone generally had the highest signal intensities, followed by LLNL buffer / 0.50\% tryptone and LLNL buffer / $1 \% \mathrm{NH}_{4} \mathrm{OH}$ which behaved similarly. With the exception of the signal detected for Xrccl, the commercial buffer / $1 \% \mathrm{NH}_{4} \mathrm{OH}$ combination gave the lowest backgroundsubtracted signal intensities. Overall, the LLNL buffer / $0.25 \%$ tryptone protocol increased signal intensity $\sim 94 \%$ to $204 \%$ compared to the signal intensities obtained for the commercial buffer / $1 \% \mathrm{NH}_{4} \mathrm{OH}$ protocol previously used in our laboratory.

\section{Tissue sample probe hybridizations}

Tissue sample hybridizations were performed to determine the combined effects of probe quantity, hybridization buffer, and microarray slide blocking procedure on background-subtracted signal intensities. The hybridization conditions traditionally used in our laboratory $\left(50 \mu \mathrm{g}\right.$ probe / commercial buffer / $\left.1 \% \mathrm{NH}_{4} \mathrm{OH}\right)$ were compared to those which used 1/2 the probe quantity and/or a different buffer and blocking reagent. 
The results showed that decreasing probe quantities only increased the backgroundsubtracted signal intensities for particular fluorophores. Unlike the trend toward increased signal intensity which was observed for lower quantities of the Alexa Fluor 488 probe, there were no notable differences in intensities based on the Alexa Fluor 546 probe quantity alone. This may suggest that the lower probe amounts resulted in reduced background for the Alexa Fluor 488 images (which would increase the magnitude of the background-subtracted signal intensity). A similar effect was probably not observed for the Alexa Fluor 546 probes because the background for these images was substantially lower than that for the Alexa Fluor 488 images. Between the two protocols which used $25 \mu \mathrm{g}$ of probe, the commercial buffer / ammonium hydroxide combination resulted in the highest number of genes with Alexa Fluor 488 signal intensities that were at least 1.5 times greater than negative control intensities, whereas the LLNL buffer / $0.25 \%$ tryptone combination resulted in the highest number of genes with Alexa Fluor 546 signal intensities that were at least 1.5 times greater than negative control intensities. However, when the results for both Alexa Fluors were considered together, the total number of genes with signal intensity ratios of at least 1.5 was similar between the hybridization procedures. This suggests that, like probe quantity, the combination of hybridization buffer and slide blocking procedure also affects signal intensity in a fluorophoredependent manner. With respect to the results for Alexa Fluor 488, it is possible that ammonium hydroxide is superior to tryptone in masking the autofluorescence of the silane-coated microarray. For Alexa Fluor 546, which tends to have much lower background, the LLNL buffer / $0.25 \%$ tryptone combination may produce larger signal 
intensities due to a decrease in fluorophore quenching during hybridization to the tryptone-blocked slide.

\section{Summary}

Hybridization conditions for the cDNA microarray experiments performed in our laboratory previously involved using commercially prepared hybridization buffers to hybridize large probe quantities $(\geq 50 \mu \mathrm{g}$ ) to slides blocked with ammonium hydroxide. The results for both the gene-specific hybridizations (irrespective of fluorophore) and the Alexa Fluor 546-labeled tissue sample hybridizations indicated that the largest signal intensities were obtained when the LLNL buffer was used in combination with the $0.25 \%$ tryptone blocking reagent. However, experience with multiple microarray hybridizations has shown that for the white light capture system used in our laboratory, images for the Alexa Fluor 546 probes are normally captured using longer integration times and higher camera gain settings than those used for the Alexa Fluor 488 probes. This indicates that the Alexa Fluor 546 signal intensities are inherently lower than the Alexa Fluor 488 intensities. Because these research findings suggest that microarray experiments visualized with this white light image capture system may show improved signal intensities by hybridizing lower probe quantities $(\sim 25 \mu \mathrm{g})$ with the in-house hybridization buffer (LLNL; $42 \%$ formamide / 2 x SSC / 10\% dextran sulfate), to $0.25 \%$ tryptone-blocked slides, this protocol was utilized in our subsequent cDNA microarray experiments (Chapter 3). 


\subsubsection{References}

Guo, Z., Guilfoyle, R.A., Thiel, A.J., Wang, R., and Smith, L.M. (1994). Direct fluorescence analysis of genetic polymorphisms by hybridization with oligonucleotide arrays on glass supports. Nucleic Acids Res. 22, 5456-5465.

Kegelmeyer, L.M., Tomascik-Cheeseman, L., Burnett, M.S., van Hummelen, P., and Wyrobek, A.J. (2001). A groundtruth approach to accurate quantitation of fluorescence microarrays. SPIE Proceed. 4266, 35-45.

Miesfeld, R.L. (1999). Biochemical basis of applied molecular genetics. Applied Molecular Genetics. New York: Wiley-Liss. pp. 6-10.

Strachan, T. and Read, A.P. (1999). Principles of nucleic acid hybridization. Human Molecular Genetics. 2nd Ed. New York: Wiley-Liss. pp. 100-5.

Wetmur, J.G. (1971). Excluded volume effects on the rate of renaturation of DNA. Biopolymers 10, 601-13. 


\subsection{Accurate quantitation of fluorescence microarrays}

\subsubsection{Abstract}

To more accurately measure fluorescent signals from microarrays, our image acquisition and analysis systems were calibrated using groundtruth samples comprised of known quantities of gene-specific DNA probes that were labeled with Cy3 and/or FITC and hybridized to cDNA targets. Slides were imaged with a full-field, white light CCD imager and analyzed using custom analysis software. The results obtained with and without preprocessing (alignment, color crosstalk compensation, dark field subtraction, and integration time) were compared for multiple genes. The accuracy of various image processing and analysis techniques (background subtraction, segmentation, quantitation and normalization) was also evaluated. This methodology was used to calibrate and validate our system for accurate, quantitative measurement of microarrays. The results show that preprocessing the images resulted in measurements that were substantially closer to the known groundtruth for these samples.

\subsubsection{Introduction}

Expression microarrays provide a means for monitoring the expression of many genes in parallel. Therefore, this technology can provide in-depth understanding of biological processes such as DNA repair, cellular differentiation, and development. Careful target selection is essential for utilizing custom-built cDNA microarrays to address pathway-specific topics. These targets must not only represent the potentially 
interesting and relevant genes but also minimize sequence homology (and thus crosshybridization) among spots. Since subtle differences in gene expression measurements can have a large impact on the interpretation of biological data, specificity and measurement accuracy are especially important.

There are many ways to perform the image processing and analysis steps needed to derive quantitative information from a microarray image (Brown et al. 2000; Chen et al. 1997; Pie'tu et al. 1996). We evaluated a number of different methods for processing and analyzing images and showed the effects of preprocessing on quantitation. Segmentation, quantitation, background subtraction, preprocessing, and normalization were defined as follows:

- Segmentation delineated the extent of each spot, and thus distinguished spots from surrounding background.

- Quantitation involved measuring intensities within the spot boundaries determined by segmentation.

- Background subtraction was used to remove the effects of autofluorescence and other effects that are not due to specific fluorescent hybridization.

- Preprocessing involved characterizing and accounting for the acquisition system parameters such as camera dark field, spectral crosstalk, image alignment, integration time and camera gain. 
- Normalization made the measurements from the 2 color channels (e.g. red and green) commensurable so they could be sensibly compared or arithmetically manipulated relative to one another. It also enabled slide-to-slide comparisons.

Each of these processes has optional techniques and implementations. Not only are there a number of different possible algorithms for each step, but the optimal combinations may also differ from system to system. We used groundtruth to determine which techniques and combination of the above options were optimal for correlating computed intensities with known probe amounts for our system. However, this methodology can be used to calibrate any acquisition and analysis system in order to improve measurement accuracy.

\subsubsection{Materials and Methods}

Generation of amino modified clones

Expressed sequence tag (EST) clones were obtained from LLNL's I.M.A.G.E. Consortium and used as the target cDNA for the microarrays. PCR with sequencespecific primers verified that each clone represented the correct gene. Two ESTs with an insert size ranging from 500 to 1500 base pairs were selected to represent each gene. Prior to spotting, inserts from the selected clones were PCR amplified from plasmid preparations using 5' C6 amino-modified, vector-specific primers and purified using 
Qiagen PCR purification columns (Qiagen Inc., Chatsworth, CA). The amplicons were precipitated and resuspended for spotting in $0.1 \mathrm{M}$ Sodium Carbonate/Bicarbonate $(\mathrm{pH}=10.2)$ to a final concentration of $2 \mu \mathrm{g} / \mu \mathrm{l}$.

Slide preparation

Slides were derivatized according to Guo et al. (1994). Briefly, glass slides were coated with 1\% 3-aminopropyltrimethoxysilane [Sigma, St. Louis, MO] in 95\% acetone/water for $2 \mathrm{~min}$., washed 10 times in acetone, and baked at $110^{\circ} \mathrm{C}$ for $45 \mathrm{~min}$. Prior to spotting, the silane was activated by incubating the slides for 2 hours in $0.2 \%$ 1,4-phenylenediisithiocyanate [Sigma, St. Louis, MO], 10\% pyridine [Sigma, St. Louis, $\mathrm{MO}$ ] and dimethylformamide [Aldrich, Milwaukee, WI]. Slides were then washed in methanol (2x 10 min.) and acetone (2x 10 min.). Slides were air dried and used immediately for spotting.

\section{Robotic arrayer}

A custom robotic high speed arrayer was used to grid cDNA onto glass microscope slides. The gridding system had a 3-axis DC servo driven gantry (GM2340R, Glentek, El Segundo, CA). The full travel of the Z-axis was $0.25 \mathrm{~m}$ with $5 \mu \mathrm{m}$ resolution and of the $\mathrm{X}$-and $\mathrm{Y}$-axis (powered by Newport-Klinger MD4 servo motor driver), $2 \mathrm{~m}$ and $1 \mathrm{~m}$, respectively, with $20 \mu \mathrm{m}$ resolution each. The system controller was a NewportKlingerMM2000 card with 3DC modules in an Intel 80486 PC. The spotting tool had 2 Beryllium-Copper plated pins with a spacing of $4.5 \mathrm{~mm}$. The grid density was $4.5 \times 4.5$ 
$\mathrm{mm}$ for each of 2 pins with a center to center spacing of $375 \mu \mathrm{m}$. After spotting, the slides were humidified in a $37^{\circ} \mathrm{C}$ incubator for 5 minutes, air dried and stored under vacuum at room temperature until hybridization.

\section{Probe labeling}

To create groundtruth over a series of 10 slides, 10 probe mixtures were made using clones for the following genes: Globin, Dna-pkcs, Tp53, Rad50, Rad52, and Ku80. Each mixture contained both Cy3 and FITC labeled probes for each of the above genes. The ratio of the FITC and $\mathrm{Cy} 3$ probe amounts shown were expected to correlate with the subsequent ratio of intensity measurements. Globin and Dna-pkcs probes had equal proportions across all slides to serve as controls (each was expected to yield a Cy3/FITC ratio of 1). Globin was used for normalization. For each of the remaining four genes, the probe amount for one dye was held constant while the probe amount for the other dye varied, forming a dilution series as shown in Table 2.3.1. Each mixture was hybridized to one slide.

Probes were generated by PCR amplification of the same I.M.A.G.E. clones that were spotted onto the array using gene-specific primers. A spectrophotometer was used to measure the quantity of each probe. The probe labeling was performed by mixing serial dilutions for each gene together per color and afterwards replacing dCTP by Cy3dCTP (Amersham Pharmacia Biotech, Piscataway, NJ) or dUTP by FITC-dUTP (dUTP (Roche, Indianapolis, IN) using a Nick Translation kit (Life Technologies, Rockville, MD) which incorporated labeled nucleotides by using the enzyme DNase I to "nick" the DNA and DNA polymerase to replace the excised nucleotides with a mixture of 
Table 2.3.1. Six genes were used to build a groundtruth series over ten microarray slides. ${ }^{\text {a }}$

\begin{tabular}{|lllll|}
\hline Globin & FITC & $2.3 \mathrm{ng}$ & $\rightarrow$ & $2.3 \mathrm{ng}$ \\
& Cy3 & $2.3 \mathrm{ng}$ & & $2.3 \mathrm{ng}$ \\
& & & & \\
Dna-pkes & FITC & $2.4 \mathrm{ng}$ & $\rightarrow$ & $2.4 \mathrm{ng}$ \\
& Cy3 & $2.4 \mathrm{ng}$ & & $2.4 \mathrm{ng}$ \\
& & & & \\
Tp53 & FITC & $20.4 \mathrm{ng}$ & & $0.01 \mathrm{ng}$ \\
& Cy3 & $3.3 \mathrm{ng}$ & $\rightarrow$ & $3.3 \mathrm{ng}$ \\
\hline
\end{tabular}

\begin{tabular}{|lllll|}
\hline Rad52 & FITC & $18.2 \mathrm{ng} \rightarrow 0.01 \mathrm{ng}$ \\
& Cy3 & $3.0 \mathrm{ng}$ & $3.0 \mathrm{ng}$ \\
& & & & \\
Ku80 & FITC & $3.2 \mathrm{ng}$ & $\rightarrow$ & $3.2 \mathrm{ng}$ \\
& Cy3 & $18.6 \mathrm{ng}$ & $0.01 \mathrm{ng}$ \\
& & & & \\
Rad50 & FITC & $3.0 \mathrm{ng}$ & $\rightarrow$ & $3.0 \mathrm{ng}$ \\
& Cy3 & $17.3 \mathrm{ng}$ & $0.01 \mathrm{ng}$ \\
\hline
\end{tabular}

${ }^{a}$ Arrows represent the serial change in the probe amount across the 10 slides. 
unconjugated and fluorescently-conjugated nucleotides. The $\mathrm{Cy} 3$ and FITC labeled probe mixtures were added together and purified with Qiaquick spin columns (Qiagen Inc., Chatsworth, CA).

\section{Hybridization}

To block non-specific probe binding, slides were incubated for $10 \mathrm{~min}$. in $1 \%$ $\mathrm{NH}_{4} \mathrm{OH}$ (Sigma, St. Louis, MO) and washed 3 x 10 minutes in double distilled water prior to hybridization. Slides were then denatured for 6 minutes in $70 \%$ Formamide $/ 2 \mathrm{xSSC}$ at $78^{\circ} \mathrm{C}$, dehydrated through a $70-85-100 \%$ ethanol series, and air

dried at room temperature. The probe mixtures hybridized to each slide had similar total concentrations. Labeled probes were concentrated using speed vacuum centrifugation and resuspended in 5-10 $\mu$ l hybridization mix containing $70 \%$ formamide, $2 x$ SSC, $10 \%$ dextran sulfate and $1 \mu \mathrm{l}$ herring DNA. The hybridization mixtures were placed on the microarray under a $22 \times 22 \mathrm{~mm}$ coverslip, sealed with rubber cement, and denatured at $72^{\circ} \mathrm{C}$ for 3 minutes. Hybridization was performed for 24 hours at $37^{\circ} \mathrm{C}$ in a moist chamber, followed by $2 \times 10$ minute washes at $37^{\circ} \mathrm{C}$ in $2 \times S S C$. Vectashield mounting media (Vector Laboratories Inc., Burlingame, CA) was used to prevent photobleaching of the fluorescent dyes.

\section{Image acquisition}

Fluorescent microarray images were acquired with a full-field (15 mm square; resolution $=0.015 \mathrm{~mm} / \mathrm{pixel})$, white light imaging system (Norgren Associates, Palo Alto, CA). Light from a 500 watt Xenon light source $(400 \mathrm{~nm}-600 \mathrm{~nm})$ was scrambled 
through a fiber optic and passed through a bandpass excitation/emission filter pair before reaching a scientific grade CCD camera. The camera was controlled via a PC with a MATROX PULSAR digital acquisition and display board. Images were collected onto the PC and then transferred to a Unix workstation for analysis. This system was modified by adding a second light source (a mercury arc lamp) for UV excitation. The UV wavelength allowed the excitation of the nucleic acid stain DAPI (4',6-Diamidino-2phenylindole) which assisted in segmentation by delineating all spots, including those with weak or absent hybridization signals.

Image analysis

Custom software was written within the SCIL-Image development platform (TNO/TPD, Delft, The Netherlands) for preprocessing, automated background subtraction, grid detection, spot detection and quantitation. Custom Perl scripts were used to ratio, normalize, summarize and plot data resulting from the image analysis.

\subsubsection{Image Processing and Analysis Methods}

\section{Preprocessing}

To calibrate the acquisition system, inherent system response characteristics were measured and corrected or accounted for in the analysis. For example, all CCD cameras have thermal noise even when no light is incident on the CCD. Dark noise, which is noise from all sources except photons, was measured and then subtracted from the images (Mullikin et al. 1994). Additionally, because the filters in the system do not have perfect 
bandpass cutoffs and light through the filters is not always parallel, spectral crosstalk (FITC signal leaking into the Cy3 channel and vice versa) occurs. All systems should also measure and correct for this (Castleman et al. 1996). Image misalignment was also corrected, via correlation methods, during preprocessing. Misalignment occurs whenever there is a physical shift of the microarray slide between capturing images with different filters. Lastly, we corrected for integration time differences between the FITC and Cy3 images. Although it is feasible to leave this correction until normalization, it is prudent to correct for known disparities in a straightforward manner. Then, the factors remaining to be corrected by normalization are those for which reliable characterization is not available.

Problems associated with two of the system response characteristics, camera gain and non-uniform illumination, were ameliorated even though they are difficult to correct. The camera gain is non-linear at higher settings, so gain was held constant during acquisition for all images in the same experiment. Non-uniform illumination was difficult to correct because of wavelength dependencies (chromatic aberration) and variation of the light source over time; therefore, the illumination pattern was optimized for uniformity as much as possible during acquisition and was not corrected computationally.

\section{Background subtraction}

Quantitative information was extracted from hybridization signals following preprocessing. First, background subtraction was performed in order to account for the various sources of fluorescent background, such as autofluorescence inherent to the glass slide or other substrate, autofluorescence of the antifade, and the non-specific binding of 
fluorescent probe to material in the area surrounding the target spots of the array. This procedure is different from camera dark field subtraction which accounts for parameters inherent to the camera.

Informal investigations have shown that different substrates have varying levels of autofluorescence. For some systems, high quality, polished quartz, such as Corning brand slides had a lower contribution to background fluorescence than standard glass microscope slides. If background fluorescence was attributable to autofluorescence of the substrate, then there was a slowly varying background intensity under the array which served as a "DC offset" to the spot signals. (All spot intensities should be above this background.) In such a case, background subtraction was a logical and necessary step for accurate quantitation of spot signals.

If background fluorescence was attributable to non-specific binding of the labeled probe, then the surrounding signal was only around the spots, because the target DNA spotted on the slide prevents the non-specific binding at the spots. In this case, the background could have higher intensity than the spots (Figure 2.3.1). When background intensity is higher than target intensity, background subtraction is unwarranted because it would result in negatively valued spot intensities. Therefore, images with this type of background were not quantitated and another array was hybridized after applying an appropriate blocking procedure to prevent non-specific probe binding. Alternatively, spots could be compared to the negative controls (spots that had no probe hybridization) to get a relative sense of their brightness, but accurate ratios may be hard to obtain, since there may still be autofluorescence from the substrate which can't be characterized or subtracted. 


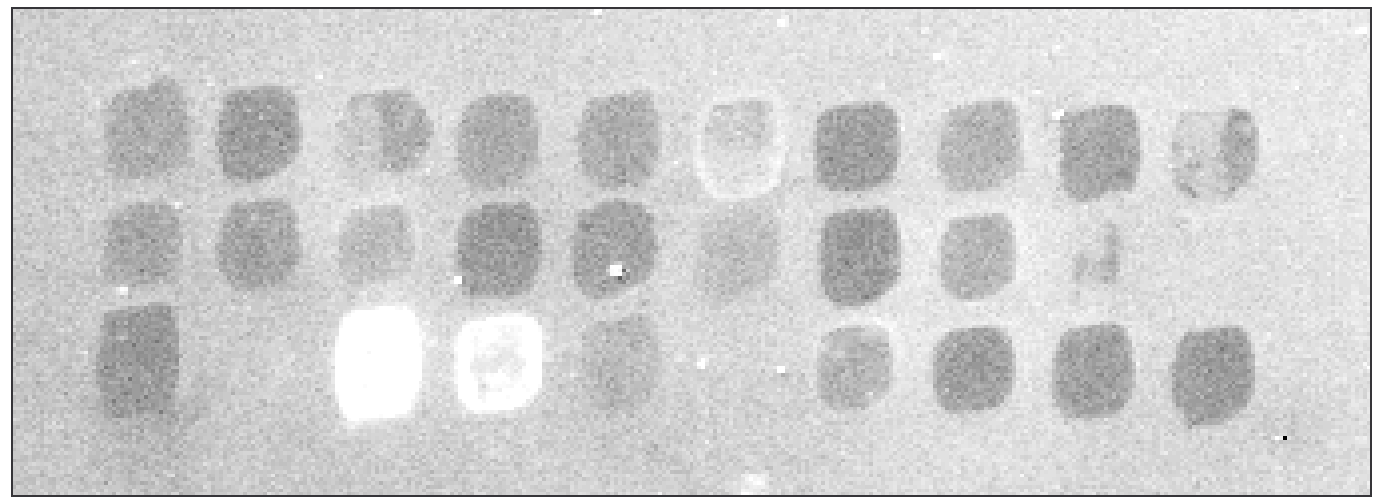

Figure 2.3.1. A contrast-enhanced example of a fluorescence microarray image with very high background. The bright white spots indicate hybridized cDNA targets. Many target cDNA spots were not hybridized and appeared darker than the surrounding background (as indicated by the black spots within the white background above). Therefore, the high background was not additive to the spot intensities, and the background intensities should not be subtracted from the target spots. 
After determining which manner of background subtraction was most appropriate for a given image, we selected from a number of methods to perform the task (sampling pixel intensities near the extremes of the image, sampling just outside of spots, etc.). The background subtraction method we employed was an adaptive, non-linear technique which continuously sampled the background and created a 2-dimensional, slowly changing "sheet" or blanket that followed the low frequency trend of intensity outside of the spots. This method, called the lower envelope subtraction (Verbeek, et al. 1988), lowered the signal intensities relative to a base value near zero (Figure 2.3.2).

\section{Semi-automated grid placement}

To detect spots with shape and location anomalies, a semi-automated grid placement algorithm was utilized which requires an operator to indicate the extent of the array and the number of spots present. With this information, the system divided the area into self-adjusted, not necessarily uniformly sized, grid squares and each square contained one spot.

\section{Three-color segmentation}

Once a grid was overlaid on the array, segmentation methods were used to determine which pixels inside a grid square belonged to the spot under investigation and which belonged to the background. As expected, segmentation was more difficult for dim or non-expressing spots than for bright spots. To address this problem, a third image of the array was acquired after ratio data was obtained for the first two images (Cy3 and FITC). This third image was captured after applying a DAPI DNA counterstain to the 


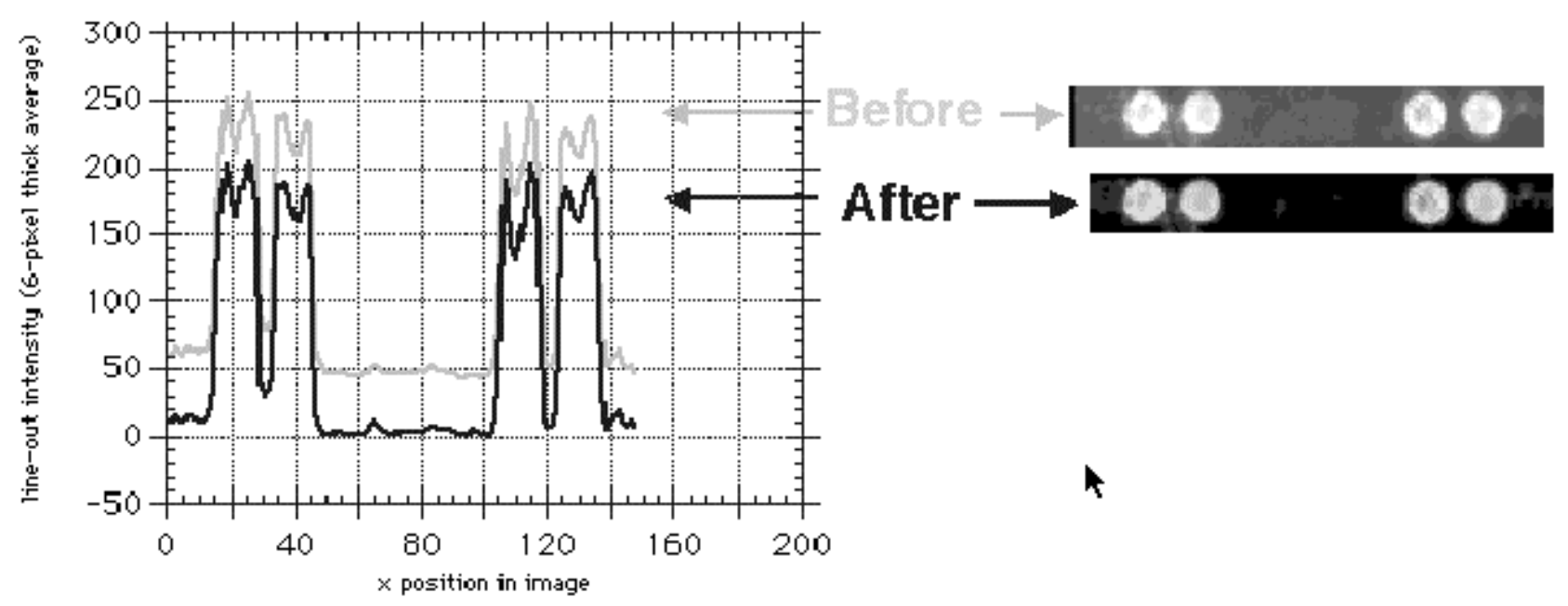

Figure 2.3.2. Removal of underlying autofluorescence and subsequent lowering of target spot intensities through background subtraction. The gray-scale microarray images of target spots (right) represent a row of hybridized spots before (top image) and after (bottom image) background subtraction. The graph (left) plots position within the image (x-axis) vs intensity for the corresponding position in the image (y-axis). Intensity measurements were made using a six pixel wide horizontal line through the image. 
slide to mark the location of all DNA target spots. The presence of DAPI stain removed any ambiguity about the presence of a valid target DNA when no expression signal was observed. It also allowed better determination of the size and shape of the DNA target for segmentation. However, DAPI was not always present in spots with a strong hybridization signal. (It is possible that the hybridization of the labeled probes changed the properties of the DNA molecule and prevented intercalation of the counterstain.) Therefore, images from all 3 dyes (Cy3, FITC, and DAPI) were superimposed and aligned in order to obtain the best signal from each spot. This resulting composite image was subsequently used for segmentation.

\section{Methods for spot segmentation}

When microarray target spots appear to be very dim, "bagel-shaped", or have other irregularities in the absence of counterstain such as DAPI, different segmentation methods define different spot areas which in turn affects the intensity measurement. As shown in Figure 2.3.3, the following segmentation methods were studied: 

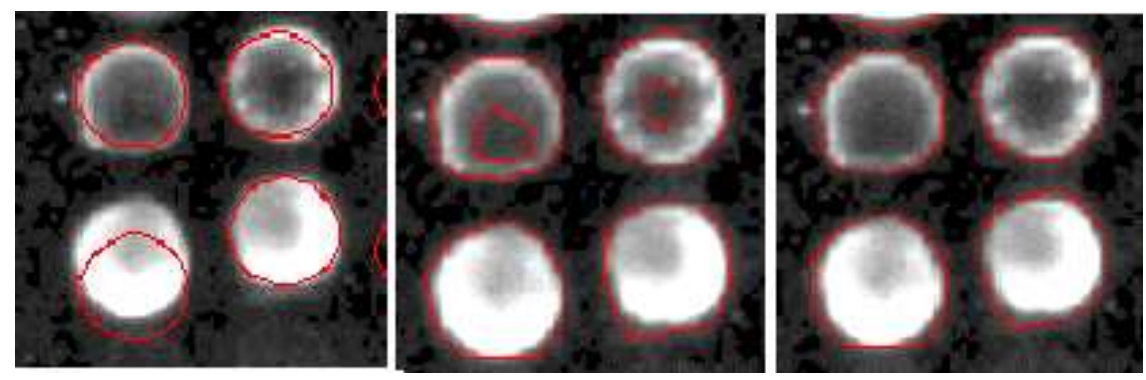

Figure 2.3.3. Contours of hybridized target spots delineated by different segmentation methods. From left to right these segmentation methods are: Circle Hough transform, Trian threshold, and Hulled Trian. Each of these segmetation methods were evaluated to determine which method resulted in ratios of computed intensities closest to the groundtruth (i.e., yielded the smallest average error for ratios of known probe quantities. 
- Circle Hough Transform: Best fit circle was found using an edge detector to determine the edges of the spot and then determine their magnitude and direction. This information was used to determine the center of the circle that best fits the edge information (Verbeek et al. 1998)

- Trian Threshold: An intensity-based histogram was drawn in a grid square containing one spot. The low-intensity peak of the histogram (which represents background values) was found and a line was fit to the falling slope on the right side, forming a triangle (hence the name trian) with the y-axis. The clipping level (intensity threshold) was set where this line crosses the $\mathrm{x}$ axis of the histogram (Ballard et al. 1981).

- Circles + Trian: A logical OR statement was used to combine the results from the two methods above.

- Hulled Trian: The morphological convex hull operation was applied to the result of the Trian Threshold.

\section{Methods for quantitation of signal intensity}

A number of methods could be used to compute the relative intensities of the red and green probe signal for a spot. The differences between the methods lie primarily in how well they accurately quantify the signal in the presence of noise or other artifacts. We implemented and evaluated a number of methods: 
- Total Intensity. Summed the intensities of all of the pixels assigned to a spot, for each color, and then divided them to get the ratio:

$$
\sum_{i=1}^{n} Y_{i} / \sum_{i=1}^{n} X_{i}
$$

where $\mathrm{Y}$ was the FITC signal, $\mathrm{X}$ was the Cy3 signal, $i$ was a pixel in the spot and $\mathrm{n}$ was the total number of pixels in the segmented region.

- Median. Found the median pixel intensity in each color and took the ratio: (Median of FITC pixel values)/(Median of Cy3 pixel values) This method was superior to the total (or averaging) method when there were noisy outliers (e.g. a few really bright or dim pixels). It also worked especially well when there was a similar number of low and high outliers.

- Pixel-to-pixel mean and average ratios. Divided the intensities of a spot on a pixel:pixel basis. Then, calculated the mean or the median of the pixel:pixel ratios for the entire spot. This method assumed that the two wavelength images were perfectly aligned and that the spot shape was consistent in both colors.

- Fit line. Since the pixel:pixel ratios within a spot can vary a lot, especially for bagel-shaped spots, another approach was to plot the pixel intensities in one wavelength versus another for each pixel and then fit a line to the resulting scatterplot. Each pixel was represented by a point on the scatterplot, with the $\mathrm{x}$ location its intensity in one wavelength and the y location its intensity in 
another. The slope of the line that passed through the 0 y-intercept represented the final ratio.

- Log geometric mean. The log geometric mean of the intensities in a spot is $10^{\mathrm{L}}$, such that

$$
\mathrm{L}=\sum_{\mathrm{i}=1}^{\mathrm{n}} \log \mathrm{Y}_{\mathrm{i}} / \mathrm{X}_{\mathrm{i}}
$$

where $\mathrm{Y}$ represented the FITC signal, $\mathrm{X}$ represented the Cy3 signal, $i$ represented one pixel in a spot and $n$ was the number of pixels in the spot.

\section{Normalization}

Once an intensity ratio was determined for a particular spot, it had to be normalized to a standard in order to account for variations due to differences in exposure time, amount of target, amount of probe, dye incorporation, rate of photobleaching, hybridization conditions, imaging conditions, etc. Normalization was achieved by dividing all spot intensities on a slide by the average ratio of positive controls, which were spots designed to have the same intensity and ratio on all slides. (Globin was hybridized using equal amounts of each color and served as the positive control for this groundtruth series.) When positive controls didn't have the expected ratio, we assumed the differences were due to the above variations, and we used the factor by which they differed as a correction factor for all other spots. 


\subsubsection{Results}

Preprocessing Results

In order to measure the effects of various analysis steps, we compared the computed intensity ratios against the known ratio of known probe quantities. As shown in Figure 2.3.4, the two were plotted such that the distance between the curves represented the error between measured and known quantities, with and without preprocessing. The curves were much closer together over a greater range of probe quantities with preprocessing. It was also possible to gauge the probe amounts at which the two curves diverge and to note that the computed intensity ratio was more accurate down to lower probe amounts following preprocessing.

Error evaluation for various analysis methods and combinations

In order to quantify the disparity among the curves for one gene, we calculated an error by summing the distance from measurement to the truth for all 10 dilutions in the series:

$$
\text { Error }=\sqrt{\sum_{n=1}^{10}[\log (\text { observed intensity ratio })-\log (\text { quantity ratio })]^{2}}
$$

where intensity ratio was computed using results from one of the quantitation methods described earlier and the quantity ratio was computed using the known probe amounts. For the graphs in Figure 4, the error for quantitation type was 1.28 without preprocessing and 0.73 with preprocessing. These values are also shown in Table 2.3.2.

Based on Table 2.3.2 error chart, preprocessing was most valuable when signal strength was low and when there was an intensity disparity between the two probe amounts. Probes that were plentiful and equal in the two colors, such as Globin and 


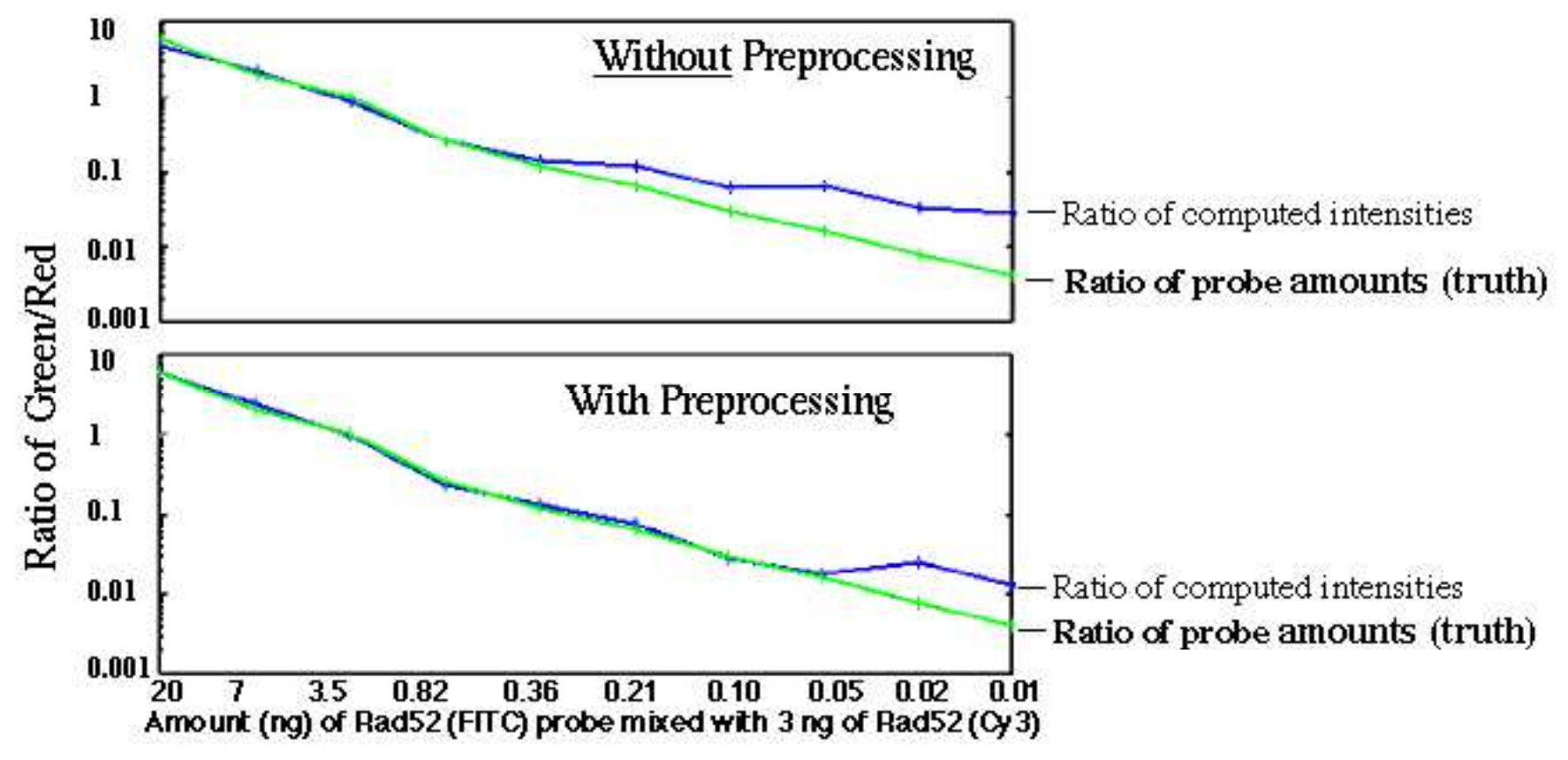

Figure 2.3.4. The groundtruth (ratio of known probe amounts) for Rad52 was tracked among the 10 slides as shown by the (lower) green line. The ratio of measured intensities is represented as the (upper) blue line. The cumulative distance between these two lines provided an error measurement that enabled different methods to be applied and compared in a quantitative manner. 
Table 2.3.2. Error measurements obtained for the groundtruth series following different image analysis methods. ${ }^{\mathrm{a}}$

\begin{tabular}{|c|c|c|c|c|c|c|}
\hline & \multicolumn{3}{|c|}{ Full preprocessing } & \multicolumn{3}{|c|}{ No preprocessing, except alignment } \\
\hline & $\begin{array}{c}\text { Total } \\
\text { intensity }\end{array}$ & Median & $\begin{array}{c}\text { Log } \\
\text { geometric } \\
\text { mean }\end{array}$ & $\begin{array}{c}\text { Total } \\
\text { intensity }\end{array}$ & Median & $\begin{array}{c}\text { Log } \\
\text { geometric } \\
\text { mean }\end{array}$ \\
\hline Globin & 0.05 & 0.07 & 0.07 & 4.34 & 0.07 & 0.07 \\
\hline Dna-pkcs & 0.33 & 0.36 & 0.35 & 0.27 & 0.29 & 0.29 \\
\hline Tp53 & 1.00 & 1.06 & 0.98 & 2.88 & 1.60 & 1.57 \\
\hline Rad50 & 1.25 & 1.29 & 1.33 & 1.89 & 1.74 & 2.07 \\
\hline $\operatorname{Rad52}$ & 0.65 & 0.73 & 0.73 & 1.25 & 1.28 & 1.35 \\
\hline Ku 80 & 1.32 & 1.39 & 1.42 & 1.91 & 1.81 & 2.10 \\
\hline \multicolumn{7}{|l|}{$\begin{array}{r}T p 53, \operatorname{Rad} 50, \\
\text { Rad52, and } K u 80\end{array}$} \\
\hline Average error & 1.06 & 1.12 & 1.12 & 1.98 & 1.61 & 1.77 \\
\hline Standard deviation & 0.30 & 0.29 & 0.32 & 0.67 & 0.24 & 0.37 \\
\hline
\end{tabular}

${ }^{\mathrm{a}}$ Error was determined by measuring the cumulative distance between the truth (quantity ratio) and measured (observed intensity ratio) curves (e.g., Figure 2.3.4). 
Dna-pkcs, did not benefit substantially from preprocessing. The other four genes, however, showed significantly larger improvements with preprocessing. This was primarily due to the color correction which accounted for spectral crosstalk by removing intensities from one color channel and adding them back to the appropriate color channel. For dim spot signals, this incremental change could be substantial, whereas bright spot signals were minimally affected.

Also shown in Table 2.3.2 are the effects of utilizing different quantitation methods. As seen in the average error along the last row of the chart, the total intensity quantitation method could result in the lowest average error $(1.06$ with full preprocessing), but it could also give the highest average error (1.98 with no preprocessing, except alignment) when data was corrupted by debris or other noise. Therefore it was not a robust quantitation method. Instead, the median and the log geometric mean error values were more consistent with lower standard deviations and overall lower error than the total intensity method and all other methods evaluated (data not shown).

Since all of the analyses used to generate the data for the chart were normalized via the Globin positive control spots, it stands to reason that the largest error occurred when the Globin control spot contained undetected debris, and the quantitative method of "total" included those values in the intensity measure for Globin (Table 2.3.2). Since that measurement was flawed, and since that value was subsequently used to normalize all of the gene intensity ratios, all computed ratios using that method were flawed.

Just as these errors were generated for various combinations of preprocessing and quantitation parameters, similar values were generated for the other analysis steps. For 
evaluation of background subtraction, we held constant the settings for preprocessing, segmentation, quantitation and normalization and only changed whether or not background was subtracted. For the genes of the dilution series, the average error improved from 1.41 to 1.12 when background was subtracted and the median or log geometric mean was used for quantitation. Further, almost all of the improvement was realized for the genes which had low probe amounts. As expected, the ratios for spots with strong intensity were least affected by background subtraction.

\subsubsection{Conclusions}

While there are numerous approaches to microarray analysis, accurate quantitation required system calibration. The methodology outlined in this paper can be used to calibrate any acquisition and analysis system and can be tailored and optimized for specific data and specific experiments for improved measurement accuracy. In order to calibrate and validate our system, we generated a dilution series with known quantities for the red and green hybridization probes. We used that groundtruth sample to evaluate the results of a number of computational techniques for preprocessing and analysis. Computed ratios were compared to the known groundtruth, and an error was calculated for each method. In order to obtain the least overall error for our groundtruth samples and our system, we found that:

- preprocessing was superior to not preprocessing

- subtracting background was superior to not doing so 
- spots were best segmented by combining a best circle fit with an intensity threshold

- quantitation was most accurate when using the median or the log geometric mean

- normalizing by a positive control was superior to not doing so.

Preprocessing had the greatest impact on bringing the computed ratios closest to the groundtruth. For the gene with the lowest cumulative error across all analysis methods, Rad52, preprocessing enabled accurate quantitation of DNA probe to $0.05 \mathrm{ng}$ (improved from a limit of $0.36 \mathrm{ng}$ without preprocessing). Future efforts will establish whether this translates to the detectable amount for samples using cDNA or RNA probes and will also evaluate metrics for signal brightness and uniformity.

\subsubsection{Auspices}

This work was performed under the auspices of the U.S. DOE by the University of California, LLNL under contract W-7405-Eng-48 with funding from NIH ES0911702, DOE KP110202, and additional support from West Virginia University and the University of California Campus Laboratory Collaboration. 


\subsubsection{References}

Ballard, D.H. (1981). Generalizing the Hough transform to detect arbitrary shapes. Pattern Recog. 13, 111-122.

Brown, M.P.S., Grundy W.N., Lin, D., Cristianini, N., Sugnet, C.W., Furey, T,S., Ares, M., and Haussler, D. (2000). Knowledge-based analysis of microarray gene expression data by using support vector machines. PNAS 97, 262-267.

Castleman, K.R., Riopka, T.P., and Wu, Q. (1996). FISH image analysis. IEEE Engineer. Med. Biol. 15, 67-75.

Chen, Y., Dougherty, E.R., and Bittner, M.L. (1997). Ratio-based decisions and the quantitative analysis of cDNA microarray images. J. Biomed. Optics 2, 364-374.

Guo, Z., Guilfoyle, R.A., Thiel, A.J., Wang, R., and Smith, L.M. (1994). Direct fluorescence analysis of genetic polymorphisms by hybridization with oligonucleotide arrays on glass supports. Nucleic Acids Res. 22, 5456-5465.

Mascio, L.N., Verbeek, P.W., Sudar, D., Kuo, W-L., and Gray, J.W. (1995). Semiautomated DNA probe mapping using digital imaging microscopy: I. System development. Cytometry 19, 51-59.

Mullikin, J.C., van Vliet, L.J., Netten, H., Boddeke, F.R., van der Feltz, G., and Young, 
I.T. (1994). Methods for CCD camera characterization. Image Acquisition and Scientific Imaging Systems, Helen C. Titus and Amir Waks Eds. 2173, 73-84.

Pie'tu, G., Alibert, O., Guichard, V., Lamy, B., Bois, F., Leroy, E., Mariage-Sampson, R., Houlgatte, R., Soularue, P., and Auffray, C. (1996). Novel gene transcripts preferentially expressed in human muscles revealed by quantitative hybridization of a high density cDNA array. Gen. Res. 6, 492-503.

Verbeek, P.W., Vrooman, H.A., and van Vliet, L.J. (1988). Low Level image processing by max-min filters. Signal Process. 17, 249-258.

Zack, G.W., Rogers, W.E., and Latt, S.A. (1977). Automatic measurement of sister chromatid exchange frequency. J. Histochem. Cytochem. 25, 741-753. 


\title{
Differential Basal Expression of Genes Associated
}

\author{
with Stress Response, Damage Control, and
}

\section{DNA Repair Among Mouse Tissues}

\subsection{Abstract}

Tissues must be capable of efficiently recognizing and repairing various types of DNA damage in order to maintain genomic integrity and the overall health of an organism. However, differential DNA damage susceptibilities and cancer incidences have been observed among tissues, and the molecular mechanisms underlying tissue-specific differences are not well understood. The purpose of this research was to compare and contrast transcription profiles among healthy adult mouse tissues (testis, brain, liver, spleen and heart) using a 417 gene cDNA microarray enriched for genes involved in DNA damage recognition and repair processes. Several tissue-specific patterns of expression were identified through cluster analysis. With respect to specific biological pathways, we found that $\sim 41 \%$ of the stress response genes, $\sim 23 \%$ of the damage control genes and $\sim 10 \%$ of DNA repair-associated genes were significantly differentially expressed among the tissues examined. In general, stress response genes exhibited the highest expression in liver and heart while DNA repair genes exhibited the highest 
expression in testis. Damage control genes associated with cell cycle regulation often had the highest expression in testis. The finding that tissues differ in their basal expression of stress response, damage control and DNA repair-associated genes raises important questions regarding tissue-specific responses to endogenous and exogenous genotoxic agents and differential genetic susceptibility to various diseases, including cancer.

\subsection{Introduction}

Health maintenance requires that all mammalian tissues be capable of recognizing and repairing a variety of insults to genomic DNA. Yet, tissue-specific differences have been observed in the response to endogenous and exogenous genotoxic agents and cancer incidence.

Several studies have reported differential tissue responses (ranging from modulations in gene expression to differences in the amount of damage induced) to a variety of DNA damaging agents. Recently, it has been suggested that transcriptional responses to ionizing radiation vary among cell lines derived from different tissue-types (Amundson et al., 1999). Valverde et al. showed that the extent of carcinogen-induced genotoxic damage also differs among tissues exposed to cadmium chloride (2000). Evaluation of single strand breakage and alkali-labile sites in various mouse tissues (e.g., lung, liver, kidney, brain, testis) suggested that a single exposure to cadmium induced relatively high amounts of DNA damage in brain and bone marrow, while the liver, testis, and kidney exhibited lower damage. 
In addition to the observed differences in DNA damage produced following various environmental exposures, cancer incidence rates are also known to vary among tissues (American Cancer Society; http://www.cancer.org/eprise/main/docroot/stt/stt_0). The distribution of the approximately 1.3 million new cancer cases expected in the United States during 2002 varies significantly, ranging from a high of 1 in 6 new cases attributable to breast cancer to a low of 1 in 1070 new cases attributable to male genital cancers, excluding testicular and prostate cancers. Cancers of the brain/nervous system and liver/intrahepatic bile duct are expected to account for 1 in $\sim 75$ and 1 in $\sim 77$ new cases, respectively. However, soft tissue cancers (including heart) and testicular cancer only account for 1 in $\sim 150$ and 1 in $\sim 170$ cases, respectively. The molecular processes contributing to these tissue-specific differences in cancer rates are not well understood.

Tissues may respond to DNA damaging conditions by activating signaling cascades involved in stress response (i.e., heat shock or oxidative stress depending on the type of exposure), regulating cell cycle progression, repairing DNA damage, and/or inducing apoptosis. Although many of the major genes in each of these biological pathways have been identified, information regarding their basal mRNA expression levels is limited. A better understanding of the in vivo baseline expression levels for these genes would provide insight on the cellular resources that are immediately available for responding to and processing DNA damage.

Several studies have examined tissue-specific differences in the baseline expression of single genes or small numbers of genes associated with damage response and repair (Burns et al., 2001; Leasure et al., 2001; Pittman et al., 1998). In contrast, genome-scale technologies such as cDNA microarrays can provide a comprehensive 
parallel evaluation of expression differences across large numbers of genes, biological pathways, and tissues. Although cDNA microarrays have been utilized to profile gene expression in tumor tissues (Alizadeh et al., 2001; DeRisi et al., 1996) as well as in tissues that have been exposed to DNA damaging agents, such as ionizing radiation (Amundson et al., 1999; Fornace et al., 1999), a microarray-based assessment of the differential basal expression of damage response genes among healthy mouse tissues has not yet been reported.

The purpose of this research was to characterize and contrast the relative basal levels of gene expression among five tissues from healthy adult male mice (testes, brain, liver, spleen, and heart) using a cDNA microarray enriched for genes associated with DNA damage recognition and repair. After assessing the reproducibility and precision of our cDNA microarray technology, we (a) compared basal gene expression profiles among tissues, (b) characterized expression differences by biological pathway, and (c) validated cDNA microarray accuracy against northern blot results for selected genes.

\subsection{Materials and Methods}

\section{Custom cDNA microarray generation}

Custom cDNA microarrays were generated to represent 417 genes involved in nucleotide excision repair, base excision repair, mismatch repair, homologous and nonhomologous recombination, stress response, apoptosis, cell cycle, transcription, translation, growth regulation, meiosis, spermatogenesis, and chromatin-remodeling. For each gene, one to four cDNA clones were obtained from either the I.M.A.G.E. 
Consortium at LLNL or Research Genetics (Huntsville, AL). Several bacterial and lambda phage sequences served as controls. Clones were PCR-amplified with 5'-C6 amino-modified vector-specific primers, purified on Qiagen purification columns (Qiagen Inc., Valencia, CA), ethanol precipitated, and resuspended in $0.1 \mathrm{M}$ sodium carbonate/bicarbonate $(\mathrm{pH}=10.2)$ for spotting onto the array slides.

Glass slides were cleaned for $30 \mathrm{~min}$ in 1:1 concentrated hydrochloric acid:methanol, soaked overnight in concentrated sulfuric acid, and washed 10 x 10 min in room temperature water and 10 min in boiling water. Slides were then submerged in $1 \%$ 3-aminopropyltrimethoxysilane (Sigma, St. Louis, MO) / 95\% acetone/ water for $2 \mathrm{~min}$, washed 10 x $5 \mathrm{~min}$ in acetone, and heated at $110^{\circ} \mathrm{C}$ for $45 \mathrm{~min}$ (Guo et al., 1994). Silanecoated slides were submerged in $0.2 \%$ 1,4 phenylene diisothiocyanate (Sigma), $10 \%$ pyridine (Sigma) and dimethylformamide (Aldrich, Milwaukee, WI) for 2 hours, washed in methanol ( $2 \times 10 \mathrm{~min})$ and acetone $(2 \times 10 \mathrm{~min})$, and air-dried. 608 clones were robotically arrayed (Norgren Systems, Palo Alto, CA) in duplicate with a $220 \mu \mathrm{m}$ centerto-center distance.

\section{RNA isolation and labeling}

Eight male B6C3F1 mice (Harlan Sprague Dawley, Indianapolis, IN) were euthanized by $\mathrm{CO}_{2}(\mathrm{~g})$ at 2 months of age. Mice were allowed food and water ad libitum and were not exposed to genotoxic agents. Testes from six mice were extracted and pooled for use as the reference tissue in each hybridization. Heart, spleen, liver, testes and whole brain were extracted from each of the two remaining mice. Tissues were stored at $-80^{\circ} \mathrm{C}$ until RNA isolation. 
Total RNA was isolated by homogenization (Omni Tissue Homogenizer, Warrenton, VA) in TRIzol Reagent (Life Technologies, Rockville, MD). RNA was ethanol precipitated twice, resuspended in RNase-free water (Sigma), and quantified using the GeneQuant spectrophotometer (Amersham Pharmacia Biotech, Piscataway, NJ). $25 \mu \mathrm{g}$ of RNA was primed with $4 \mu \mathrm{g}$ of 20 mer oligo-dT (Life Technologies) and reverse transcribed at $42^{\circ} \mathrm{C}$ using Superscript II reverse transcriptase (Life Technologies) in the presence of unlabeled dUTPs (Amersham Pharmacia Biotech) and either Alexa Fluor 488-dUTPs (pooled testes reference; green fluorescence) or Alexa Fluor 546dUTPs (test tissue; red fluorescence) from Molecular Probes, Inc. (Eugene, OR). For each hybridization, pooled testes and test tissue probes were co-purified on Qiagen columns (Qiagen, Inc.) and ethanol precipitated.

\section{Microarray hybridization}

Prepared slides were placed in $0.25 \%$ tryptone (Difco Laboratories, Detroit, MI) in water, agitated at $100 \mathrm{rpm}$ for 1 hour, denatured $2 \mathrm{~min}$. in $94-98^{\circ} \mathrm{C}$ water, dehydrated using an ice cold 70-85-100\% ethanol series, and air dried. Probes were resuspended in $2.75 \mu \mathrm{l}$ water and added to $0.25 \mu \mathrm{L} 10 \% \mathrm{SDS}, 10 \mu \mathrm{g}$ mouse cot-1 DNA (Life Technologies), $10 \mu \mathrm{g}$ poly A+ (Amersham Pharmacia Biotech) and $10 \mu \mathrm{L}$ of $60 \%$ formamide / 3xSSC / 10\% dextran sulfate. Hybridization mixtures were denatured at $78^{\circ} \mathrm{C}$ for $6 \mathrm{~min}$. and snap-cooled on ice. An in situ frame (Eppendorf, Westbury, NY) was used to confine the probe mixture over the arrayed area. Slides were hybridized 12 hours at $37^{\circ} \mathrm{C}$ and washed $2 \times 2$ min. in $42^{\circ} \mathrm{C}$ water. 


\section{Image capture and processing}

Image capture and processing was performed as described by Kegelmeyer et al. (2001). Briefly, images were acquired with a full-field white light imaging system. Arrays were exposed to bandpass-filtered excitation light from a Xenon source. The resulting emitted light was bandpass-filtered and collected by a scientific-grade CCD camera (resolution $=0.015 \mathrm{~mm} /$ pixel). Custom algorithms, built within SCIL-Image (Delft, The Netherlands), corrected for CCD dark noise, spectral cross-talk, misaligned images and integration time variation. Additional processing algorithms determined the "segmentation mask" for each cDNA spot. The raw red and green intensities for all spots were computed by taking the geometric mean of all pixels within the segmentation mask that were greater than zero after background subtraction. Spots covered by debris were eliminated from all subsequent processing.

\section{Normalization and expression ratio calculations}

Logarithms were used to transform the raw red to green intensity ratio for each spot into red minus green intensity differences. This logarithmic transformation helped stabilize the variance. Logarithms to the base 2 were used for convenience in interpretation: a log-ratio of plus or minus one corresponds to a red to green ratio of 2:1 or $1: 2$, respectively.

Log-ratios were normalized using an intensity-dependent normalization similar to Yang et al. (2001). Two normalizations were performed in succession: (1) a normalization that adjusted the log-ratio based on the average of the log-transformed red and green intensities (called "A") and (2) a subsequent normalization that adjusted the 
log-ratio based on the Euclidean distance of the spot from the center of the array. This second normalization was performed to counter illumination differences between the center and edges of the array. Both normalizations used the "lowess" procedure in SPLUS (Venables and Ripley, 1999) to draw a smooth curve through the data while downweighting outliers that might affect the fit. The log-ratio for each spot was normalized by subtracting the value of the smooth curve at the "A" value (or Euclidean distance) associated with that spot.

An expression ratio was then computed for each gene on a slide by averaging the normalized log-ratios for all cDNA target spots representing that gene. The resulting ratios for each gene were then averaged across replicate hybridizations. Log-ratios were then converted into fold-differences.

\section{Statistical analysis of expression differences among tissues}

For each gene, ten log-ratio measurements (two mice $\mathrm{x}$ five tissues) were combined into an $\mathrm{F}$ statistic to determine whether expression ratio measurements varied among tissues. The F statistic consisted of a ratio of a numerator (the variability of the average log-ratio measurements among tissues) to a denominator (the variability of measurements for a given tissue between mice). Higher variability among tissues than within a tissue indicated that the average log-ratios differed between tissues. The numerator was computed by summing twice the squared differences between individual tissue average log-ratios (averaged across the two observations for a tissue) and the overall average log-ratio, and dividing by four (the number of tissues minus one). The denominator was computed by summing the squared difference between each 
measurement and the average of the two measurements for that tissue, and dividing by five (the number of measurements minus the number of tissues). Some F statistics were inflated by artificially low denominators (data not shown); therefore, the denominator was replaced by the maximum of the computed denominator for that gene and the median of the computed denominators across all genes.

The significance of each F-ratio was assessed by re-sampling methods (Good, 1994; Dudoit et al., in press). Briefly, if there were no expression differences among tissues, then the tissue label associated with each measurement would be considered irrelevant and could be permuted without affecting the random properties of the $\mathrm{F}$ statistic. An F statistic was computed for each possible assignment of the labels to measurements. The $\mathrm{p}$ value was then calculated as the proportion of the resulting $\mathrm{F}$ statistics that are at least as large as the statistic actually obtained. For a balanced experiment of five tissues and two mice per tissue, the number of distinct assignments is 113,400. However, these assignments can be broken down into 945 distinct groups, each of size 120 , in which the statistic has the same value. Hence, in this experimental design only $945 \mathrm{~F}$ statistics need to be evaluated for each gene, and the p value is one of 1/945, $2 / 945, \ldots, 945 / 945$.

Adjusted $\mathrm{p}$ values were calculated to account for the fact that $412 \mathrm{p}$ values, one for each gene with a full complement of ten measurements, were calculated. The stepdown algorithm described by Dudoit et al., and based on Algorithm 4.1 of Westfall and Young (1993), was applied to adjust p values upward.

Expression ratios for a gene were considered indistinguishable whenever the unadjusted $\mathrm{p}$ value exceeded 0.05 or the log-ratios differed by less than 2.6 times an 
estimate of the residual standard deviation for that gene. The number 2.6 corresponds to the threshold for Fisher's LSD method of multiple comparisons, which simplifies to the value of the upper 0.25 tail of the $t$ distribution with five degrees of freedom.

Cluster analysis of gene expression

Expression trends were evaluated using CLUSFAVOR (CLUSter and Factor Analysis Using Varimax Orthogonal Rotation; Peterson, 2002). Briefly, $\log _{10}$ gene expression ratios were clustered using the centroid average Euclidean distance between joining nodes. The resulting dendograms identified groups of differentially expressed genes among tissues.

Northern blot hybridization

Expression ratios were verified for Araf, Catalase, Cdk2, Gadd153, Gpxl, Gstp2, Rad52, Stat4 and Tdg using Multiple Tissue Northern (MTN) Blots (CLONTECH Laboratories, Inc., Palo Alto, CA). Probes were generated by PCR-amplification of mouse QUICK-Clone cDNA (CLONTECH Laboratories, Inc.) using the following primer sequences: Araf fwd: 5'-ATCCGCTCCACATCTACTCC-3' and rev: 5'CTATCCCCAAACCCAAGAGG-3; Cas-1 fwd: 5'-CCGTTCGGTTCTCCACAGTC-3 and rev: 5'-TGCGTTCTTAGGCTTCTCAG-3'; Cdk2 fwd: 5'TGCAGAGGGGTCCATCAAGC-3' and rev: 5'-AGGCCCAGGGTCAAGTCAGA-3'; Gadd153 fwd: 5'-GTCCCTGCCTTTCACCTTGG-3' and rev: 5'GGCGCTCGATTTCNTGCTTG-3'; Gpx1 fwd: 5'-CCACCGTGTATGCCTTCTCC-3' and rev: 5'-AGGCTATCCAAAAGGTGACA-3'; Gstp2 fwd: 5'- 
TGGAGACCTCACCCTTTACC-3' and rev: 5'-CCACTACTGTTTGCCATTGC-3'; Rad52 fwd: 5'-GTTACAATGGCTGGGCACAC-3' and rev: 5'CCCACATTTCAAGGTTCTCT-3'; Stat4 fwd:. 5'-ACTGGGAGTAAAGGAAACGAG3' and rev: 5'-GCACCAAGTGAGAAAGAGAGC-3'; and $T d g$ fwd: 5'GACCCGAGAGCAGGAAGAAG-3' and rev: 5'-CCCCGGACTCGTTACTCACC-3'. Primer specificity was confirmed using NCBI's BLAST. Amplicon sizes were confirmed on a $2 \%$ agarose gel. PCR products were purified, labeled, hybridized, and visualized as described by Coleman et al. (2000). Briefly, $100 \mathrm{ng}$ of each probe was $\left[\alpha-{ }^{32} \mathrm{P}\right] \mathrm{dCTP}-$ labeled using the Megaprime DNA Labeling System (Amersham, Arlington Heights, IL). Hybridizations were performed according to manufacturer's instructions. Probes were visualized with the Storm 860 PhosphorImager (Molecular Dynamics, Sunnyvale, CA). Quantitation was performed using a gel documentation system (NucleoTech, San Mateo, CA). All blots were normalized to actin- $\beta$. Normalized gene expression ratios were calculated by dividing each tissue measurement by the testis measurement. Ratio differences $\leq 2.0$-fold indicated similar expression among tissues.

\subsection{Results}

Normalization and expression ratio measurement variation

The plot of the non-normalized average log intensity vs. log expression ratio for each cDNA target in the pooled testes vs. pooled testes hybridization (i.e., two separate aliquots from pooled testes reference labeled with either Alexa Fluor 488-dUTPs or Alexa Fluor 546-dUTPs) showed a striking dependence on intensity (Figure 3.1A). After applying a lowess normalization (see Materials and Methods), the data scattered around a 
A.

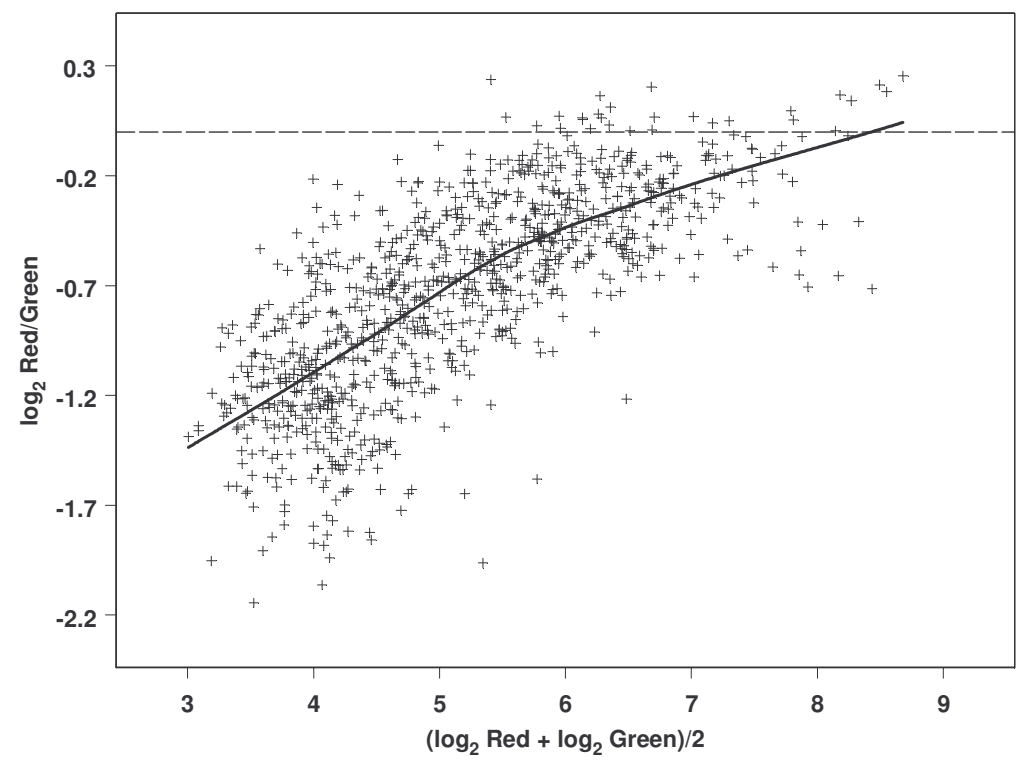

B.

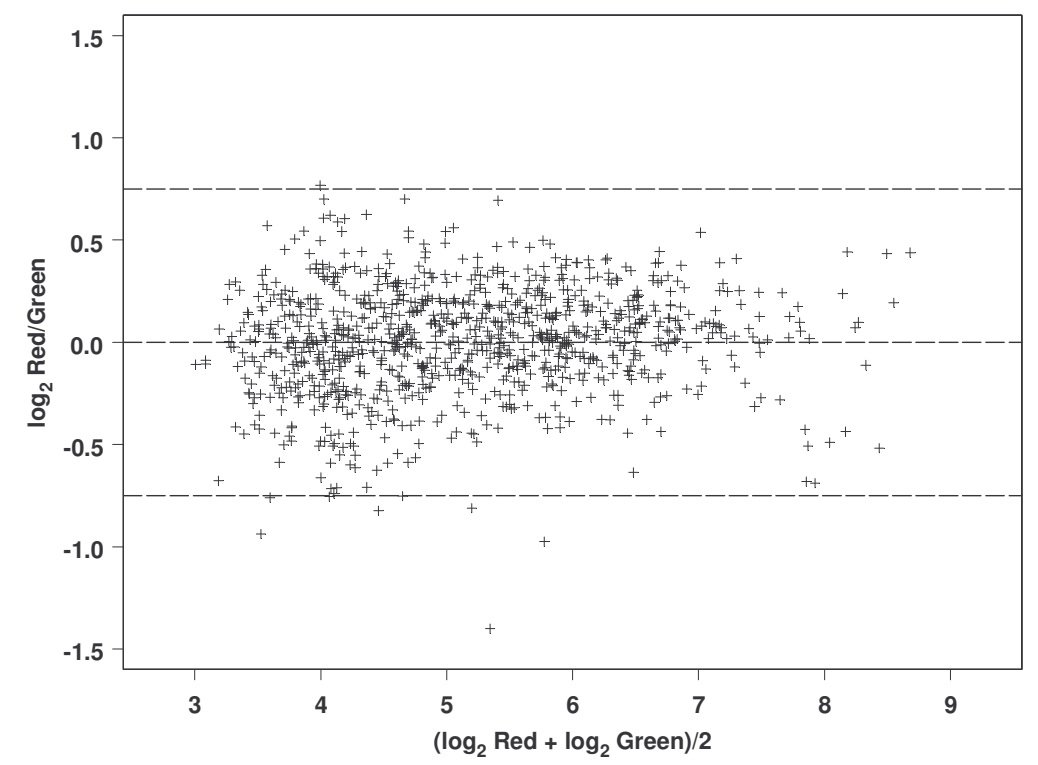

Figure 3.1. Intensity-based normalization of cDNA microarray data. Two aliquots from a pool of B6C3F1 testes were labeled with either Alexa Fluor 488 or Alexa Fluor 546 and co-hybridized onto the microarray. The average of the log of the red and green intensities (x-axis) vs. the log of the red:green ratio (y-axis) was plotted for each spot. The horizontal dashed line at a log-ratio of zero represents the expected ratio of 1. (A) The average log-intensity vs. log ratio for each cDNA spot on the array prior to normalization. The solid line represents the smooth curve drawn using the lowess procedure. (B) Data distribution following intensity-dependent normalization (see Materials and Methods section for details). 
log-ratio of zero (Figure 3.1B), as expected, with little residual bias due to intensity. In replicate pooled testes vs. pooled testes hybridizations, $>95 \%$ of the cDNA targets had log-ratios between -0.75 and +0.75 , corresponding to ratios between 0.60 and 1.68 . Because these normalization methods effectively minimized fluorophore- and intensitybased biases, they were applied to each microarray hybridization in this study.

To determine whether transcripts were similarly represented in the pooled testes sample and individual testis samples, expression ratio profiles for replicate individual testis vs. pooled testes hybridizations were analyzed. Gene expression ratios were not significantly different between the replicate hybridizations (data not shown); therefore, the replicate ratios for each gene were averaged (gray columns in Figure 3.2). These average gene expression ratios were similarly distributed around the expected value of 1.0 with $\sim 98 \%$ of all individual testis vs. pooled testes ratios between 0.60 and 1.68 (sum of all columns $\leq 1.7$ in Figure 3.2). Because this ratio distribution was not significantly different from the pooled testes vs. pooled testes ratio distribution, pooled testes were used as the reference tissue in subsequent hybridizations.

Animal-to-animal variation was assessed by analyzing the differences in gene expression ratios between replicate hybridizations of testis, spleen, brain or liver vs. pooled testes (Table 3.1). Average expression ratio differences at the $25^{\text {th }}, 50^{\text {th }}, 75^{\text {th }}$ and $95^{\text {th }}$ percentiles were $0.06,0.13,0.24$, and 0.62 , respectively. These differences were not significantly different from those observed for the pooled testes vs. pooled testes hybridizations. The minor amount of variation between replicate animals allowed gene expression ratios from replicate hybridizations to be averaged for subsequent analyses. 


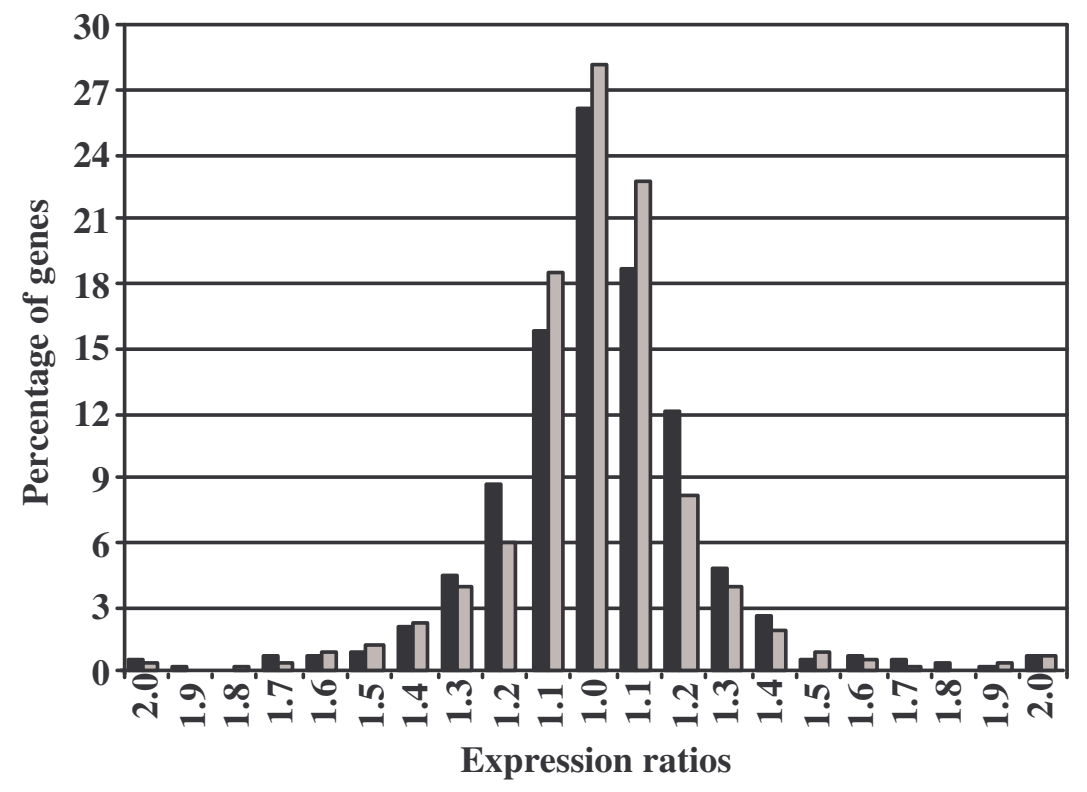

Figure 3.2. Distribution of normalized expression ratios for testes vs. testes hybridizations. The graph illustrates the percentage of genes (y-axis) with a given expression ratio (x-axis) following testes vs. testes hybridizations. Black columns represent the distribution of average expression ratios obtained from two independent hybridizations of pooled testes vs. pooled testes. Gray columns represent the distribution of average expression ratios obtained from two independent hybridizations of individual testis vs. pooled testes. Ratios that were higher in the Alexa Fluor 546-labeled pooled testes or individual testis samples are to the left of 1.0. Ratios that were higher in the Alexa Fluor 488-labeled pooled testes reference are to the right of 1.0. 
Table 3.1. Differences in the gene expression ratios from replicate independent hybridizations.

Differences between replicate ratio measurements ${ }^{\mathrm{a}}$

\begin{tabular}{|c|c|c|c|c|c|c|}
\hline \multirow[t]{2}{*}{ Percentile } & \multicolumn{5}{|c|}{ Tissues from individual mice ${ }^{b}$} & \multirow[t]{2}{*}{$\begin{array}{c}\text { Pooled } \\
\text { testes }\end{array}$} \\
\hline & Testis & Spleen & Brain & Liver & Average & \\
\hline 25th & 0.05 & 0.06 & 0.06 & 0.07 & 0.06 & 0.09 \\
\hline 50th & 0.10 & 0.12 & 0.13 & 0.16 & 0.13 & 0.17 \\
\hline 75th & 0.18 & 0.24 & 0.27 & 0.29 & 0.24 & 0.28 \\
\hline 95th & 0.34 & 0.57 & 0.69 & 0.91 & 0.62 & 0.62 \\
\hline
\end{tabular}

${ }^{\mathrm{a}}$ For each gene, the absolute value of the difference in replicate hybridization expression ratio measurements was determined. Differences were rank-ordered from lowest to highest and were examined at the 25th, 50th, 75th, and 95th percentiles.

${ }^{\mathrm{b}}$ Two hybridizations were performed for individual mouse tissues (testis, spleen liver, or brain) vs. pooled testes. Absolute differences were not calculated for heart because $>50 \%$ of the cDNA targets were irregularly shaped in one hybridization.

${ }^{c}$ Pooled testes vs. pooled testes hybridizations were used as an indicator of technical variation. 
Comparison of gene expression profiles among healthy adult mouse tissues

Based on the results above, gene expression ratios $\leq 0.68$ or $\geq 1.68$ were further evaluated for differential expression among tissues. Ratios $\leq 0.60$ indicated higher expression in the testis, while ratios $\geq 1.68$ indicated higher expression in brain, heart, liver or spleen. Figure 3.3 summarizes the distribution of the 152 genes that were differentially expressed in at least one tissue-tissue comparison (brain, spleen, heart, or liver vs. testis). See Appendix A for a complete list of the 152 genes showing differential expression among mouse tissues. A subset of 105 genes showed significantly higher expression (unadjusted $\mathrm{p}$ values $\leq 0.05$ ) in a single tissue ( 71 genes), in two tissues ( 23 genes), in three tissues ( 7 genes) or in four tissues ( 4 genes). Relatively higher baseline levels of gene expression were observed most often in heart (24 genes higher only in heart; 37 genes higher in heart and at least one other tissue) and testis (21 genes higher only in testis; 43 genes higher in testis and at least one other tissue).

Genes with expression ratios outside of the 0.60 to 1.68 range were further analyzed for tissue-specific differences in expression using cluster analysis (Figure 3.4). When a vertical line was drawn through the cluster branch points so that the joining nodes to the immediate right of the line would group only $\sim 10 \%$ of the genes into subclusters of $\leq 5$ genes, nine major ( $>5$ genes) and seven minor ( $\leq 5$ genes) sub-clusters were observed. Among these sub-clusters, we identified groups of genes whose expression was specifically higher in either heart (sub-cluster I), brain (sub-cluster III), liver (sub-cluster V), spleen (sub-cluster X), or testis (sub-clusters VII, VIII, and XI). For example, Acrv1 and Sycp3, which are known to be involved in spermatogenesis and fertility, were part of the testis-specific sub-cluster XI. We also identified clusters of 


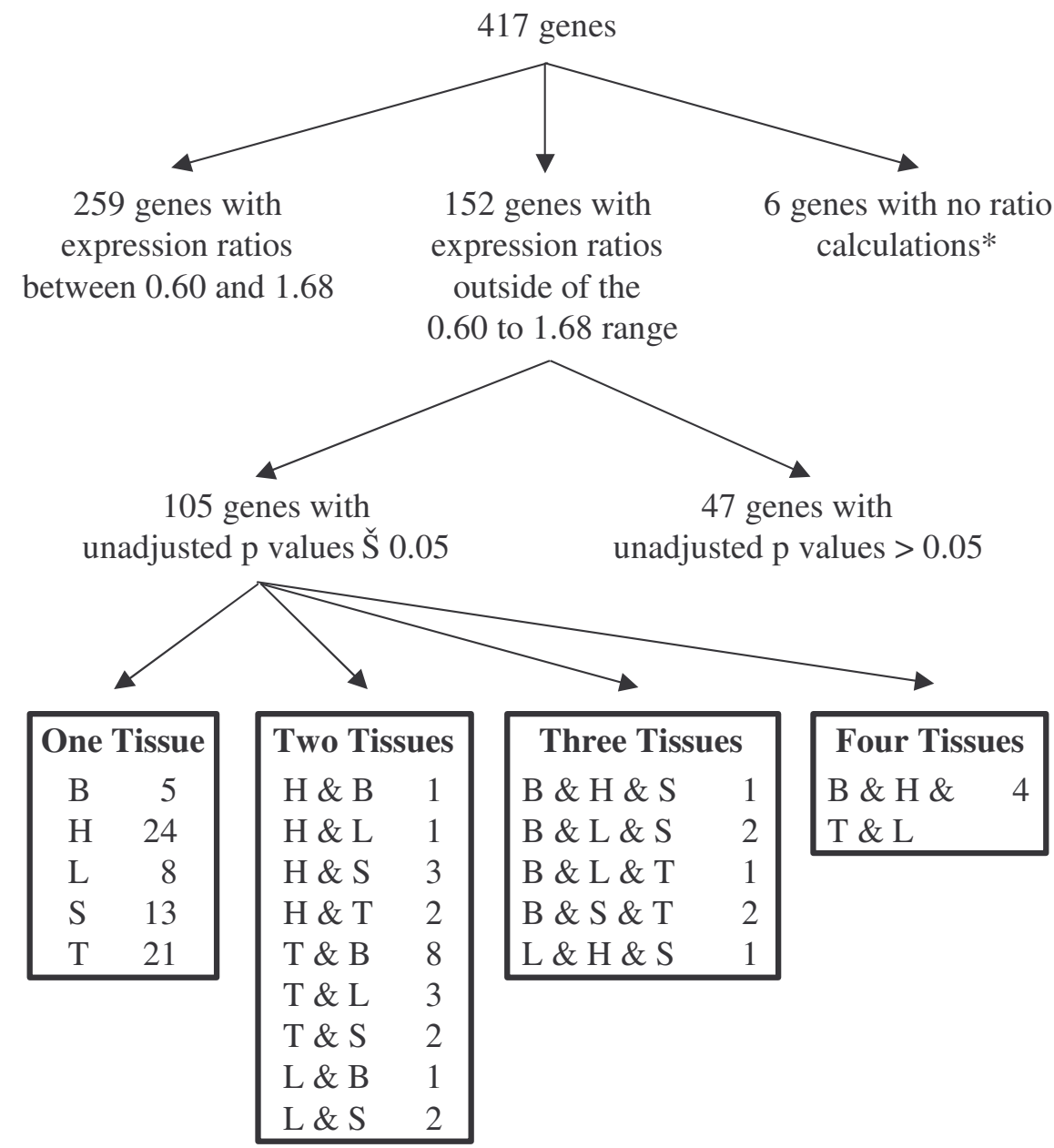

Figure 3.3. Distribution of gene expression results among tissues. Genes with ratios $\leq$ 0.60 are considered to be higher in testes. Genes with ratios $\geq 1.68$ are considered to be higher in brain, liver, spleen, and/or heart. $\mathrm{H}=$ Heart, $\mathrm{L}=$ Liver, $\mathrm{T}=$ Testis, $\mathrm{S}=$ Spleen, $\mathrm{B}$ $=$ Brain. $*$ No ratio calculations were made for 1 or more replicate hybridizations because the target spots representing these genes were obscured by debris. 


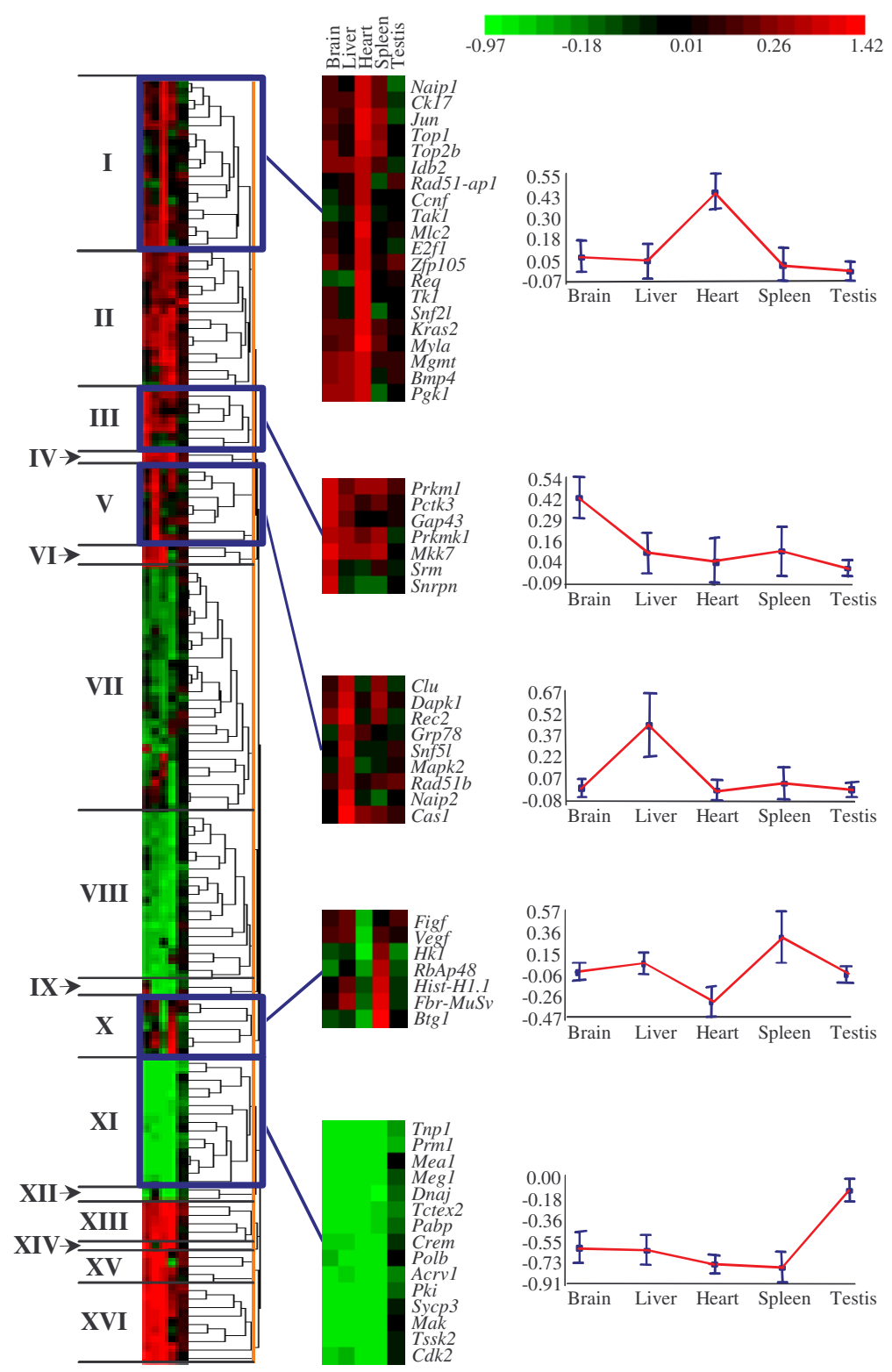

Figure 3.4. Cluster analysis of genes using CLUSFAVOR. Each column in the cluster represents one tissue (from left to right: brain, liver, heart, spleen, and testis). Each row represents one gene. Joining nodes to the immediate right of the orange vertical line determined the extent of each sub-cluster. The sixteen sub-clusters are indicated by Roman numerals I-XVI. Highlighted regions of the dendogram illustrate examples of genes that cluster together based on tissuespecific elevated expression (e.g., top sub-cluster shows genes with elevated heart expression compared to other tissues). Graphs corresponding to each sub-cluster illustrate the mean log expression ratio for the subcluster ( \pm the standard deviation for that sub-cluster) in each tissue. 
genes with relatively higher expression in either two, three, or four tissues (e.g., Gstp2, which is involved in stress response, was higher in heart, brain, and liver than in spleen and testis).

Genes with expression ratios outside of the 0.60 to 1.68 range were then grouped into one of eight biological pathways (Table 3.2). The stress response pathway had the greatest percentage of genes $(55 \%)$ with differential expression while genes involved in DNA repair had the lowest percentage (20\%) of differential expression. Approximately $32 \%$ of the genes involved in damage control were differentially expressed among tissues.

As shown in Table 3.3, the stress response genes were further subdivided, based on function, into oxidative stress or heat shock response. Oxidative stress genes were generally expressed highest in the heart (e.g., Sod3) and in the liver (e.g., Cas 1), with the exception of heme-oxygenase 2 (Hmox2) which exhibited the highest expression in testis. Among the heat shock response genes, the Dnaj-related genes had higher expression in the testis, while the Hsp110-related gene Apglb tended to have elevated expression in non-testis tissues.

For genes involved in DNA repair, the highest levels of expression were generally observed in testis (e.g., Pol-b, Pcna and Mre11). However, a few genes exhibited higher expression in other tissues (i.e., $T d g$ and $M g m t$ were highly expressed in spleen and heart, respectively).

Genes with functions related to damage control (i.e., apoptosis and cell cycle) exhibited differential expression among tissues as well. The cell cycle-related genes tended to have higher expression in testis (e.g., $C d k 2$ ), while the genes involved in 
Table 3.2. Distribution of $F$ ratios for differentially expressed genes with respect to biological pathway.

\begin{tabular}{|c|c|c|c|c|c|c|}
\hline \multirow[b]{2}{*}{ Biological pathway } & \multirow[b]{2}{*}{$\begin{array}{l}\text { \# genes } \\
\text { arrayed } \\
\end{array}$} & \multirow[b]{2}{*}{$\begin{array}{c}\% \text { differentially } \\
\text { expressed genes }\end{array}$} & \multicolumn{4}{|c|}{ F ratio ${ }^{b}$} \\
\hline & & & $<6$ & $6-10$ & $11-25$ & $>25$ \\
\hline \multirow[t]{2}{*}{ Chromatin-related } & 24 & 46 & 13 & 21 & 4 & 8 \\
\hline & & & (4) & (21) & $(0)$ & (8) \\
\hline \multirow[t]{2}{*}{ Damage control } & 65 & 32 & 14 & 5 & 8 & 6 \\
\hline & & & (6) & $(5)$ & (6) & (6) \\
\hline \multirow[t]{2}{*}{ DNA repair } & 51 & 20 & 12 & 4 & 2 & 2 \\
\hline & & & (2) & (4) & (2) & (2) \\
\hline \multirow[t]{2}{*}{ Growth regulation } & 80 & 36 & 16 & 5 & 11 & 4 \\
\hline & & & (6) & $(5)$ & (11) & (4) \\
\hline \multirow[t]{2}{*}{$\begin{array}{l}\text { Meiosis / } \\
\text { Spermatogenesis }\end{array}$} & 20 & 45 & 30 & 5 & 5 & 5 \\
\hline & & & (10) & $(0)$ & (5) & $(5)$ \\
\hline \multirow[t]{2}{*}{$\begin{array}{l}\text { Stress response / } \\
\text { Stress induced }\end{array}$} & 22 & 55 & 14 & 5 & 9 & 27 \\
\hline & & & $(0)$ & (5) & (9) & (27) \\
\hline \multicolumn{7}{|l|}{ Transcription / } \\
\hline \multirow[t]{2}{*}{ Translation } & 58 & 41 & 14 & 10 & 12 & 5 \\
\hline & & & $(5)$ & (9) & (12) & (5) \\
\hline \multirow[t]{2}{*}{ Miscellaneous } & 97 & 37 & 10 & 8 & 7 & 11 \\
\hline & & & $(0)$ & $(8)$ & (7) & (11) \\
\hline \multirow[t]{2}{*}{ Total } & 417 & 36 & 14 & 7 & 8 & 7 \\
\hline & & & (4) & (7) & (7) & (7) \\
\hline
\end{tabular}

${ }^{a}$ Genes with expression ratios outside of the 0.60 to 1.68 range in at least one tissue.

${ }^{b}$ Percentage of genes in each $\mathrm{F}$ ratio category; Number in parentheses indicate the percentage of genes with significant unadjusted $\mathrm{p}$ values( $\breve{\mathrm{S}}$ 0.05). See Materials and Methods. 
Table 3.3. Differentially expressed stress response, DNA repair and damage control genes.

Pathway \& gene
Function $^{\text {a } \quad \text { Ratio to pooled testes }}$

Testis Brain Liver Spleen Heart Num. Denom. Ratio ${ }^{\text {b }}$

Unadj. p value $^{c}$

\section{Stress \\ response}

Apg $1 b$

Dnaj

Dnajl1

Cas-1

Gadd153

Gpx 1

Gstp2

Hmox 2

Sod3

DNA repair

Pol- $\beta$

Tdg

Ung

Mgmt

Mrel1

Rad51B

$R f_{c} 40$

Pcna

Damage

control

Bmp4

Gap43

Gas2

Naip2

Rip1

Smp30

Tfar15

Mcll

Btg1

Cdc 2

Cdc $2 a$

Cdc 42

$C d k 2$

Paga

$\begin{array}{lccccccccc}\text { GS } & 0.9 & 0.8 & 0.6 & 0.5^{*} & 0.7 & 0.19 & 0.09 & 2.1 & 0.204 \\ \text { HS } & 1.1 & 1.8^{*} & 2.2^{*} & 1.5 & 2.5^{*} & 0.42 & 0.02 & 9.2^{\wedge} & 0.001 \\ \text { HS } & 0.7 & 0.2^{*} & 0.2^{*} & 0.1^{*} & 0.2^{*} & 1.99 & 0.03 & 43.5^{\wedge} & 0.001 \\ \text { HS } & 0.9 & 0.6 & 0.6 & 0.3^{*} & 0.5 & 0.94 & 0.02 & 20.7^{\wedge} & 0.001 \\ \text { OS } & 1.1 & 1.0 & 8.3^{*} & 1.2 & 1.4 & 3.26 & 0.10 & 31.3 & 0.017 \\ \text { OS } & 1.1 & 1.8 & 1.9 & 0.6 & 5.4^{*} & 2.79 & 0.10 & 28.6 & 0.003 \\ \text { OS } & 1.1 & 3.4^{*} & 4.2^{*} & 2.1^{*} & 26.5^{*} & 5.93 & 0.13 & 46.2 & 0.003 \\ \text { OS } & 1.1 & 4.0^{*} & 5.2^{*} & 0.9 & 18.0^{*} & 6.05 & 0.06 & 106.0 & 0.001 \\ \text { OS } & 0.8 & 0.6^{*} & 0.5^{*} & 0.3^{*} & 0.3^{*} & 0.82 & 0.05 & 15.1 & 0.001 \\ \text { OS } & 1.2 & 2.6^{*} & 2.6^{*} & 0.8 & 8.8^{*} & 3.59 & 0.06 & 62.4 & 0.002\end{array}$

BER

$\begin{array}{llllll}1.0 & 0.5 * & 0.3 * & 0.2 * & 0.2 * & 2.32\end{array}$

0.05

$50.8^{\wedge}$

0.001

BER

$1.3 \quad 1.9 * \quad 1.8^{*} \quad 4.4^{*} \quad 1.9 *$

0.88

0.01

$19.3^{\wedge}$

0.001

BER

$0.9 \quad 0.5^{*} \quad 0.5$

$0.5^{*}$

$0.3 *$

0.13

4.9

0.221

DDR

$1.1 \quad 1.4$

DSBR

1.0

$0.8 \quad 0.6$

$\begin{array}{ccc}1.6 & 1.1 & 2.8^{*} \\ 0.6 & 0.5^{*} & 0.7\end{array}$

61

0.0

NER

0.9

1.12.

NER

1.0

$0.6 \quad 0.5$

.0*

1.1
$0.4^{*}$

1.0

0.28

0.08

$7.0^{\wedge}$

0.001

.001

0.100

0.017

${ }^{\mathrm{a}} \mathrm{GS}=$ Generalized Stress Response; OS = Oxidative Stress; HS = Heat-Shock; BER = Base Excision Repair; DDR = Direct Damage Reversal; DSBR = Double Strand Break Repair; NER = Nucleotide Excision Repair; AP = Apoptosis; $\mathrm{CC}=$ Cell Cycle

${ }^{\mathrm{b}} \mathrm{F}$ ratio $=$ Numerator/Denominator (see Materials and Methods)

${ }^{\mathrm{c}}$ Unadjusted $p$ values for the F ratios (see Materials and Methods)

*Replicate hybridizations had expression ratios Š 0.60 or $\square 1.68$.

${ }^{\wedge}$ Denominator was replaced by the median denominator value $(0.0456)$ before calculating the $\mathrm{F}$ ratio. 
apoptosis tended to be more highly expressed in non-testis tissue (e.g., Smp30 in liver and Rip1 in heart).

\section{Northern blot confirmation of cDNA microarray results}

Expression ratios obtained from the cDNA microarrays were verified for nine genes using northern blots. These genes were selected across the following biological pathways: stress response (Cas1, Gstp2, Gadd153, Gpxl), DNA repair (Rad52, Tdg), damage recognition (Cdk2), growth regulation (Araf), and transcription/translation (Stat4). Although the specific expression ratios varied slightly between the microarrays and the multiple tissue northern blots, there was strong agreement overall between the relative rank-order of expression among tissues (Figure 3.5). For example, although the microarray-based ratio measurements for $G p x l$ were consistently higher than the northern blot measurements, the relative rank-order of expression was very similar with the exception of heart, which had a much higher ratio than all of the other tissues according to the microarray. Additionally, both methods showed that the oxidative stress response gene Cas 1 exhibited the highest levels of expression in the liver (microarray: 8.3-fold higher than testis; northern blot: 9.0-fold higher than testis) with similar levels of expression among the testes, spleen, and brain (microarray range: 1.0 to 1.4-fold; northern blot: 0.8 to 1.0 -fold). 
A.

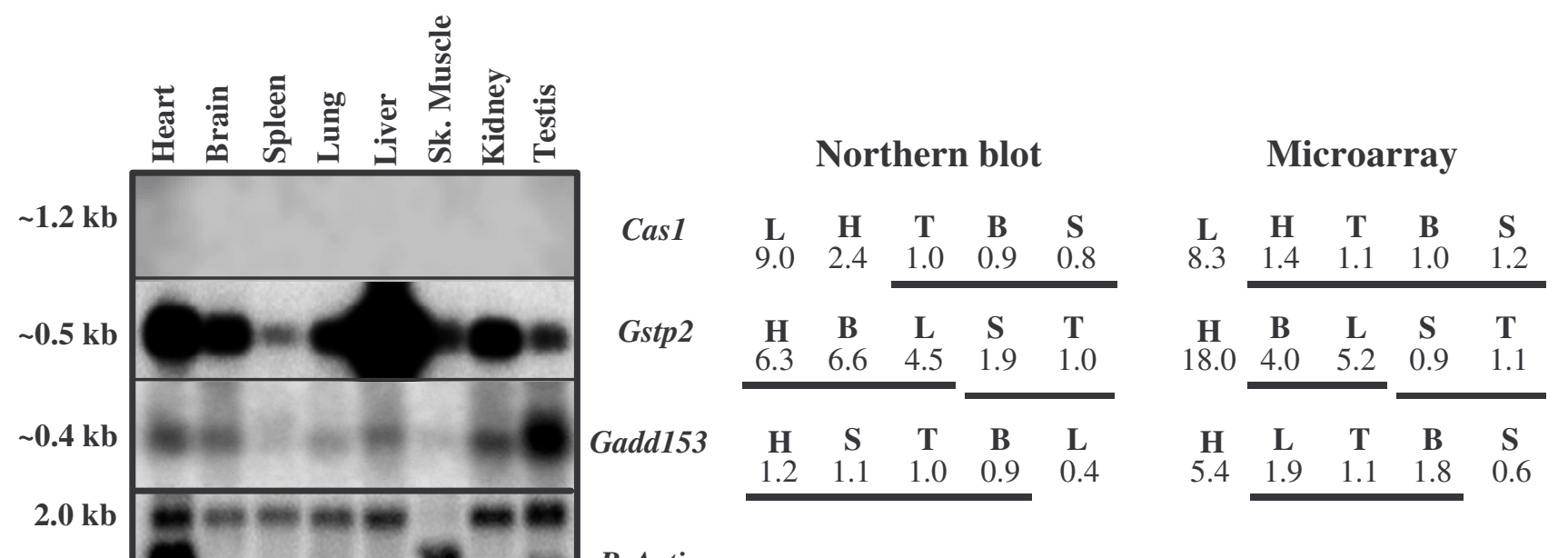

B-Actin

B.

\begin{tabular}{|c|c|c|c|c|c|c|c|c|c|c|}
\hline \multirow[b]{2}{*}{ Araf } & \multicolumn{5}{|c|}{ Northern blot } & \multicolumn{5}{|c|}{ Microarray } \\
\hline & $\begin{array}{r}\mathbf{H} \\
1.3\end{array}$ & $\begin{array}{c}\mathbf{L} \\
1.1\end{array}$ & $\begin{array}{c}\mathbf{T} \\
1.0\end{array}$ & $\begin{array}{c}\mathbf{S} \\
0.9\end{array}$ & $\begin{array}{c}\text { B } \\
0.7\end{array}$ & $\begin{array}{r}\mathbf{H} \\
1.0\end{array}$ & $\begin{array}{c}\mathbf{L} \\
0.9\end{array}$ & $\begin{array}{c}\mathbf{T} \\
1.0\end{array}$ & $\begin{array}{c}\mathbf{S} \\
0.7\end{array}$ & $\begin{array}{c}\text { B } \\
0.9\end{array}$ \\
\hline$C d k 2$ & $\begin{array}{c}\mathbf{T} \\
1.0\end{array}$ & $\begin{array}{c}\mathbf{S} \\
0.6\end{array}$ & $\begin{array}{c}\mathbf{L} \\
0.4\end{array}$ & $\begin{array}{c}\mathbf{B} \\
0.4\end{array}$ & $\begin{array}{c}\mathbf{H} \\
0.2\end{array}$ & $\begin{array}{c}\mathbf{T} \\
0.9\end{array}$ & $\begin{array}{c}\mathbf{S} \\
0.2\end{array}$ & $\begin{array}{c}\mathbf{L} \\
0.5\end{array}$ & $\begin{array}{c}\mathbf{B} \\
0.3\end{array}$ & $\begin{array}{c}\mathbf{H} \\
0.2\end{array}$ \\
\hline Gpx1 & $\begin{array}{c}\mathbf{S} \\
1.4\end{array}$ & $\begin{array}{c}\mathbf{B} \\
1.2\end{array}$ & $\begin{array}{c}\mathbf{T} \\
1.0\end{array}$ & $\begin{array}{c}\mathbf{H} \\
0.9\end{array}$ & $\begin{array}{c}\mathbf{L} \\
0.7\end{array}$ & $\begin{array}{c}\mathbf{S} \\
2.1\end{array}$ & $\begin{array}{c}\text { B } \\
3.4\end{array}$ & $\begin{array}{c}\mathbf{T} \\
1.1\end{array}$ & $\begin{array}{c}\mathbf{L} \\
4.2 \\
\end{array}$ & $\underset{26.5}{\mathbf{H}}$ \\
\hline Rad52 & $\begin{array}{c}\mathbf{L} \\
1.4\end{array}$ & $\begin{array}{c}\mathbf{H} \\
1.0\end{array}$ & $\begin{array}{c}\mathbf{T} \\
1.0\end{array}$ & $\begin{array}{c}\text { B } \\
0.5\end{array}$ & $\begin{array}{c}\mathbf{S} \\
0.0\end{array}$ & $\begin{array}{c}\mathbf{L} \\
0.9 \\
\end{array}$ & $\begin{array}{c}\mathbf{H} \\
0.8\end{array}$ & $\begin{array}{c}\mathbf{T} \\
1.1 \\
\end{array}$ & $\begin{array}{c}\mathbf{B} \\
0.8\end{array}$ & $\begin{array}{c}\mathbf{S} \\
0.8\end{array}$ \\
\hline Stat4 & $\underset{1.0}{\mathbf{T}}$ & $\begin{array}{c}\mathbf{L} \\
0.1\end{array}$ & $\begin{array}{c}\mathbf{S} \\
0.2\end{array}$ & $\begin{array}{c}\text { B } \\
0.2\end{array}$ & $\begin{array}{c}\mathbf{H} \\
0.0\end{array}$ & $\begin{array}{c}\mathbf{T} \\
0.8\end{array}$ & $\begin{array}{c}\mathbf{L} \\
1.0\end{array}$ & $\begin{array}{c}\mathbf{S} \\
0.2\end{array}$ & $\begin{array}{c}\mathbf{B} \\
0.3\end{array}$ & $\begin{array}{c}\mathbf{H} \\
0.2\end{array}$ \\
\hline Tdg & $\begin{array}{c}\mathbf{B} \\
2.1\end{array}$ & $\begin{array}{c}\mathbf{S} \\
1.9\end{array}$ & $\begin{array}{c}\mathbf{H} \\
1.6\end{array}$ & $\begin{array}{c}\mathbf{L} \\
1.0\end{array}$ & $\begin{array}{l}\mathbf{T} \\
1.0\end{array}$ & $\underset{4.4}{\mathbf{S}}$ & $\begin{array}{c}\text { B } \\
1.9\end{array}$ & $\begin{array}{r}\mathbf{H} \\
1.9\end{array}$ & $\begin{array}{c}\mathbf{L} \\
1.8\end{array}$ & $\begin{array}{c}\mathbf{T} \\
1.3\end{array}$ \\
\hline
\end{tabular}

Figure 3.5. Comparison of northern blot and cDNA microarray results for selected genes. Expression ratios were calculated as the value for the tissue of interest divided by the value for testis. Tissues were rank-ordered from highest to lowest expression on the northern blot. $(\mathrm{H}=$ Heart, $\mathrm{L}=$ Liver, $\mathrm{T}=$ Testis, $\mathrm{S}=$ Spleen, $\mathrm{B}=$ Brain.) Genes differing by $\leq 2$-fold among tissues on the northern blot were considered to be similarly expressed (horizontal bar). Microarraybased $\log$ expression ratios for each gene were also rank-ordered (highest to lowest). If the log-ratio difference between 2 tissues was $<2.6 \mathrm{x}$ (square root of the residual standard deviation), the gene was similarly expressed (horizontal bar). (A) Northern blot images and northern blot vs. microarray results. (B) Northern blot vs. microarray results for additional genes. 


\subsection{Discussion}

cDNA microarray hybridizations revealed tissue-specific differences in the basal levels of transcript abundance for chromatin-related, damage recognition, DNA repair, growth regulation, meiosis, stress response, and transcription/translation genes. Overall, 152 of the 417 arrayed genes (36\%) had expression ratios outside of the 0.60 to 1.68 range, and $25 \%$ were significantly differentially expressed among healthy tissues.

Experiments with split samples and replicate hybridizations demonstrated the precision and reproducibility of the microarray protocols used in this study. The generally strong agreement between the microarray and northern blot data demonstrated the accuracy of our findings.

The unadjusted p-values used to assess the significance of differential gene expression among tissues were expected to be somewhat overly optimistic. With over 400 genes being tested, we expected $\sim 20$ genes to appear significantly different at the 0.05 level, even when no expression differences existed between tissues. However, after applying an extremely conservative indicator of differential expression (see Materials and Methods), only $\sim 7 \%$ of the genes were still significantly differentially expressed (adjusted $\mathrm{p} \leq 0.05$ ) among tissues. In fact, when evaluated by their adjusted p-values, only genes with $\mathrm{F}$ ratios $\geq 25$ were considered to be significantly different among tissues. The challenge for future microarray studies will be to develop statistical analyses methods that compromise between the overly conservative adjusted p-values and the overly permissive unadjusted p-values.

Sixteen general patterns of differential tissue expression were observed following cluster analysis. Among the major sub-clusters, we identified genes that were similarly 
expressed across tissues with the exception of higher expression in (a) one tissue (testis, heart, liver, brain, or spleen), (b) two tissues (heart and spleen), or (c) three tissues (brain, liver, and heart). We also identified minor sub-clusters of genes that had similar expression across tissues with the exception of higher expression in (a) two tissues (brain and testis), (b) three tissues (brain, liver, and heart or brain, heart, and spleen), or (c) four tissues (brain, liver, heart, and spleen or brain, heart, spleen, and testis).

After assigning genes into one of eight biological pathways, we observed that the stress response genes showed the most variation in basal gene expression among tissues, DNA repair genes had the lowest variation among tissues, and damage control genes showed intermediate levels of variation.

Stress response genes

Oxidative damage produced by reactive oxygen species (ROS) has been implicated in mutagenesis, inflammatory and autoimmune diseases, aging and cancer (Guyton et al., 1996; Lenzen et al., 1996; Loft and Poulsen, 2000; Li et al., 2001). ROS are continuously generated through the process of aerobic metabolism; however, the extent of ROS-related damage in cells depends upon the balance between ROS production, antioxidant scavenger capacity, and the efficiency of repair (Hollensworth et al., 2000; Loft and Poulsen, 2000).

We found that higher expression of oxidative stress response genes was generally observed in liver, heart, and brain compared to spleen and testis (with the exception of Hmox2). Similar tissue-specific expression patterns have been reported for several of these oxidative stress-related genes, including catalase and glutathione peroxidase, 
(Lenzen et al., 1996). These results, considered together with the observation that certain stress genes (e.g., Gadd153) have significantly higher basal expression levels in $\mathrm{O}_{2^{-}}$ resistant versus control cell lines (Guyton et al., 1996), raise the question of whether these tissues may have differential responses to oxidative stress.

Heat shock response provides protection against a variety of stress-inducing agents (including heat shock, oxidative stress, heavy metals, and inflammation) by either refolding or degrading damaged proteins (Jolly and Morimoto, 2000). We found that the differentially expressed heat shock response genes typically exhibited the highest expression in the testis, with the exception of Apglb. Since up-regulation of heat shock gene expression occurs during stress and non-stress (e.g., cell cycle and differentiation) conditions (Jolly and Morimoto, 2000; Pirkkala et al., 2001), it is uncertain whether our finding may simply reflect variations in tissue physiology or tissue-specific variations in the ability to respond to stress stimuli.

\section{Damage control genes}

In our study, genes involved in apoptosis and/or cell cycle regulation were categorized as damage control genes. Cells that have been damaged by various environmental exposures (e.g., ionizing radiation) may be removed by apoptosis, or programmed cell death. However, apoptosis is also critical for day-to-day health maintenance in the absence of exogenous exposures. It has been shown to play an important role in processes such as physiological cell turnover (Medh and Thompson, 2000) and development (Meier et al., 2000). Our results indicate that the baseline expression of apoptosis-associated genes is usually highest in liver and heart and lowest 
in testis and spleen. We found that Smp30 had significantly higher basal gene expression levels in the liver than the other tissues evaluated. This finding correlates well with the suggestion by Fujita that SMP30 is essential for some of the highly differentiated functions of the liver (1999). Furthermore, we found that the differentially expressed genes function in different portions of the apoptotic pathway (e.g., initial signaling events, caspase substrates, etc.).

While the cell division cycle genes $C d c 2$ and $C d c 2 a$ and the cyclin dependent kinase gene $C d k 2$ exhibited the highest expression in testis (Table III), the remaining cell cycle-related genes exhibited higher expression in non-testis tissues even though some of them have similar functions. For example, both $C d k 2$ and $C d c 42$ are involved in progression through G1 into the S-phase of the cell cycle (Olson et al., 1995; Tsai et al., 1993). Yet, we found that these genes have very different patterns of expression among tissues.

\section{DNA repair genes}

We found that genes involved in nearly every DNA repair pathway were differentially expressed among tissues and that testis generally exhibited the highest levels of expression. Genes involved in base excision repair (BER) tended to be more highly expressed in the testis, with the exception of $T d g$ which exhibited the highest levels of expression in the spleen and other somatic tissues. These findings correlate well with the finding that BER activity initiated by uracil DNA glycosylase is highest in mixed testicular germ cell extracts (Intano et al., 2001). More specifically, Intano et al. 
found that protein levels for polymerase $\beta$ were much higher in mixed germ cells than in brain and liver.

We found that the direct damage reversal (DDR) enzyme Mgmt (or O6methylguanine-DNA methyltransferase), which is responsible for removing DNA lesions caused by alkylation, had the highest expression in heart. To our knowledge, this is the first report that Mgmt transcripts have higher abundance in the heart than in liver, brain, spleen and testis.

Among the genes involved in double stranded DNA break repair, we found that Mrell showed the highest expression in testis which complements the finding of Chamankhah et al. in human testis (1998). Our finding that Rad51B was most highly expressed in the liver contrasts the suggestion by Albala et al. who reported that the expression of this gene is highest in actively recombining tissues (1997). However, it should also be noted liver was not among the tissues evaluated in the study by Albala et al.

Our results show that a few of the nucleotide excision repair (NER) genes represented on our cDNA microarray were differentially expressed among tissues. Genes encoding the p40 subunit of replication factor C (RFC) and Pcna exhibited the highest levels of expression in testis. These results are particularly interesting because the p40 subunit represents 1 of 5 RFC subunits required for Pcna-dependent DNA synthesis (Uhlmann et al. 1997).

Although DNA repair genes showed the least variation in expression among all of the biological pathways surveyed, we found that genes involved in four out of five DNA repair pathways were differentially expressed among tissues. A possible explanation why 
differential expression was not detected for more of the DNA repair genes represented on our microarray is that low signal intensities may have affected our ability to detect expression differences for certain genes. Other groups have also reported low transcript abundance for certain DNA repair genes under normal physiological conditions (e.g., Xrcc1, Walter et al., 1994).

Our finding that transcriptional profiles for DNA repair genes vary among tissues may suggest that tissues have different DNA repair capacities. This suggestion is further supported by the finding that the induction of genotoxic damage, by chemicals such as acrylamide and acrylonitrile, may result in tissue-specific carcinogenic activity (Butterworth et al. 1992).

\section{Summary}

Through the use of cDNA microarray technology, this study takes an important step toward understanding global differences in gene expression among healthy adult tissues. Differences in basal gene expression levels among tissues may contribute to the observed differential tissue responses to DNA damaging agents such as cadmium, lead, ionizing radiation, etc. (Amundson et al. 1999; Fornace et al. 1999; Valverde et al. 2000; Valverde et al. 2002). By characterizing the differential basal expression of genes involved in DNA damage response, recognition, and repair processes among tissues, this research contributes to our understanding of tissue-specific responses to genotoxic agents and may also provide insight on the differential susceptibility to the onset and progression of cancer. 
Future studies are needed to address the relative contributions of tissue microenvironments to differential basal expression levels among healthy tissues and to evaluate the involvement of these microenvironments in differential tissue responses to DNA damaging conditions. In addition, endeavors to identify groups of genes with coordinated expression (i.e., synexpression groups) and to assess transcript vs. protein abundance as well as post-transcriptional and post-translational differences among tissues will further enhance our understanding of variations in the response to and processing of DNA damage among healthy tissues.

\subsection{Acknowledgements}

Special thanks to Brenda Marsh for her preparation of the cDNA microarray targets, Dr. Rajiv Raja for his assistance in arraying the cDNA targets, Dorreyah SchahinReed for her assistance with the tissue extractions, and Dr. Leif E. Peterson for his assistance with the CLUSFAVOR analysis of the microarray data. This work was performed under the auspices of the U.S. Department of Energy by the University of California, Lawrence Livermore National Laboratory under Contract No. W-7405-Eng48 with support from NIH ES09117; NIEHS Superfund P4ZES04705; the Low Dose Radiation Research Program, Biological and Environmental Research (BER), U.S. DOE grant KP110202; the University of California and West Virginia University. 


\subsection{References}

Albala, J.S., Thelen, M.P., Prange, C., Fan, W., Christensen, M., Thompson, L.H., and Lennon, G.G. (1997). Identification of a novel human RAD51 homolog, RAD51B. Genomics 46, 476-479.

Alizadeh, A.A., Ross, D.T., Perou, C.M., and van de Rijn, M. (2001). Towards a novel classification of human malignancies based on gene expression patterns. J. Pathol. 195, 41-52.

Amundson, S.A., Bittner, M., Meltzer, P., Trent, J., and Fornace, A.J. (2001). Induction of gene expression as a monitor of exposure to ionizing radiation. Radiat. Res. 156, 657661.

Amundson, S.A., Bittner, M., Chen, Y., Trent, J., Meltzer, P., and Fornace, A.J. (1999). Fluorescent cDNA microarray hybridization reveals complexity and heterogeneity of cellular genotoxic stress responses. Oncogene 18, 3666-72.

Burns, T.F., Bernhard, E.J., and El-Deiry, W.S. (2001). Tissue specific expression of p53 target genes suggests a key role for KILLER/DR5 in p53-dependent apoptosis in vivo. Oncogene 20,4601-12. 
Butterworth, B.E., Eldridge, S.R., Sprankle, C.S., Working, P.K., Bentley, K.S., and Hurtt, M.E. (1992). Tissue-specific genotoxic effects of acrylamide and acrylonitrile. Environ. Mol. Mutagen. 20, 148-55.

Chamankhah, M., Wei, Y.F., and Xiao, W. (1998). Isolation of hMRE11B: failure to complement yeast mre11 defects due to species-specific protein interactions. Gene 225, 107-116.

Coleman, M.A., Eisen, J.A., and Mohrenweiser, H.W. (2000). Cloning and characterization of HARP/SMARCAL1: A prokaryotic HepA-related SNF-2 helicase protein from human and mouse. Genomics 65, 274-282.

DeRisi, J., Penland, L., Brown, P.O., Bittner, M.L., Meltzer, P.S., Ray, M., Chen, Y., Su, Y.A., and Trent, J.M. (1996). Use of a cDNA microarray to analyse gene expression patterns in human cancer. Nat. Genet. 14, 457-60.

Dudoit, S., Yang, Y. H, Speed, T. P., and Callow, M. J. (2002). Statistical methods for identifying differentially expressed genes in replicated cDNA microarray experiments. Statistica Sinica. In press.

Fornace, A.J., Amundson, S.A., Bittner, M., Myers, T.G., Meltzer, P., Weinsten, J.N., and Trent, J. (1999). The complexity of radiation stress responses: analysis by informatics and functional genomics approaches. Gene Expr. 7, 387-400. 
Fujita, T. (1999). Senescence marker protein-30 (SMP30): structure and biological function. Biochem. Biophys. Res. Commun. 254, 1-4.

Good, P. (1994). Permutation Tests. New York: Springer-Verlag.

Guo, Z., Guilfoyle, R.A., Thiel, A.J., Wang, R., and Smith, L.M. (1994). Direct fluorescence analysis of genetic polymorphisms by hybridization with oligonucleotide arrays on glass supports. Nucleic Acids Res. 22, 5456-5465.

Guyton, K.Z., Spitz, D.R., and Holbrook, N.J. (1996). Expression of stress response genes Gadd153, c-jun, and heme oxygenase-1 in $\mathrm{H}_{2} \mathrm{O}_{2}$ - and $\mathrm{O}_{2}$-resistant fibroblasts. Free Radic. Biol. Med. 20, 735-741.

Hollensworth, S.B., Shen, C.C., Sim, J.E., Spitz, D.R., Wilson, G.L., and LeDoux, S.P. (2000). Glial cell type-specific responses to menadione-induced oxidative stress. Free Radic. Biol. Med. 28, 1161-1174.

Intano, G.W., McMahan, C.A., Walter, R.B., McCarrey, J.R., and Walter, C.A. (2001). Mixed spermatogenic germ cell nuclear extracts exhibit high base excision repair activity. Nucleic Acids Res. 29, 1366-1372. 
Jolly, C., and Morimoto, R.I. (2000). Role of the heat shock response and molecular chaperones in oncogenesis and cell death. J. Nat. Can. Inst. 92, 1564-1572.

Kegelmeyer, L.M., Tomascik-Cheeseman, L., Burnett, M.S., van Hummelen, P., and Wyrobek, A.J. (2001). A groundtruth approach to accurate quantitation of fluorescence microarrays. SPIE Proceed. 4266, 35-45.

Leasure, C.S., Chandler, J., Gilbert, D.J., Householder, D.B., Stephens, R., Copeland, N.G., Jenkins, N.A., and Sharan, S.K. (2001). Sequence, chromosomal location and expression analysis of the murine homologue of human RAD51L2/RAD51C. Gene 271, $59-67$.

Lenzen, S., Drinkgern, J., and Tiedge, M. (1996). Low antioxidant enzyme gene expression in pancreatic islets compared with various other mouse tissues. Free Radic. Biol. Med. 20, 463-466.

Li. W.G., L., Miller, F.J., Zhang, H.J., Spitz, D.R., Oberley, L.W., and Weintraub, N.L. (2001). $\quad \mathrm{H}_{2} \mathrm{O}_{2}$-induced $\mathrm{O}_{2}$ production by a non-phagocytic NAD(P)H oxidase causes oxidant injury. J. Biol. Chem. 276, 29251-29256.

Loft, S., and Poulsen, H.E. (2000). Antioxidant intervention studies related to DNA damage, DNA repair and gene expression. Free Radic. Res. 33, S67-83. 
Medh, R.D., and Thompson, E.B. (2000). Hormonal regulation of physiological cell turnover and apoptosis. Cell Tissue Res. 301, 101-24.

Meier, P., Finch, A., and Evan, G. (2000). Apoptosis in development. Nature 407, 796801.

Olson, M.F., Ashworth, A., and Hall, A. (1995). An essential role for Rho, Rac, and Cdc42 GTPases in cell cycle progression through G1. Science 269, 1270-2.

Peterson, L.E. (2002). Factor analysis of cluster-specific gene expression levels from cDNA microarrays. Comput. Methods Programs Biomed. In press.

Pirkkala, L., Nykanen, P., and Sistonen, L. (2001). Roles of the heat shock transcription factors in regulation of the heat shock response and beyond. FASEB J. 15, 1118-31.

Pittman, D.L., Weinberg, L.R., and Schimenti, J.C. (1998). Identification, characterization, and genetic mapping of Rad51d, a new mouse and human RAD51/RecArelated gene. Genomics 49, 103-11.

Tsai, L.H., Lees, E., Faha B., Harlow, E., and Riabowol, K. (1993). The cdk2 kinase is required for the G1-to-S transition in mammalian cells. Oncogene 8, 1593-602. 
Uhlmann, F., Gibbs, E., Cai, J., O’Donnell, M., and Hurwitz, J. (1997). Identification of regions within the four small subunits of human replication factor $\mathrm{C}$ required for complex formation and DNA replication. J. Biol. Chem. 272, 10065-10071.

Valverde, M., Fortoul, T.I., Diaz-Barriga, F., Mejia, J., and del Castillo, E.R. (2000). Induction of genotoxicity by cadmium chloride inhalation in several organs of CD-1 mice. Mutagen. 15, 109-114.

Valverde, M., Fortoul, T.I., Diaz-Barriga, F., Mejia, J., and del Castillo, E.R. (2002). Genotoxicity induced in CD-1 mice by inhaled lead: differential organ response. Mutagen. 17, 55-61.

Venables, W.N., and Ripley, B.D. (1999). Modern Applied Statistics with S-Plus. 3rd Ed. New York:Springer-Verlag.

Walter, C.A., Lu, J., Bhakta, M., Zhou, Z.Q., Thompson, L.H., and McCarrey, J.R. (1994). Testis and somatic Xrcc-1 DNA repair gene expression. Somat. Cell. Mol. Genet. 20, 451-61.

Westfall, P.H., and Young, S.S. (1993). Resampling-based multiple testing: examples and methods for p-value adjustment. Wiley Series in Probability and Mathematical Statistics. New York: Wiley. 
Yang, Y. H., Dudoit, S., Luu, P., and Speed, T. P. (2001). Normalization for cDNA microarray data. SPIE Proceed. 4266, 141-152. 


\section{Mitotic and Meiotic Gene Expression Profiling of}

\section{Male Germ Cells}

\subsection{Abstract}

The purpose of this research was to characterize gene expression profiles for $\sim 10,000$ genes as germ cells differentiated from spermatogonia into primary spermatocytes and to identify the genes and biological pathways associated with these periods in spermatogenesis. Expression was characterized in the testes of prepubertal B6C3F1 mice during spermatogonial mitosis (postnatal day 7), at the onset of meiosis (postnatal day 9), and during the mid-pachytene stage of meiosis I (postnatal day 14). Approximately 550 genes were found to be differentially expressed across these time points, including 428 genes that exhibited differential expression between spermatogonial mitosis and the onset of meiosis (383 with relatively higher spermatogonial expression; 45 genes with relatively higher preleptotene expression). An additional 70 genes showed differential expression between early and mid-meiosis I (25 with higher pachytene expression; 35 with higher preleptotene expression). The remaining 46 genes exhibited complex temporal expression patterns (differential expression during the mitosis to meiosis transition and also during meiosis I). These results show that a genome-scale 
approach for investigating gene expression during spermatogenesis allows the (a) characterization of temporal expression patterns for genes with known roles in germ cell differentiation, (b) identification of new spermatogenesis-related roles for genes with functions previously characterized in other biological pathways, and (c) discovery of novel pre-meiosis and meiosis-enriched genes. These findings lay the foundation for understanding molecular mechanisms of the mitotic to meiotic transition and meiosis, genetic changes associated with male infertility, and susceptibility factors affecting the transmission of mutations to offspring following paternal exposure to genotoxic agents.

\subsection{Introduction}

Spermatogenesis can be divided into three phases: proliferative (mitosis), meiotic, and post-meiotic. Both the mitotic and meiotic phases occur within the seminiferous tubules of the testis. Spermiogenesis begins in the seminiferous tubules, and final sperm maturation occurs in the epididymis. The timing of germ cell progression through spermatogenesis has been well characterized in humans and rodents (Ham, 1974; Bellve et al., 1977).

Male germ cell development begins in the fetal mouse at 8-8.5 days post-coitum (d.p.c.) when cells in the primitive ectoderm differentiate to form primordial germ cells (PGCs). These PGCs, or prespermatogonia, divide and migrate to the genital ridge by 13.5 d.p.c where they arrest in $\mathrm{G}_{1}$ of the mitotic cell cycle until after birth (Hogan et al., 1986). The first wave of spermatogenesis begins in the prepubertal mouse at postnatal (p.n.) day 5-6 with the initiation of spermatogonial stem cell mitosis (Bellve et al., 1977). 
Mitotic divisions give rise to other spermatogonial stem cells and type $A_{1}$ spermatogonia that will subsequently differentiate and mitotically divide to form $\mathrm{A}_{2^{-}}, \mathrm{A}_{3^{-}}, \mathrm{A}_{4^{-}}$, Intermediate-, and B-type spermatogonia (Thomas et al., 1989). On p.n. day 9, the first type B spermatogonia divide to form spermatocytes (meiotic cells). Preleptotene spermatocytes undergo the last DNA replication (S phase) and enter the long prophase of meiosis I (Bellve et al., 1977). During prophase I, the leptotene spermatocytes differentiate through zygotene (chromosome synapsis), pachytene (recombination and increased RNA synthesis), and diplotene (synaptonemal complex degeneration and RNA synthesis). This prolonged prophase I lasts until p.n. day 18 when the primary spermatocytes undergo a reductional division to become secondary spermatocytes (Thomas et al. 1989). The first and second meiotic divisions occur in rapid succession, forming the first round spermatids by p.n. day 20 (Bellve et al., 1977). The process of spermiogenesis takes approximately 13.5 days (Gilbert, 1994). It is estimated that a new wave of mouse spermatogenesis is initiated every 8.6 days (Oakberg, 1956); therefore, the second wave of spermatogenesis is initiated at approximately p.n. day 14-15 in the prepubertal mouse.

The histophysiological characteristics of germ cell differentiation in the testis have been well documented (e.g., Bellve et al., 1977; Russell et al., 1990). Germ cells remain connected by intercellular cytoplasmic bridges as they differentiate from the type $A_{1}$ spermatogonial stage through the spermatid stage (Gilbert, 1994). This syncytial organization is thought to promote synchronous male germ cell differentiation by allowing ions, molecules and gene products to be shared among cells (Braun et al., 1989; Gilbert, 1994). A number of studies have shown that the expression of one or a small 
number of genes across critical phases of germ cell development affects progression through mouse spermatogenesis. For example, Schrans-Stassen et al. showed that $c$-kit expression is a molecular marker for the transition of prespermatogonial cells into differentiating type A spermatogonial cells (1999). Additionally, it has been suggested that the stage-specific expression of certain genes, such as topoisomerase II, may be required for progression through meiosis I (Cobb et al., 1997). Recent advances in expression microarray technology provide an opportunity to develop a more complete understanding of the expression profiles of a large number of genes that contribute to the onset and progression of spermatogenesis.

The objective of this research was to investigate the expression profiles of genes in the prepubertal mouse testis as germ cells differentiate through the mitotic and meiotic compartments during the first wave of spermatogenesis. Random oligonucleotide microarrays containing $~ 10,000$ annotated genes and unannotated sequences were used to identify clusters of genes that were differentially expressed (a) during the transition from spermatogonial mitosis to meiosis and (b) during early and mid-meiosis I (preleptotene vs. pachytene I).

\subsection{Materials and Methods}

\section{Probe generation}

B6C3F1 male mice (Harlan Sprague Dawley, Indianapolis, IN) were kept on a 12 hour light/dark cycle and were allowed food and water ad libitum. Mice were euthanized by cervical dislocation at each of the following postnatal time points: spermatogonial 
mitosis (day 7), onset of meiosis/preleptotene (day 9), mid-meiosis/pachytene (day 14), and adult mice ( 8 weeks). Immediately following euthanization, testes were extracted from 4 - 6 mice per experimental time point, and microdissected under a dissection microscope to remove the tunica albuginea and isolate the seminiferous tubules. The tubules were stored at $-80^{\circ} \mathrm{C}$ until RNA isolation was performed.

Total RNA was isolated by homogenization (Omni Tissue Homogenizer, Warrenton, VA) in TRIzol Reagent (Life Technologies, Rockville, MD). RNA was ethanol precipitated twice, resuspended in RNase-free water (Sigma, St. Louis, MO), and purified using RNeasy (Qiagen, Valencia, CA). Purified RNA was quantitated using the GeneQuant spectrophotometer (Amersham Pharmacia Biotech, Piscataway, NJ).

First and second strand cDNA synthesis was performed using a starting quantity of $8 \mu \mathrm{g}$ of total RNA. To synthesize first strand cDNA, RNA was primed with an HPLC purified T7-(dT) 24 primer (final concentration: 100 pmol; Integrated DNA Technologies, Coralville, IA) and reverse transcribed at $42^{\circ} \mathrm{C}$ using Superscript II reverse transcriptase (Life Technologies) in the presence of unlabeled dNTPs (Amersham Pharmacia Biotech). Second strand synthesis was performed using DNA polymerase I (Life Technologies) and DNA ligase (Life Technologies) in the presence of RNase H (Life Technologies) to incorporate unlabeled dNTPs (Amersham Pharmacia Biotech). The synthesized cDNA was purified using the QIAquick Purification Kit (Qiagen). RNA was biotin-labeled during in vitro transcription reactions using the BioArray HighYield RNA Transcript Labeling Kit (Enzo Diagnostics, Inc., Farmingdale, NY). The amplified, labeled RNA was then purified using the RNeasy Mini Kit (Qiagen). Prior to hybridization, approximately $20 \mu \mathrm{g}$ of labeled RNA was fragmented in a buffer comprised of $200 \mathrm{mM}$ 
tris-acetate (Sigma), $500 \mathrm{mM}$ potassium acetate (Sigma), and $150 \mathrm{mM}$ magnesium acetate (Sigma).

\section{Hybridization and image capture}

Two pools of independently prepared testes were hybridized per experimental group. The fragmented labeled probe was hybridized to Affymetrix Murine Genome U74Av.1 microarrays (Affymetrix, Inc., Santa Clara, CA) according to manufacturer's directions. Briefly, the probe mixture for each hybridization was comprised of $5 \mu \mathrm{g}$ fragmented probe, Affymetrix eukaryotic hybridization controls (BioB: 1.5 pmol; BioC: 5 pmol; BioD: 25 pmol; cre: $100 \mathrm{pmol}$ ), $10 \mu \mathrm{g}$ herring sperm DNA (Life Technologies), 50 $\mu \mathrm{g}$ acetylated bovine serum albumin (Life Technologies), and the Affymetrix hybridization buffer (100 mM MES/1M sodium salt/20 mM EDTA/0.01\% Tween 20). Hybridizations were performed for 16 hours at $45^{\circ} \mathrm{C}$ in an Affymetrix hybridization oven set at $60 \mathrm{rpm}$. The hybridized arrays were then washed and stained with streptavidin phycoerythrin (SAPE) on the Affymetrix Fluidics Station according to manufacturer's directions (Affymetrix, Inc.). Images were captured using the Agilent Gene Array laser scanner (Agilent Technologies, Palo Alto, CA).

\section{Data normalization and analysis}

To normalize the array data, a quantile normalization scheme was applied at the probe level (Irizarry et al., 2002) using an R statistical package that is publicly available at: http://biosun01.biostat.jhsph.edu/ ririzarr/Raffy. Following normalization, all genes with MicroArray Suite 5.0 (Affymetrix, Inc.) detection p-values $\leq 0.005$ (in at least one 
hybridization) were selected for pairwise comparisons of gene expression between time points. Using the replicate $\log _{2}$ intensity values obtained for each gene, a two-sample student's t distribution was performed, assuming unequal variance (Dowdy and Wearden, 1991), for each of the following comparisons: spermatogonial mitosis vs. onset of meiosis, onset of meiosis vs. mid-pachytene of MI, and mid-pachytene of MI vs. adult. Genes with t-test p-values $\leq 0.05$ and expression ratios $\geq 1.8$ were considered to be differentially expressed between time points and were further characterized according to their function in a given biological pathway.

\section{Cluster analysis of expression}

Expression trends were characterized for all genes with a MicroArray Suite 5.0 detection p-value $\leq 0.005$ using the unsupervised hierarchical cluster analysis program CLUSFAVOR (CLUSter and Factor Analysis Using Varimax Orthogonal Rotation; Peterson, 2002). Briefly, $\log _{10}$ gene expression intensities were clustered using the centroid average Euclidean distance between joining nodes. The resulting dendograms identified groups of genes that were differentially expressed between specific time points during the first wave of spermatogenesis in the prepubertal mouse and full spermatogenesis in the adult mouse. 


\subsection{Results}

Temporal Gene Expression During the First Wave of Mouse Spermatogenesis

As shown in Figure 4.1, gene expression profiles were investigated in the seminiferous tubules obtained from prepubertal mice euthanized at times that correspond to when the most advanced cell types of the first wave of spermatogenesis were at the following: spermatogonial mitosis (p.n. day 7), onset of meiosis (preleptotene; p.n. day 9), and mid-pachytene stage of meiosis I (MI; p.n. day 14). Of approximately 10,000 genes evaluated on the Affymetrix Murine U74Av.1 microarray, 3986 genes had significant signal intensities (Affymetrix MAS 5.0 detection p-value $\leq 0.005$ ) at one or more experimental time points, indicating that they were expressed. Of these, 544 genes (231 annotated genes and 313 unannotated sequences) exhibited significant temporal changes in expression (Student's t-test p-value $\leq 0.05$ ) in the prepubertal mouse testis, as further described below. Among the 544 differentially expressed genes, 428 were differentially expressed between spermatogonial mitosis and preleptotene (but were not differentially expressed between preleptotene and pachytene), 70 were differentially expressed between preleptotene and pachytene (but were not differentially expressed between spermatogonial mitosis and preleptotene), and 46 exhibited complex patterns of expression (i.e., differential expression between spermatogonial mitosis and preleptotene and also between preleptotene and pachytene). The temporally expressed annotated genes have a variety of biological functions, as shown in Tables $4.1-4.3$ and Appendix B. Therefore, each gene was also classified according to whether or not it had a previously described role in germ cell development or differentiation, meiosis, spermatogenesis, and/or fertilization. 


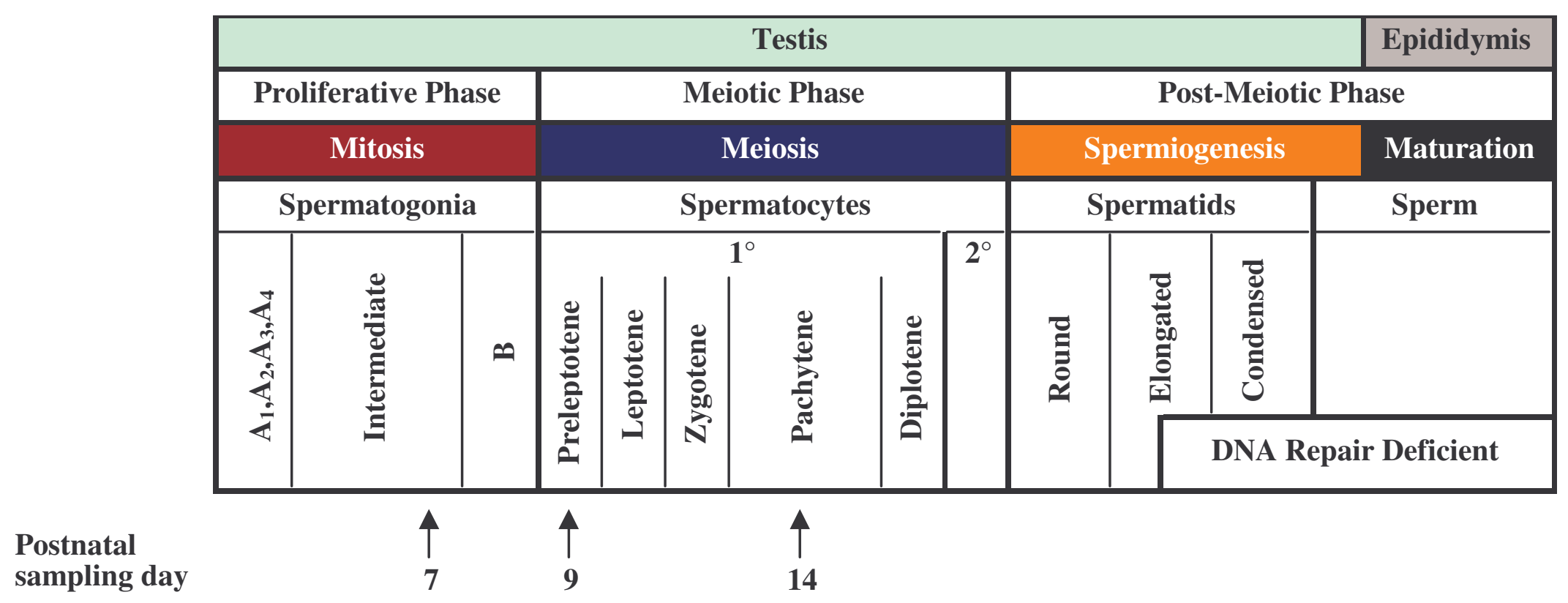

Figure 4.1 Ge rm cell progression through mouse spermatogen esis. Male germ cells differentiate through three phas es: proliferative, meiotic, andpos t-meiotic (left to right). The proliferative phas e inc ludes the mitotic divisions of sper matogon ial cells. The meiotic pha se includes the first and second divisions of primary and seconda ry spermatocy tes, resp ective ly. The post-meiotic phas e include s the morphological tran sformation of the round haploid spermatid into testicu lar spe rm, and biochemical maturation of spe rm which occu rs in the epididymis. 
The genes that were differentially expressed between spermatogonial mitosis and the onset of meiosis may have important functions during the transition from mitosis to meiosis. As shown in Figure 4.2, 187 of the 428 genes were annotated while the remaining 241 were unannotated sequences. Among the 187 annotated genes, 14 exhibited higher expression at the onset of meiosis, and the remaining 173 genes had higher expression during spermatogonial mitosis. The expression data for these 187 annotated genes is listed in Appendix B. Specific roles in spermatogenesis were previously reported for only $37(\sim 20 \%)$ of the annotated genes (Appendix B). Examples of the annotated genes that exhibited relatively higher expression levels during the onset of meiosis are listed in Table 4.1. These genes may be important for the transition into the meiotic phase of spermatogenesis. For example, $Z f x$ which is important for cellular differentiation during spermatogenesis is expressed $\sim 2.7$-fold higher in preleptotene cells than in the mitotic cells $(\mathrm{p}=0.05)$ and this higher level of expression is still observed in pachytene cells $(\mathrm{p}=0.2$; data not shown). Examples of genes that exhibited relatively higher expression during spermatogonial mitosis are also listed in Table 4.1. These genes may have important roles in spermatogonial mitosis; however, it is also possible that their decreased expression is necessary for the transition into meiosis. For example, the cell cycle-related gene $P l k l$ had higher expression during mitosis than in preleptotene cells $(\sim 2.6$-fold increase; $\mathrm{p}=0.03)$ and the lower level of expression in preleptotene cells was still observed during pachytene I ( $\mathrm{p}=0.60$; data not shown). The 241 differentially expressed unannotated sequences (31 with higher preleptotene expression; 210 with higher mitotic expression), which may represent novel genes with roles in the mitosis to meiosis transition, are listed in Appendix C. 


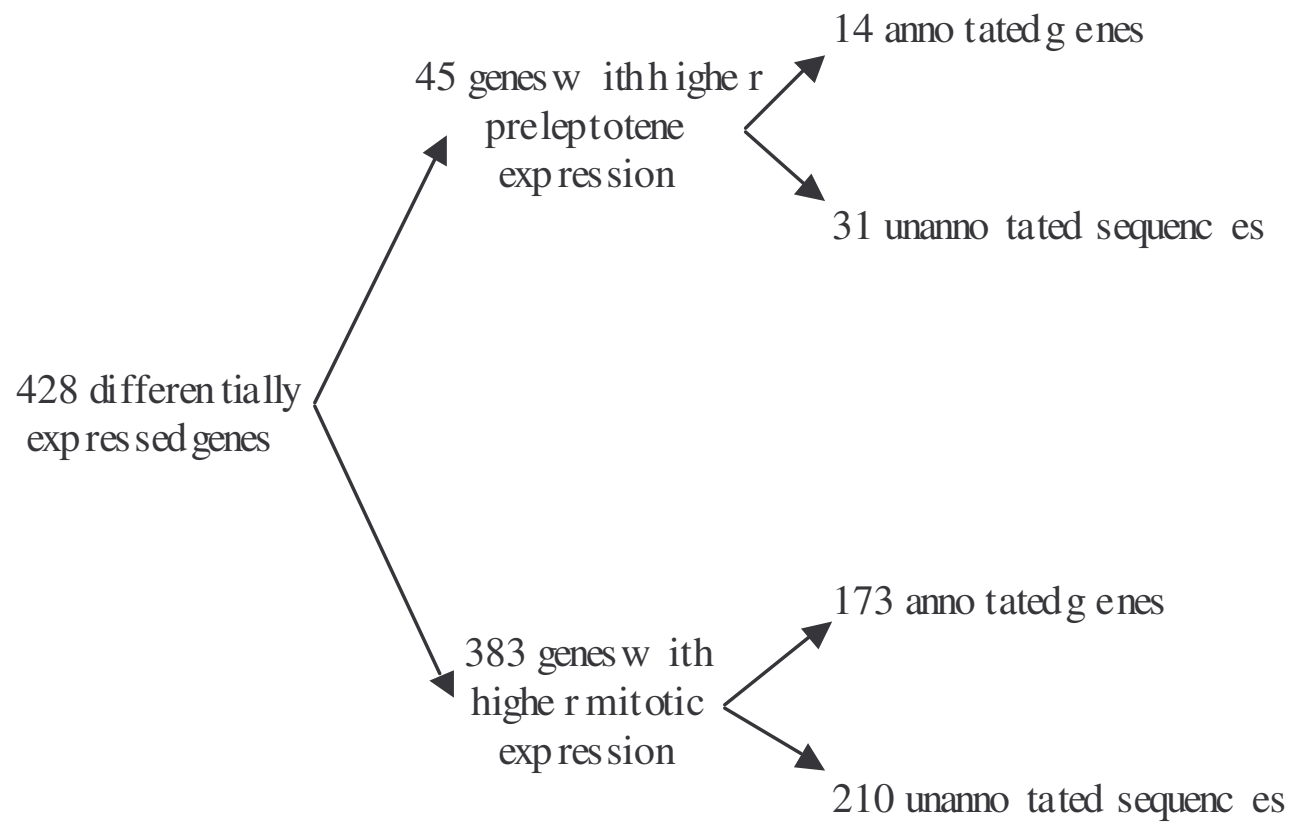

Figure 4.2. Gene s that were differen tially expressed be tween mitosis and the ons et of meiosis (but not be tween early and mid-meios is). 
Table 4.1. Examples of genes with differential expression between mitosis and the onset of meiosis.

\begin{tabular}{|c|c|c|c|c|c|c|c|}
\hline \multirow[t]{2}{*}{ Name } & \multirow[t]{2}{*}{ Symbol } & \multirow[t]{2}{*}{ Function } & \multirow{2}{*}{$\begin{array}{c}\text { GenBank } \\
\text { Accession } \\
\text { ID }\end{array}$} & \multicolumn{2}{|c|}{$\begin{array}{l}\text { Fold-difference in } \\
\text { expression }\end{array}$} & \multirow{2}{*}{\multicolumn{2}{|c|}{$\begin{array}{l}\text { Previously described role in } \\
\text { reproduction? }{ }^{\mathrm{b}}\end{array}$}} \\
\hline & & & & Ratio & P-value ${ }^{a}$ & & \\
\hline \multicolumn{8}{|c|}{ Genes with increased expression as germ cells progress from mitosis to the onset of meiosis } \\
\hline Ig germline H-chain gene V-region & $\operatorname{IgH}($ germline $)$ & Immune response & M16724 & 6.8 & 0.001 & Yes & (Kerr and Burrows, 1991) \\
\hline Zinc finger protein $\mathrm{X}$-linked & $Z f x$ & Cellular differentiation & M32309 & 2.7 & 0.05 & Yes & (Luoh et al., 1997) \\
\hline DNA methyltransferase & Dnmt1 & Transcription & AF036008 & 1.7 & 0.01 & Yes & (Mertineit et al., 1998) \\
\hline Methylmalonyl coenzyme A mutase & Mut & Metabolism & X51941 & 11.9 & 0.04 & No & \\
\hline Sprouty-4 & Spry4 & Signal transduction & AB019280 & 5.6 & 0.02 & No & \\
\hline Transactivating transcription factor 3 & Sp3 & Transcription & AF062567 & 3.8 & 0.01 & No & \\
\hline ADP-ribosyltransferase 5 & Art5 & Protein modification & U60881 & 2.3 & 0.03 & No & \\
\hline Cryptochrome 1 & Cryl & Molecular clock & AB000777 & 2.1 & 0.01 & No & \\
\hline \multicolumn{8}{|c|}{ Genes with decreased expression as germ cells progress from mitosis to the onset of meiosis } \\
\hline Glutathione peroxidase 4 & Gpx4 & Stress response & D87896 & 44.1 & 0.03 & Yes & (Giannattasio et al., 1997) \\
\hline DEAD box polypeptide, Y chromosome & Dby & RNA helicase & AJ007376 & 11.4 & 0.03 & Yes & (Mazeyrat et al., 2001) \\
\hline Flap structure specific endonuclease 1 & Fenl & DNA repair & L26320 & 7.0 & 0.04 & Yes & (Harrington and Lieber, 1994) \\
\hline Bcl2-associated X protein & $\operatorname{Bax}$ & Apoptosis & L22472 & 6.4 & 0.01 & Yes & (Russell et al., 2002) \\
\hline Breast cancer 2 & Brca2 & DNA repair & U89652 & 3.5 & 0.02 & Yes & (Connor et al., 1997) \\
\hline Polo-like kinase 1 & Plk1 & Cell cycle & U73170 & 2.6 & 0.03 & Yes & (Matsubara et al., 1995) \\
\hline RNA binding motif 3 & $R b m 3$ & Stress response & AB016424 & 1.9 & 0.04 & Yes & (Danno et al., 2000) \\
\hline Myeloid cell leukemia sequence 1 & Mcll & Apoptosis & U35623 & 14.9 & 0.02 & No & \\
\hline Thioredoxin & Txn1 & Stress response & X77585 & 10.9 & 0.001 & No & \\
\hline Cyclin F & Ccnf & Cell cycle & Z47766 & 9.0 & 0.04 & No & \\
\hline Programmed cell death 6 & Pdcd6 & Apoptosis & U49112 & 4.4 & 0.01 & No & \\
\hline DNA polymerase zeta catalytic subunit & $\operatorname{Rev} 3 l$ & DNA repair & AF083464 & 2.8 & 0.02 & No & \\
\hline
\end{tabular}

a Student's t-test p-values Š 0.05 indicate significant differences in expression across time points (see Materials and Methods)

${ }^{\mathrm{b}}$ Genes with described roles in germ cell development or differentiation, meiosis, spermatogenesis, or fertilization 
As shown in Figure 4.3, there were 70 genes that were differentially expressed between preleptotene and pachytene of meiosis I (25 with higher pachytene expression; 35 with higher preleptotene expression). Only 25 of the 70 genes were annotated, including 10 with known roles related to spermatogenesis (Table 4.2). Nine of the 25 annotated genes showed higher expression during pachytene I (e.g., the recombinationassociated gene Sycpl was $\sim 5.7$-fold higher in pachytene compared to preleptotene; $\mathrm{p}=$ 0.02). The remaining 16 annotated genes exhibited higher expression during preleptotene (e.g., Zfp49 had 3.8-fold higher expression in preleptotene compared to pachytene; $\mathrm{p}=$ 0.01). The expression of these genes may be important for spermatogonial mitosis and the onset of meiosis and/or their decreased expression may be necessary for progression through meiosis I. The 45 unannotated sequences that were also differentially expressed during meiosis I (16 with higher pachytene expression; 29 with higher preleptotene expression; Figure 4.3) are listed in Appendix C.

Forty-six genes (19 annotated and 27 unannotated) showed complex patterns of expression. They were differentially expressed between spermatogonial mitosis and the onset of meiosis and also between the onset of meiosis and mid-meiosis I (Figure 4.4). As shown in Figure 4.4 and Table 4.3, three temporal patterns of expression were observed: (1) increased expression from mitosis to preleptotene and decreased expression from preleptotene to pachytene (1 annotated gene; 2 unannotated sequences); (2) decreased expression from mitosis to preleptotene and increased expression from preleptotene to pachytene (10 annotated genes; 15 unannotated sequences); and (c) continual decrease in expression from mitosis to preleptotene and from preleptotene to 


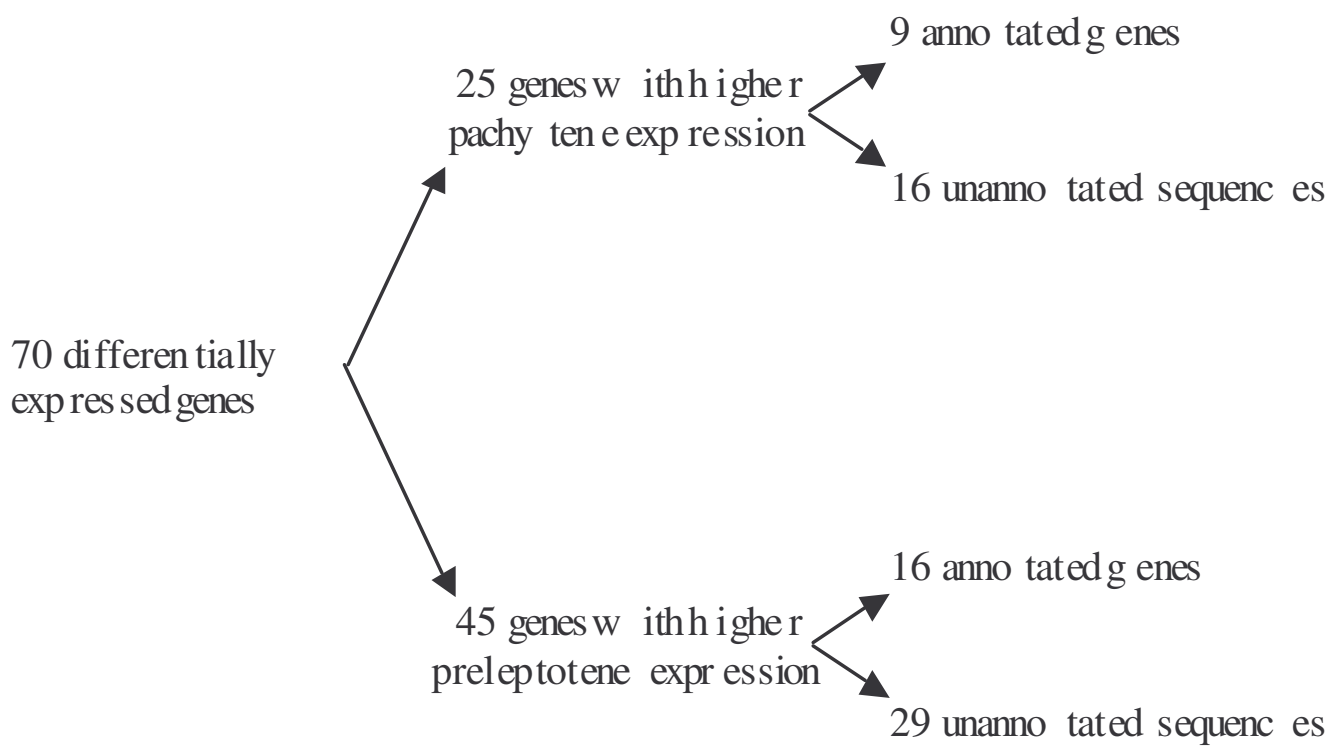

Figure 4.3. Gene $s$ that were differentially expressed between the onset of meiosis and mid-meiosis I (bu t not be tween mitosis and prelep totene ). 
Table 4.2. Genes with significant differential expression between the onset and middle of meiosis I.

\begin{tabular}{|c|c|c|c|c|c|c|c|}
\hline \multirow[t]{2}{*}{ Name } & \multirow[t]{2}{*}{ Symbol } & \multirow[t]{2}{*}{ Function } & \multirow{2}{*}{$\begin{array}{c}\text { GenBank } \\
\text { Accession } \\
\text { ID }\end{array}$} & \multicolumn{2}{|c|}{$\begin{array}{c}\text { Fold-difference in } \\
\text { expression }\end{array}$} & \multirow{2}{*}{\multicolumn{2}{|c|}{$\begin{array}{l}\text { Previously described role in } \\
\text { reproduction? }\end{array}$}} \\
\hline & & & & Ratio & P-value ${ }^{\text {a }}$ & & \\
\hline \multicolumn{8}{|c|}{ Genes with increased expression as germ cells progress from the onset of meiosis to mid-meiosis I } \\
\hline Hematopoietic cell transcript & HemT & Cellular differentiation & AJ242830 & 78.1 & 0.02 & Yes & (Xue et al., 1999) \\
\hline Lipase, hormone sensitive & Lipe & Metabolism & U69543 & 11.2 & 0.02 & Yes & (Chung et al., 2001) \\
\hline Lactate dehydrogenase 3 & $L d h 3$ & Metabolism & M17587 & 9.2 & 0.04 & Yes & (Kao et al., 1988) \\
\hline Synaptonemal complex protein 1 & Sycpl & Recombination & D88539 & 5.7 & 0.02 & Yes & (Tureci et al., 1998) \\
\hline Acid phosphatase 2 , lysosomal & Acp2 & Signal transduction & X57199 & 8.9 & 0.02 & No & \\
\hline Ganglioside-induced differentiation 3 & Gdap3 & Unknown & Y17852 & 3.9 & 0.04 & No & \\
\hline Protein kinase inhibitor p58 & Ipk & Protein modification & U28423 & 3.2 & 0.05 & No & \\
\hline Glutamyl-tRNA synthetase & $\begin{array}{l}\text { Glut-tRNA } \\
\text { synthetase }\end{array}$ & Biosynthesis & X54327 & 2.4 & 0.01 & No & \\
\hline House-keeping protein 1 & Hkpl & Misc. & M74555 & 2.2 & 0.02 & No & \\
\hline \multicolumn{8}{|c|}{ Genes with decreased expression as germ cells progress from the onset of meiosis to mid-meiosis I } \\
\hline Hydroxysteroid (17-beta) dehydrogenase 3 & $H s d 17 b 3$ & Metabolism & U66827 & 6.6 & 0.01 & Yes & (Sha et al., 1996) \\
\hline Zinc finger protein 35 & Zfp35 & Cellular differentiation & M36146 & 3.8 & 0.01 & Yes & (Cunliffe et al., 1990) \\
\hline Integrin alpha 6 & Itga6 & Cell adhesion & X69902 & 3.4 & 0.005 & Yes & (Husen et al., 1999) \\
\hline Glutathione-S-transferase, alpha 1 & Gstal & Stress response & L06047 & 2.9 & 0.01 & Yes & (Benbrahim-Tallaa et al., 2002) \\
\hline Diazepam-binding inhibitor & $D b i$ & Metabolism & X61431 & 2.7 & 0.01 & Yes & (Kolmer et al., 1997) \\
\hline Zinc finger protein 49 & Zfp49 & Cellular differentiation & AB013357 & 2.6 & 0.02 & Yes & (Cunliffe et al., 1990) \\
\hline GA repeat binding protein, beta 1 & Gabpbl & Transcription & M74516 & 7.0 & 0.03 & No & \\
\hline Tissue factor pathway inhibitor & Tfpi & Misc. & AF004833 & 6.3 & 0.03 & No & \\
\hline N-myristoyltransferase 2 & $\mathrm{Nmt2}$ & Biosynthesis & AF043327 & 5.1 & 0.04 & No & \\
\hline Monocyte macrophage 19 & Mmrp19 & Immune response & AB028863 & 4.9 & 0.001 & No & \\
\hline Smoothened homolog & Smoh & Signal transduction & AF089721 & 4.1 & 0.01 & No & \\
\hline Prolyl oligopeptidase & Prep & Protein modification & AB022053 & 3.6 & 0.001 & No & \\
\hline Lysosomal-associated, transmembrane 4 & Laptm4 & Intercellular transport & U34259 & 3.1 & 0.05 & No & \\
\hline Fas-associated death domain & Fadd & Apoptosis & U50406 & 2.8 & 0.03 & No & \\
\hline Annexin III & Anx3 & Metabolism & AJ001633 & 2.4 & 0.004 & No & \\
\hline Ryanodine receptor 3 & Ryr3 & Signal transduction & D38218 & 2.0 & 0.04 & No & \\
\hline
\end{tabular}

${ }^{a}$ Student's t-test p-values Š 0.05 indicate significant differences in expression across time points (see Materials and Methods)

${ }^{b}$ Genes with described roles in germ cell development or differentiation, meiosis, spermatogenesis, or fertilization 


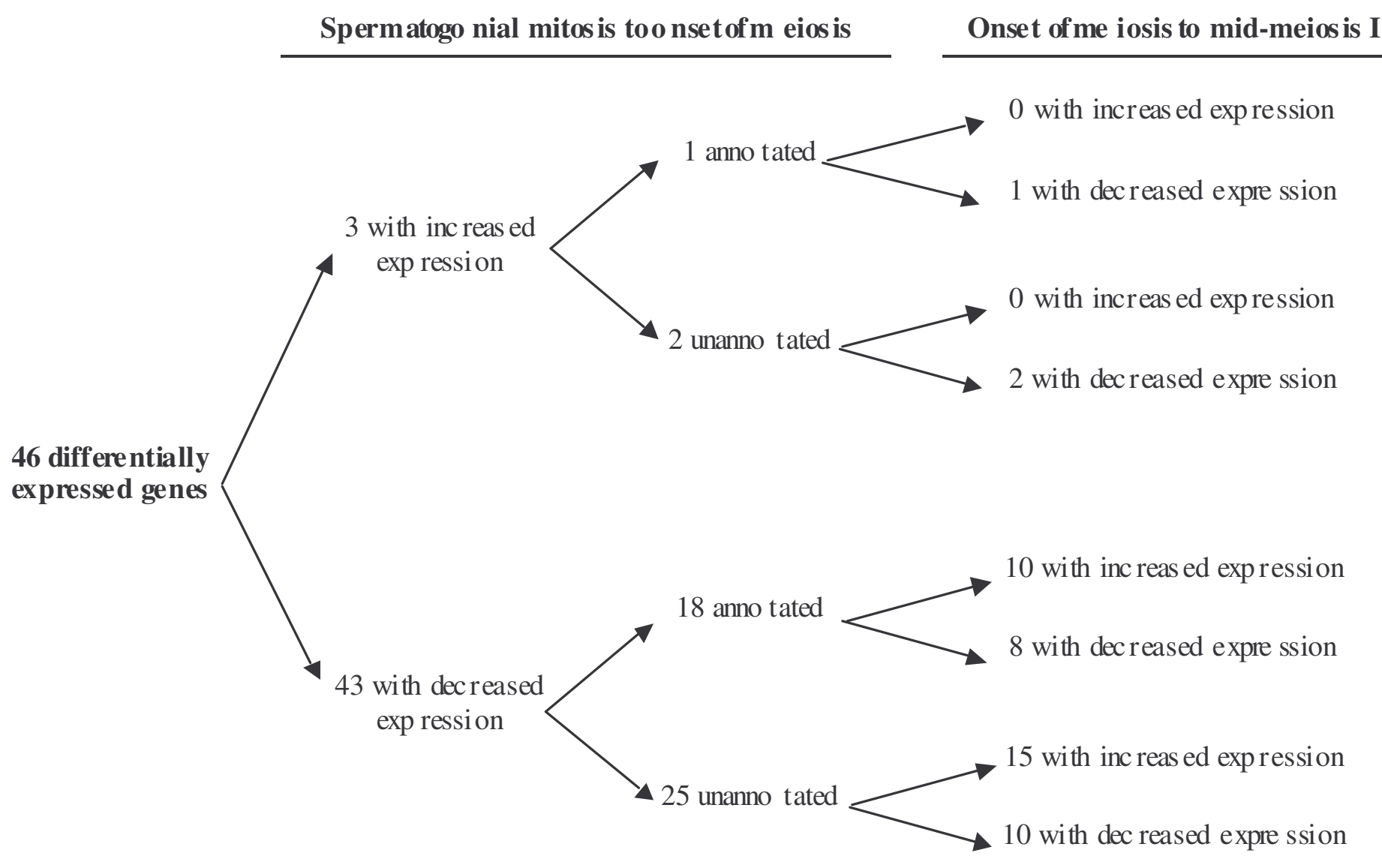

Figure 4.4. Gene $s$ with co mplex pattems of differential expression from mitos is to mid-meiosis I. The se gen es sho $w$ exp ression changes bo thb etween mitosis and the onse $t$ of meios is and between the onse $t$ of meios is and midmeios is I. 
Table 4.3. Genes with complex patterns of differential expression from mitosis to mid-meiosis I.

\begin{tabular}{|c|c|c|c|c|c|c|c|c|}
\hline \multirow[t]{2}{*}{ Name } & \multirow[t]{2}{*}{ Symbol } & \multirow[t]{2}{*}{ Function } & \multirow{2}{*}{$\begin{array}{l}\text { GenBank } \\
\text { Accession } \\
\text { ID }\end{array}$} & \multirow{2}{*}{$\begin{array}{c}\text { Relative } \\
\text { Expression } \\
\text { Pattern }^{\mathbf{a}}\end{array}$} & \multicolumn{2}{|c|}{$\begin{array}{c}\text { Preleptotene / } \\
\text { Spermatogonial } \\
\text { Mitosis }\end{array}$} & \multicolumn{2}{|c|}{$\begin{array}{l}\text { Pachytene / } \\
\text { Preleptotene }\end{array}$} \\
\hline & & & & & Ratio $^{b}$ & P-value ${ }^{c}$ & Ratio $^{\text {b }}$ & P-value ${ }^{c}$ \\
\hline \multicolumn{9}{|l|}{$\begin{array}{l}\text { Genes with described roles in germ } \\
\text { cell development or differentiation, } \\
\text { meiosis, spermatogenesis, or } \\
\text { fertilization }\end{array}$} \\
\hline Degenerative spermatocyte homolog & Mdes & Meiosis & Y08460 & DD & -7.5 & 0.01 & -2.1 & 0.02 \\
\hline Growth arrest specific 6 & Gas6 & Growth regulation & X59846 & $\mathrm{DD}$ & -7.3 & 0.04 & -3.6 & 0.02 \\
\hline Ornithine decarboxylase antienzyme 2 & $\mathrm{Oaz} 2$ & Misc. & D78643 & DI & -23.4 & 0.01 & 2.9 & 0.03 \\
\hline Secreted protein acidic and rich in cysteine & Sparc & Extracellular matrix & X04017 & DI & -4.6 & 0.02 & 1.9 & 0.02 \\
\hline Outer dense fiber 1 & Odf1 & Cytoskeletal element & X79446 & ID & 4.8 & 0.01 & 2.3 & 0.04 \\
\hline \multicolumn{9}{|l|}{$\begin{array}{l}\text { Genes with no known role in germ } \\
\text { cell development or differentiation, } \\
\text { meiosis, spermatogenesis, or } \\
\text { fertilization }\end{array}$} \\
\hline Cardiac troponin $\mathrm{T}$ isoform $\mathrm{A} 3 \mathrm{~b}$ & $C t n T A 3 b$ & Metabolism & L47600 & $\mathrm{DD}$ & -11.6 & 0.02 & -2.3 & 0.04 \\
\hline DEAD box polypeptide 4 & Dbp4 & RNA helicase & D14859 & $\mathrm{DD}$ & -2.4 & 0.02 & -1.8 & 0.04 \\
\hline Glutathione transferase mu 3 & Gstm3 & Stress response & J03953 & DD & -2.1 & 0.02 & -2.3 & 0.02 \\
\hline Inosine monophosphate dehydrogenase & Impdh & Biosynthesis & M33934 & DD & -5.1 & 0.01 & -2.6 & 0.02 \\
\hline Suppressor of cytokine signaling 2 & Socs 2 & Growth regulation & U88327 & DD & -4.5 & 0.01 & -5.9 & 0.04 \\
\hline Transcytosis associated protein $\mathrm{p} 115$ & Tap & Intracellular transport & AF096868 & $\mathrm{DD}$ & -2.6 & 0.01 & -1.8 & 0.01 \\
\hline Adenylosuccinate synthetase & Adss & Biosynthesis & L24554 & DI & -5.6 & 0.004 & 1.9 & 0.05 \\
\hline Cop9 complex subunit 6 & Cops6 & Protein modification & AF071315 & DI & -32.8 & 0.01 & 3.3 & 0.01 \\
\hline Fibroblast secretory protein & Fsp & Growth regulation & M70642 & DI & -12.2 & 0.02 & 1.6 & 0.01 \\
\hline Fibulin extracellular matrix glyroprotein & $F b \ln 1$ & Cell adhesion & X70853 & DI & -6.9 & 0.001 & 5.1 & 0.002 \\
\hline Peroxisomal integral membrane protein 34 & Pmp34 & Intracellular transport & AJ006341 & DI & -3.8 & 0.04 & 3.7 & 0.01 \\
\hline Spastin & Spast & Cytoskeletal element & $\mathrm{AJ} 246002$ & DI & -7.4 & 0.03 & 5.2 & 0.04 \\
\hline TEA domain family member 4 & Tead4 & Transcription & X94441 & DI & -2.7 & 0.03 & 3.8 & 0.05 \\
\hline Translocase of inner membrane 23 & $\operatorname{Tim} 23$ & Intracellular transport & AB021122 & DI & -4.7 & 0.01 & 2.5 & 0.05 \\
\hline
\end{tabular}

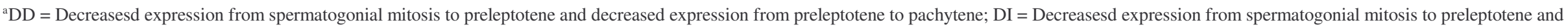
increased expression from preleptotene to pachytene; ID = Increasesd expression from spermatogonial mitosis to preleptotene and decreased expression from preleptotene to pachytene

${ }^{b}$ Fold difference in expression for preleptotene vs. spermatogonial mitosis or pachytene vs. preleptotene; Negative numbers indicate decreased expression as germ cells differentiate

'Student's t-test p-values Š 0.05 indicate significant differences in expression across time points (see Materials and Methods) 
pachytene (8 annotated genes; 10 unannotated sequences). Only 5 of the 19 annotated genes have described roles related to germ cell development or progression through spermatogenesis. The 27 unannotated sequences that have significant expression differences across all time points evaluated and, therefore, may be important for progression through the first wave of spermatogenesis are listed in Appendix C.

\section{Cluster Analysis of Temporal Gene Expression}

Unsupervised hierarchial cluster analysis was performed to identify clusters of genes with similar patterns of expression (CLUSFAVOR; Peterson 2002). These similar expression patterns may indicate that these genes belong to common molecular/biochemical pathways. All genes with significant differential expression were analyzed by cluster analysis. Expression data for the adult mouse was also included in order to compare the onset and progression of meiosis in the prepubertal mouse with expression during full spermatogenesis. Cluster analysis revealed the presence of 44 major ( $\geq 4$ genes) and 83 minor $(<4$ genes) sub-clusters. Examples of the major subclusters, which contain both annotated genes and unannotated sequences, are shown in Figure 4.5. Clusters were identified that contain genes which are highly expressed during spermatogonial mitosis (Figure 4.5 A). It also identified groups of unannotated sequences that exhibit the highest or lowest expression levels at the onset of meiosis (Figure 4.5 B and C, respectively). Groups of known genes and unannotated sequences that have increased (Figure 4.5 D) or decreased (Figure 4.5 E) expression across meiosis I were 


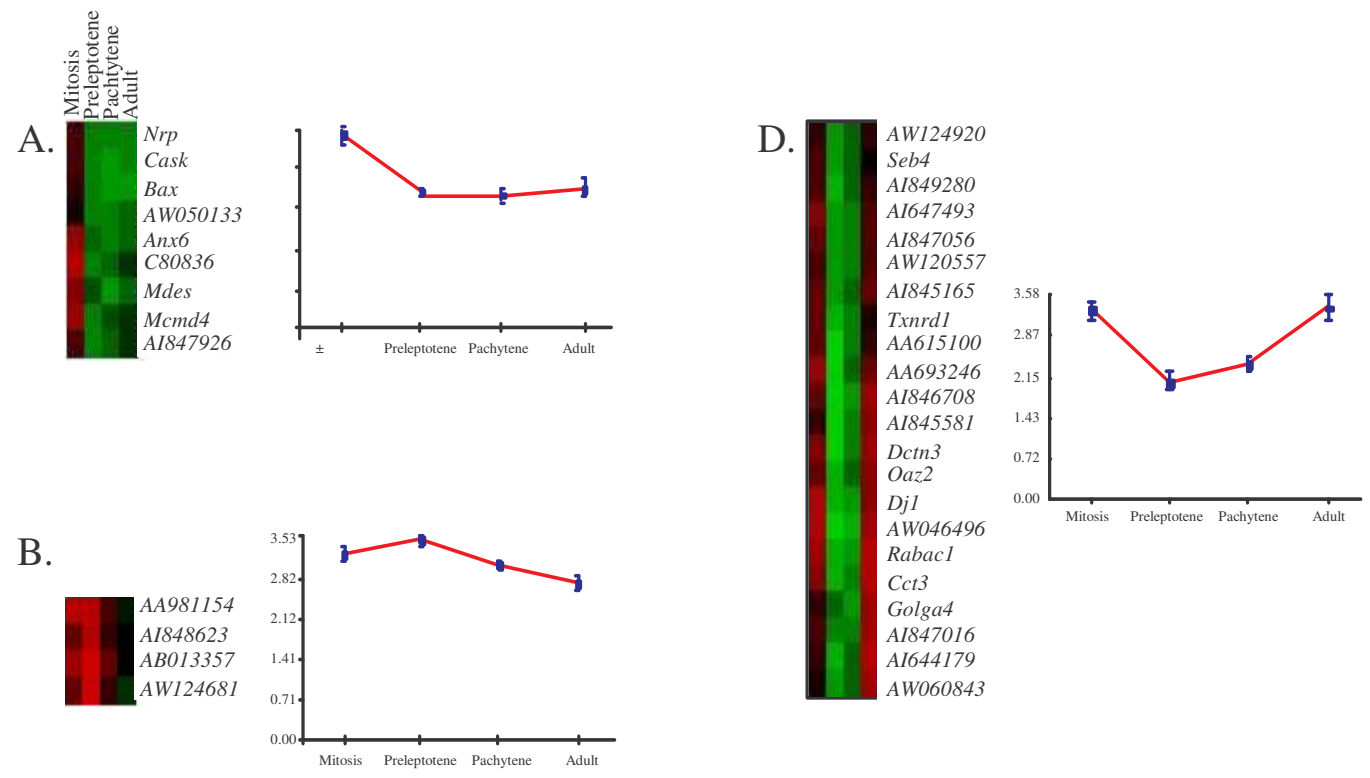

C.

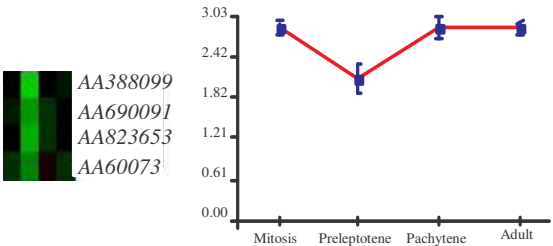

E.

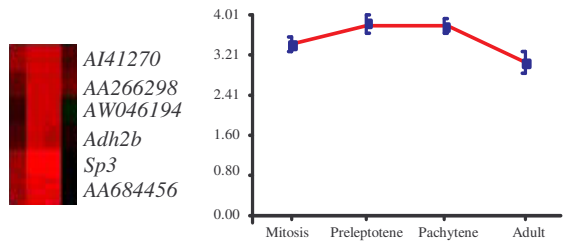

Figure 4.5. Examples of gene sub-clusters obtained using CLUSFAVOR. Each colv in the sub-cluster represents one time point (from left to right: spermatogonial mitos preleptotene, pachytene I, and adult). Each row represents one gene. Graphs corresponding to each sub-cluster illustrate the mean log expression ratio for that sul cluster ( \pm the standard deviation for that sub-cluster) at each time point. A.) Genes exhibiting relatively elevated expression during spermatogonial mitoßs) Genes with slightly elevated expression in preleptotenE.) Genes with decreased expression durin preleptotene and similar (higher) expression at all other time poilds) Genes that have decreased expression during both meiosis I samplings (preleptotene and pachytere). Genes showing relative increased expression during both meiosis I samplings 


\subsection{Discussion}

Spermatogenesis is a complex and highly synchronized differentiation process. During spermatogenesis, the expression of genes that encode proteins with key roles during specific periods of germ cell development is strictly regulated (Hecht, 1998; Grootegoed et al., 2000). Temporal changes in gene expression as specific germ cell types appear during spermatogenesis have been reported for a small number of genes (e.g., Willison and Ashworth 1987; Thomas et al.,1989; Hecht 1998). However, a global analysis of gene expression across critical timepoints during spermatogenesis (e.g., transition from mitosis to meiosis) is necessary to thoroughly understand germ cell progression through spermatogenesis and to identify genes that play critical roles in controlling the development and formation of mature germ cells.

In the present study, random oligonucleotide microarrays were used to characterize temporal changes in gene expression in the prepubertal mouse testis as germ cells differentiated from spermatogonia to pachytene spermatocytes. Differential gene expression was observed between every stage analyzed in this study. This finding supports the suggestion that all stages of spermatogenesis are characterized by selective gene expression (Thomas et al. 1989). Out of $\sim 10,000$ genes investigated, we identified 544 genes (231 annotated genes and 313 unannotated sequences) that were differentially expressed during the transition from mitosis to meiosis and/or during meiosis I. Among the 231 differentially expressed annotated genes, only 53 were known to have functions related to spermatogenesis. Therefore, the remaining 178 annotated genes and 313 unannotated sequences represent candidate genes with novel roles in spermatogenesis. 


\section{Differential gene expression between spermatogonial mitosis and the onset of meiosis}

Approximately $79 \%$ of the genes (428 out of 544) showed differential expression during the mitotic to meiotic transition. As shown in Figure 4.2, the majority of these genes showed a decrease in expression as spermatogonia committed to meiosis. Among the annotated genes with decreased expression were several apoptosis-related genes such as Bax, Mcll and Pdcd6 (Table 4.1). Apoptosis plays a key role during spermatogenesis to regulate sperm production. During the first wave of spermatogenesis in particular, an early wave of apoptosis, which is necessary for the development of functional spermatogenesis, is coincident with a temporarily high expression of Bax (Rodriguez et al 1997). Recent data indicate that Bax promotes cell death specifically in type A spermatogonia (Russell et al 2002). Therefore, the reduced expression of Bax as spermatogonia move to meiosis is in agreement with the known involvement of Bax in regulating sperm production.

Several genes associated with DNA repair and stress response were also shown to decrease in expression as cells proceeded from mitosis to meiosis (Table 4.1). Differential expression of DNA repair and stress response genes among the various spermatogenic phases has been reported in the rat, and it has been suggested that such

differential expression contributes to the selective susceptibilities of germ cells to stress (Aguilar-Mahecha et al., 2001). The present results show that a similar trend is present in the mouse.

Only 45 of the 428 differentially expressed annotated genes and unannotated sequences genes showed higher expression in meiotic cells with respect to mitotic cells. Their higher expression suggest an important role in meiosis for these genes. The limited 
number of genes that was detected as having higher expression in preleptotene cells is probably related to the fact that the Affymetrix Murine U74Av.1 microarray used in this study is highly enriched for genes with functions in somatic tissues.

\section{Differential gene expression between the onset of meiosis and mid-meiosis I}

As shown in Figure 4.3, there was also a trend toward down-regulated gene expression as cells proceeded through meiosis. Of the 70 genes that were differentially expressed during meiosis I, approximately $2 / 3$ had relatively higher expression at the onset of meiosis compared to mid-meiosis. Among the 25 annotated genes and unannotated sequences with higher expression during pachytene I, we identified SycpI which exhibited a 5.7-fold increase in expression. Sycp1 is an integral component of the synaptonemal complex which is assembled during pachytene I (Tureci et al 1998).

\section{Complex temporal patterns of gene expression}

Forty-six genes had a complex pattern of expression across the periods of spermatogenesis evaluated in this study (Table 4.3). Further analysis of the temporal patterns of expression for these genes may provide clues to their function. For example, genes with increased expression as spermatogonia differentiate into preleptotene spermatocytes and decreased expression as the preleptotene spermatocytes differentiate into pachytene I spermatocytes, (i.e., Odf increased 4.8-fold and subsequently decreased $\sim 2.3$-fold), may have roles in the onset of meiosis. Genes with decreased expression from mitosis to preleptotene followed by increased expressed from preleptotene to pachytene, (e.g., Spast decreased $\sim 7.1$-fold and then increased $\sim 5.2$-fold), may represent 
genes whose repression is necessary for the transition from mitosis to meiosis. Genes whose expression decreased between spermatogonial mitosis and preleptotene and then decreased further from preleptotene to pachytene, (e.g., Mdes expression decreased by 7.7-fold from spermatogonial mitosis to preleptotene and decreased $\sim 2.1$-fold from preleptotene to pachytene I), may be mitosis-associated genes.

\section{Cluster analysis of gene expression}

Cluster analysis has found widespread use in functional genomics studies for classifying genes based on gene expression levels from cDNA microarrays. Several clustering methods have been developed for analyzing gene expression data (Eisen et al 1998; Sneath and Sokol, 1973; Peterson, 2002). We used hierarchical cluster analysis to identify groups of genes (sub-clusters) that shared identical expression patterns across the various spermatogenic periods (Figure 4.5). A total of 44 major ( $\geq 4$ genes) and 83 minor ( $<4$ genes) sub-clusters were identified. Genes within each group may have similar cellular functions. For example, four of the known genes in sub-cluster A in Figure 4.5 (Nrp, Cask, Anx6 and Mdes) encode for plasma membrane-associated proteins suggesting that they may all be part of the cellular modification processes associated with spermatogonial proliferation and differentiation. Genes belonging to the same cluster can also be used to search for common regulatory elements that may be responsible for their coordinated expression (Werner, 2001). This approach has been successfully used in yeast to identify transcription factors involved in cell cycle control (Jelinsky et al 2000; Futcher, 2000). 


\section{Summary}

By characterizing the temporal coordination of gene expression in the prepubertal testis as germ cells differentiate from spermatogonia to pachytene spermatocytes, this research has identified $\sim 550$ genes whose function may be associated with male germ cell differentiation. Characterizing the function of these genes will greatly expand our understanding of the molecular mechanisms associated with the onset and progression of spermatogenesis. The prepubertal mouse model utilized in this study provides a unique method for future investigations of (a) the molecular basis of male infertility (e.g., meiotic arrest in mutant mice) and (b) the genetic causes of adverse reproductive outcomes following paternal exposure to various genotoxic agents (e.g., acrylamide, ENU, ionizing radiation, etc.).

\subsection{Acknowledgements}

Special thanks to Dorreyah Schahin-Reed for her assistance with the testis extractions and Shea Gardner for normalizing the Affymetrix data. Work was performed under the auspices of the US DOE by the University of California, LLNL under contract W-7405-ENG-48 with support from NIH ES09117-02; NIEHS Superfund P42ES04705; the Low Dose Radiation Research Program, Biological and Environmental Research (BER), U.S. DOE grant KP110202; the University of California and West Virginia University. 


\subsection{References}

Adamali, H. I., Somani, I. H., Huang, J. Q., Gravel, R. A., Trasler, J. M., and Hermo, L. (1999a). II. Characterization and development of the regional- and cellular- specific abnormalities in the epididymis of mice with beta- hexosaminidase A deficiency. J. Androl. 20, 803-24.

Adamali, H. I., Somani, I. H., Huang, J. Q., Mahuran, D., Gravel, R. A., Trasler, J. M., and Hermo, L. (1999b). I. Abnormalities in cells of the testis, efferent ducts, and epididymis in juvenile and adult mice with beta-hexosaminidase A and B deficiency. J. Androl. 20, 779-802.

Aguilar-Mahecha, A., Hales, B. F., and Robaire, B. (2001). Expression of stress response genes in germ cells during spermatogenesis. Biol. Reprod. 65, 119-127.

Bellve, A.R., Cavicchia, J.C., Millette, C.F., O’Brien, D.A., Bhatnagar, Y.M., and Dym, M. (1977). Spermatogenic cells of the prepuberal mouse: isolation and morphological characterization. J. Cell Biol. 74, 68-85.

Benbrahim-Tallaa, L., Tabone, E., Tosser-Klopp, G., Hatey, F., and Benahmed, M. (2002). Glutathione S-transferase alpha expressed in porcine Sertoli cells is under the control of follicle-stimulating hormone and testosterone. Biol. Reprod. 66, 1734-42. 
Bernard, P., Maure, J. F., and Javerzat, J. P. (2001). Fission yeast Bub1 is essential in setting up the meiotic pattern of chromosome segregation. Nat. Cell. Biol. 3, 522-6.

Bo, J. and Wensink, P. C. (1989). The promoter region of the Drosophila alpha 2tubulin gene directs testicular and neural specific expression. Development 106, 581-7.

Braun, R.E., Behringer, R.R., Peschon, J.J., Brinster, R.L., and Palmiter, R.D. (1989). Genetically haploid spermatids are phenotypically diploid. Nature 337, 373-6.

Broceno, C., Ruiz, P., Reina, M., Vilaro, S., and Pons, G. (1995). The muscle-specific phosphoglycerate mutase gene is specifically expressed in testis during spermatogenesis. Eur. J. Biochem. 227, 629-35.

Bucci, L. R., Brock, W. A., Goldknopf, I. L., and Meistrich, M. L. (1984). Characterization of high mobility group protein levels during spermatogenesis in the rat. J. Biol. Chem. 259, 8840-6.

Burmester, S. and Hoyer-Fender, S. (1996). Transcription and translation of the outer dense fiber gene (Odf1) during spermiogenesis in the rat. A study by in situ analyses and polysome fractionation. Mol. Reprod. Dev. 45, 10-20. 
Cai, L., Chen, S., Evans, T., Deng, D. X., Mukherjee, K., and Chakrabarti, S. (2000). Apoptotic germ-cell death and testicular damage in experimental diabetes: prevention by endothelin antagonism. Urol. Res. 28, 342-7.

Castellano, L. E., Martinez-Cadena, G., Lopez-Godinez, J., Obregon, A., and GarciaSoto, J. (1997). Subcellular localization of the GTP-binding protein Rho in the sea urchin sperm. Eur. J. Cell Biol. 74, 329-35.

Chan, M. C., Mather, J. P., McCray, G. and Lee, W. M. (2000). Identification and regulation of receptor tyrosine kinases Rse and Mer and their ligand Gas6 in testicular somatic cells. J. Androl. 21, 291-302.

Chung, S., Wang, S. P., Pan, L., Mitchell, G., Trasler, J., and Hermo, L. (2001). Infertility and testicular defects in hormone-sensitive lipase-deficient mice. Endocrinology 142, 4272-81.

Cobb, J., Reddy, R.K., Park, C., and Handel, M.A. (1997). Analysis of expression and function of topoisomerase I and II during meiosis in male mice. Mol. Reprod. Dev. 46, $489-98$.

Connor, F., Bertwistle, D., Mee, P. J., Ross, G. M., Swift, S., Grigorieva, E., Tybulewicz, V. L., and Ashworth, A. (1997). Tumorigenesis and a DNA repair defect in mice with a truncating Brca2 mutation. Nat. Genet. 17, 423-30. 
Cunliffe, V., Koopman, P., McLaren, A., and Trowsdale, J. (1990). A mouse zinc finger gene which is transiently expressed during spermatogenesis. EMBO J. 9, 197-205.

Cunningham, D.B., Segretain, D., Arnaud, D., Rogner, U.C., and Avner, P. (1998). The mouse Tsx gene is expressed in Sertoli cells of the adukt testis and transiently in premeiotic germ cells during puberty. Dev. Biol. 15, 345-60.

Danno, S., Itoh, K., Matsuda, T., and Fujita, J. (2000). Decreased expression of mouse Rbm3, a cold-shock protein, in Sertoli cells of cryptorchid testis. Am. J. Pathol. 156, $1685-92$.

Desseyn, J. L., Burton, K. A., and McKnight, G. S. (2000). Expression of a nonmyristylated variant of the catalytic subunit of protein kinase A during male germ-cell development. Proc. Natl. Acad. Sci. USA 97, 6433-8.

Di Agostino, S., Rossi, P., Geremia, R., and Sette, C. (2002). The MAPK pathway triggers activation of Nek2 during chromosome condensation in mouse spermatocytes. Development 129, 1715-27.

Dowdy, S. and Wearden, S. (1991). Student's t distribution. Statistics for Research. 2nd Ed. New York: Wiley-Interscience. pp. 193-228. 
Edelmann, L., Stankiewicz, P., Spiteri, E., Pandita, R. K., Shaffer, L., Lupski, J. R., and Morrow, B. E. (2001). Two functional copies of the DGCR6 gene are present on human chromosome 22q11 due to a duplication of an ancestral locus. Genome Res 11, 208-17.

Eisen, M. B., Spellman, P. T., Brown, P. O., and Botstein, D. (1998). Cluster analysis and display of genome-wide expression patterns. Proc. Natl. Acad. Sci. USA 95, 1486314868.

Endo, K., Matsuda, Y., and Kobayashi, S. (1997). Mdes, a mouse homolog of the Drosophila degenerative spermatocyte gene is expressed during mouse spermatogenesis. Dev. Growth Differ. 39, 399-403.

Fouquet, J., Kann, M., Soues, S., and Melki, R. (2000). ARP1 in Golgi organisation and attachment of manchette microtubules to the nucleus during mammalian spermatogenesis. J. Cell Sci. 113, 877-86.

Fulcher, K. D., Welch, J. E., Klapper, D. G., O'Brien, D. A., and Eddy, E. M. (1995). Identification of a unique mu-class glutathione S-transferase in mouse spermatogenic cells. Mol. Reprod. Dev. 42, 415-24.

Futcher, B. (2000). Microarrays and cell cycle transcription in yeast. Curr. Opin. Cell Biol. 12, 710-715. 
Giannattasio, A., Girotti, M., Williams, K., Hall, L., and Bellastella, A. (1997). Puberty influences expression of phospholipid hydroperoxide glutathione peroxidase (GPX4) in rat testis: probable hypophysis regulation of the enzyme in male reproductive tract. J. Endocrinol. Invest. 20, 439-44.

Gilbert, S.F. (1994). The saga of the germ line. Developmental Biology. 4th Ed. Sunderland:Sinauer Associates, Inc. pp. 798-801.

Grootegoed, J. A., Siep, M., and Baarends, W. M. (2000). Molecular and cellular mechanisms in spermatogenesis. Baill. Clin. Endocrin. Metab. 14, 331-343.

Ham, A.W. (1974). The male reproductive system. Histology. $7^{\text {th }}$ Ed. Philadelphia: J.B. Lippincott Company, pp. 900-35.

Hansis, C., Jahner, D., Spiess, A. N., Boettcher, K., and Ivell, R. (1998). The gene for the Alzheimer-associated beta-amyloid-binding protein (ERAB) is differentially expressed in the testicular Leydig cells of the azoospermic by w/w(v) mouse. Eur. J. Biochem. 258, 53-60.

Harrington, J. J. and Lieber, M. R. (1994). The characterization of a mammalian DNA structure-specific endonuclease. EMBO J. 13, 1235-46. 
Hogan, B., Costantini, F., and Lacy, E. (1986). Summary of mouse development. Manipulating the Mouse Embryo: A Laboratory Manual. New York: Cold Spring Harbor Laboratory. pp. 19-27.

Husen, B., Giebel, J., and Rune, G. (1999). Expression of the integrin subunits alpha 5, alpha 6 and beta 1 in the testes of the common marmoset. Int. J. Androl. 22, 374-84.

Irizarry, R.A., Hobbs, B., Collin, F., Beazer-Barclay, Y.D., Antonellis, K.J., Scherf, U., and Speed, T.P. (2002). Exploration, normalization, and summaries of high density oligonucleotide array probe level data. Submitted to: Biostatistics and available at: http://biosun01.biostat.jhsph.edu/ ririzarr/papers/index.html.

Ivanov, I. P., Rohrwasser, A., Terreros, D. A., Gesteland, R. F., and Atkins, J. F. (2000). Discovery of a spermatogenesis stage-specific ornithine decarboxylase antizyme: antizyme 3. Proc. Natl. Acad. Sci. USA 97, 4808-13.

Jelinsky, S. A., Estep, P., Church, G. M., and Samson, L. D. (2000). Regulatory networks revealed by transcriptional profiling of damaged Saccharomyces cerevisiae cells: Rpn4 links base excision repair with proteasomes. Mol. Cell. Biol. 20, 8157-67.

Kanai, Y., Kanai-Azuma, M., Tajima, Y., Birk, O. S., Hayashi, Y., and Sanai, Y. (2000). Identification of a stromal cell type characterized by the secretion of a soluble integrinbinding protein, MFG-E8, in mouse early gonadogenesis. Mech. Dev. 96, 223-7. 
Kao, F. T., Wu, K. C., Law, M. L., Hartz, J. A., and Lau, Y. F. (1988). Assignment of human gene encoding testis-specific lactate dehydrogenase $\mathrm{C}$ to chromosome 11 , region p14.3-p15.5. Somat. Cell Mol. Genet. 14, 515-8.

Kerr, W. G. and Burrows, P. D. (1991). Stage-specific transcription of germline IgH C gamma and $\mathrm{C}$ alpha regions during human B cell differentiation. Int. Immunol. 3, 105965.

Kilpatrick, D. L., Zinn, S. A., Fitzgerald, M., Higuchi, H., Sabol, S. L., and Meyerhardt, J. (1990). Transcription of the rat and mouse proenkephalin genes is initiated at distinct sites in spermatogenic and somatic cells. Mol. Cell. Biol. 10, 3717-26.

Kim, E., Waters, S. H., Hake, L. E., and Hecht, N. B. (1989). Identification and developmental expression of a smooth-muscle gamma- actin in postmeiotic male germ cells of mice. Mol. Cell. Biol. 9, 1875-81.

Kolmer, M., Pelto-Huikko, M., Parvinen, M., Hoog, C., and Alho, H. (1997). The transcriptional and translational control of diazepam binding inhibitor expression in rat male germ-line cells. DNA Cell Biol. 16, 59-72. 
Komada, M., McLean, D. J., Griswold, M. D., Russell, L. D., and Soriano, P. (2000). EMAP-115, encoding a microtubule-associated protein, is a retinoic acid-inducible gene required for spermatogenesis. Genes Dev. 14, 1332-42.

Kurth, B. E., Klotz, K., Flickinger, C. J., and Herr, J. C. (1991). Localization of sperm antigen SP-10 during the six stages of the cycle of the seminiferous epithelium in man. Biol. Reprod. 44, 814-21.

Le Douarin, B., Nielsen, A. L., Garnier, J. M., Ichinose, H., Jeanmougin, F., Losson, R., and Chambon, P. (1996). A possible involvement of TIF1 alpha and TIF1 beta in the epigenetic control of transcription by nuclear receptors. EMBO J. 15, 6701-15.

Lindner, K., Gregan, J., Montgomery, S., and Kearsey, S. E. (2002). Essential role of MCM proteins in premeiotic DNA replication. Mol. Biol. Cell 13, 435-44.

Luoh, S. W., Bain, P. A., Polakiewicz, R. D., Goodheart, M. L., Gardner, H., Jaenisch, R., and Page, D. C. (1997). Zfx mutation results in small animal size and reduced germ cell number in male and female mice. Development 124, 2275-84.

Manandhar, G., Moreno, R. D., Simerly, C., Toshimori, K., and Schatten, G. (2000). Contractile apparatus of the normal and abortive cytokinetic cells during mouse male meiosis. J. Cell Sci. 113, 4275-86. 
Matsubara, N., Yanagisawa, M., Nishimune, Y., Obinata, M., and Matsui, Y. (1995). Murine polo like kinase 1 gene is expressed in meiotic testicular germ cells and oocytes. Mol. Reprod. Dev. 41, 407-15.

Matsumoto, M., Kurata, S., Fujimoto, H., and Hoshi, M. (1993). Haploid specific activations of protamine 1 and hsc70t genes in mouse spermatogenesis. Biochim. Biophys. Acta 1174, 274-8.

Mazeyrat, S., Saut, N., Grigoriev, V., Mahadevaiah, S. K., Ojarikre, O. A., Rattigan, A., Bishop, C., Eicher, E. M., Mitchell, M. J., and Burgoyne, P. S. (2001). A Y-encoded subunit of the translation initiation factor Eif 2 is essential for mouse spermatogenesis. Nat. Genet. 29, 49-53.

Mertineit, C., Yoder, J. A., Taketo, T., Laird, D. W., Trasler, J. M., and Bestor, T. H. (1998). Sex-specific exons control DNA methyltransferase in mammalian germ cells. Development 125, 889-97.

Mulholland, D. J., Dedhar, S., and Vogl, A. W. (2001). Rat seminiferous epithelium contains a unique junction (Ectoplasmic specialization) with signaling properties both of cell/cell and cell/matrix junctions. Biol. Reprod. 64, 396-407.

Oakberg, E.F. (1956). Duration of spermatogenesis in the mouse and timing of stages of the cycle of the seminiferous epithelium. Am. J. Anat. 99, 507-16. 
Pei, L. (1999). Pituitary tumor-transforming gene protein associates with ribosomal protein S10 and a novel human homologue of DnaJ in testicular cells. J. Biol. Chem. $274,3151-8$.

Peterson, L.E. (2002). Factor analysis of cluster-specific gene expression levels from cDNA microarrays. Comput. Methods Programs Biomed. In press.

Ramalho-Santos, J. and Moreno, R. D. (2001). Targeting and fusion proteins during mammalian spermiogenesis. Biol. Res. 34, 147-52.

Rodriguez, I., Ody, C., Araki, K., Garcia, I., and Vassalli, P. (1997). An early and massive wave of germinal cell apoptosis is required for the development of functional spermatogenesis. EMBO J. 16, 2262-2270.

Roscoe, W. A., Barr, K. J., Mhawi, A. A., Pomerantz, D. K., and Kidder, G. M. (2001). Failure of spermatogenesis in mice lacking connexin43. Biol. Reprod. 65, 829-38.

Russell, D. L. and Kim, K. H. (1996). Expression of triosephosphate isomerase transcripts in rat testis: evidence for retinol regulation and a novel germ cell transcript. Biol. Reprod. 55, 11-8. 
Russell, L. D., Chiarini-Garcia, H., Korsmeyer, S. J., and Knudson, C. M. (2002). Baxdependent spermatogonia apoptosis is required for testicular development and spermatogenesis. Biol. Reprod. 66, 950-8.

Russell, L., Ettlin, R., Sinha-Hikim, A., and Clegg, E. (1990). Mammalian spermatogenesis. Histological and Histopathological Evaluation of the Testis. Illinois:Cache River Press. pp. 1-58.

Schrans-Stassen, B.H., van de Kant, H.J., de Rooij, D.G., and van Pelt, A.M. (1999). Differential expression of c-kit in mouse undifferentiated and differentiating type A spermatogonia. Endocrinology 140, 5894-900.

Sha, J., Baker, P., and O'Shaughnessy, P. J. (1996). Both reductive forms of 17 betahydroxysteroid dehydrogenase (types 1 and 3) are expressed during development in the mouse testis. Biochem. Biophys. Res. Commun. 222, 90-4.

Shih, D. M. and Kleene, K. C. (1992). A study by in situ hybridization of the stage of appearance and disappearance of the transition protein 2 and the mitochondrial capsule seleno-protein mRNAs during spermatogenesis in the mouse. Mol. Reprod. Dev. 33, $222-7$.

Sneath, P. H. A. and Sokol, R. R. (1973). Numerical Taxonomy. W. H. Freeman Co., New York. 
Tanaka, K., Tamura, H., Tanaka, H., Katoh, M., Futamata, Y., Seki, N., Nishimune, Y., and Hara, T. (2002). Spermatogonia-dependent expression of testicular genes in mice. Dev. Biol. 246, 466-79.

Thomas, K.H., Wilkie, T.M., Tomashefsky, P., Bellve, A.R., and Simon, M.I. (1989). Differential gene expression during mouse spermatogenesis. Biol. Reprod. 41, 729-39.

Tosaka, Y., Tanaka, H., Yano, Y., Masai, K., Nozaki, M., Yomogida, K., Otani, S., Nojima, H., and Nishimune, Y. (2000). Identification and characterization of testis specific ornithine decarboxylase antizyme (OAZ-t) gene: expression in haploid germ cells and polyamine-induced frameshifting. Genes Cells 5, 265-76.

Tsuruta, J. K., O'Brien, D. A., and Griswold, M. D. (1993). Sertoli cell and germ cell cystatin C: stage-dependent expression of two distinct messenger ribonucleic acid transcripts in rat testes. Biol. Reprod. 49, 1045-54.

Tureci, O., Sahin, U., Zwick, C., Koslowski, M., Seitz, G., and Pfreundschuh, M. (1998). Identification of a meiosis-specific protein as a member of the class of cancer/testis antigens. Proc. Natl. Acad. Sci. USA 95, 5211-6.

Vernon, R. B. and Sage, H. (1989). The calcium-binding protein SPARC is secreted by Leydig and Sertoli cells of the adult mouse testis. Biol. Reprod. 40, 1329-40. 
Wakayama, T., Ohashi, K., Mizuno, K., and Iseki, S. (2001). Cloning and characterization of a novel mouse immunoglobulin superfamily gene expressed in early spermatogenic cells. Mol. Reprod. Dev. 60, 158-64.

Welch, J. E., Schatte, E. C., O'Brien, D. A., and Eddy, E. M. (1992). Expression of a glyceraldehyde 3-phosphate dehydrogenase gene specific to mouse spermatogenic cells. Biol. Reprod. 46, 869-78.

Werner, T. (2001). Target gene identification from expression array data by promoter analysis. Biomol. Eng. 17, 87-94.

Wine, R. N. and Chapin, R. E. (1999). Adhesion and signaling proteins spatiotemporally associated with spermiation in the rat. J. Androl. 20, 198-213.

Xue, H., O'Neill, D., Wang, X., Wolgemuth, D. J., and Bank, A. (1999). HemT-3, an alternative transcript of mouse gene HemT specific to male germ cells. Gene 240, 193-9. 


\section{5 \\ Conclusions}

Characterizing variations in gene expression is essential for thoroughly understanding the molecular events associated with diverse biological functions including: normal cell and tissue physiology, tissue response to DNA damaging conditions, susceptibility to genetic disease, and cellular differentiation during development. The large and continuing increase in genome sequence information has facilitated the development of expression microarrays for analyzing the differential expression of hundreds to thousands of genes in parallel. The goal of this research was to use expression microarray technology to (a) understand the natural tissue variation in stress response and DNA repair-associated gene expression and (b) characterize differential gene expression during male germ cell differentiation from mitotic to meiotic cells and discover new candidate genes associated with the onset and progression of spermatogenesis.

To address these issues, this research utilized two separate approaches. Custom cDNA microarrays comprised of genes selected a priori were used to characterize the variation in gene expression among tissues, and random oligonucleotide microarrays were used to discover new genes associated with early male germ cell differentiation. First, cDNA microarray hybridization and image analysis techniques were optimized (Chapter 2). A custom cDNA microarray was built to detect the differential basal 
expression of 417 genes associated with chromatin remodeling, damage control, DNA repair, growth regulation, meiosis, stress response, transcription, and translation among adult mouse tissues (testis, brain, liver, spleen, and heart). Approximately $25 \%$ of the arrayed genes were differentially expressed among healthy tissues. Genes associated with stress response showed the most variation among tissues, while DNA repair genes showed the least variation. Damage control genes showed intermediate variation (Chapter 3). These findings identify candidate stress response, DNA repair, and damage control genes whose variation in expression among tissues may contribute to tissuespecific differences in the response to DNA damage and in genetic disease susceptibility.

A random oligonucleotide microarray was then utilized to identify genes whose expression profile changed as germ cells differentiated from spermatogonia into primary spermatocytes during the first wave of spermatogenesis (Chapter 4). Expression profiling of the prepubertal mouse testis characterized the temporal modulations in gene expression that underlie cellular differentiation during spermatogenesis. Specifically, differential expression was observed for 231 annotated genes and 313 unannotated sequences (544 total). Spermatogenesis-related roles were previously reported for only 53 of these 231 annotated genes $(\sim 23 \%)$. Thus, this research has identified potential spermatogenesis-related functions for 178 annotated genes and 313 unannotated sequences that had not been previously associated with male germ cell development. The identification of $\sim 500$ new candidate genes associated with the onset and progression of spermatogenesis opens the door to a better understanding of the molecular events controlling male germ cell development.

The findings of this dissertation research suggest that future work is needed to (a) 
link tissue-specific variations in gene expression with genetic disease phenotypes, (b) characterize the specific functions of candidate genes associated with germ cell progression through spermatogenesis, (c) identify groups of genes with coordinated expression (i.e., syn-expression groups), (d) assess differences in transcript vs. protein abundance, and (e) investigate the relative contributions of tissue microenvironments to differences in expression. 


\section{APPENDIX A}

Symbols, names, biological pathways, I.M.A.G.E. clone IDs, and cDNA microarray data for 152 genes with differential expression among healthy adult mouse tissues 
Complete list of microarray information for genes identified as having differential expression among healthy, adult mouse tissues a

Gene Symbol

Gene Name

Pathways (General)

I.M.A.G.E. ID

Ratio to Pooled Testis
Spleen Heart Liver

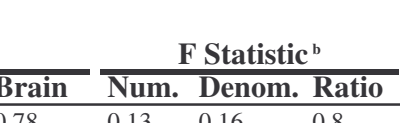

Growth regulation

Growth regulation

Acetyltransferase

Chromatin related

$14-3-3$ tau

$\begin{array}{lll}\text { Acetyltransferase } & \text { Acetyltransferase } & \text { Acrosomal vesicle protein } 1\end{array}$

\begin{tabular}{ll}
\hline Acrv1 & Acrosomal vesic \\
\hline Actb & Actin, beta \\
\hline
\end{tabular}

\begin{tabular}{ll} 
Actb & Actin, beta \\
\hline Adk1 & Adenylate kinase isozyme 1 \\
\hline Apg1b
\end{tabular}

Housekeeping

\begin{tabular}{ll}
\hline Apg-1b & Apg-1b \\
\hline B2m & Beta-2 microglobulin \\
\hline
\end{tabular}

Stress response/ Stress inducible $\quad 992475,989387$

Stress response/ Stress induced $\quad 901984$

Growth regulation 596438

Spleen Heart Liver Brain Num. Denom. Ratio \begin{tabular}{llllllllll}
636783 & 0.95 & 0.66 & 0.74 & 0.60 & 0.78 & 0.13 & 0.16 & 0.8 & 1.00 \\
849982 & 1.00 & 0.66 & 0.43 & 0.54 & 1.43 & 0.95 & $* 0.03870$ & 20.9 & 0.12 \\
\hline 577211 & 0.89 & 0.47 & 0.89 & 1.66 & 0.66 & 0.92 & 0.10 & 9.3 & 0.20
\end{tabular}

\begin{tabular}{lll} 
& Growth regulation & 596438 \\
\hline
\end{tabular}

Bmp4 Bone morphogenetic protein $4 \quad$ Damage recognition, cell cycle, apoptosis 873328

$\begin{array}{lllll}\text { Bp-h5 } & \text { Brain protein h5 } & \text { Other } & 876821 & 1.3\end{array}$

Btg1 B-cell translocation gene 1 $\quad$ Damage recognition, cell cycle, apoptosis 634804

$\begin{array}{llll}\text { Cas1 } & \text { Catalase 1 } & \text { Stress response/ Stress induced } & 573840\end{array}$

\begin{tabular}{llll} 
Ctnnb1 & Catenin, beta 1 & Transcription/ Translation & 777028 \\
\hline & Cell & D &
\end{tabular}

\begin{tabular}{llll} 
Cdc2 & Cell division cycle 2 & Damage recognition, cell cycle, apoptosis & 375194,7 \\
\hline Cdc2a & Cell division cycle 2a & Damage recognition, cell cycle, apoptosis & 582109 \\
\hline
\end{tabular}

\begin{tabular}{llll}
$\mathrm{Cdc} 42$ & Cell division cycle 42 & Damage recognition, cell cycle, apoptosis & 97745 \\
\hline
\end{tabular}

\begin{tabular}{lll} 
Cdk2 & Cyclin dependent kinase 2 & Damage recognition, cell cycle, apoptosis 876724 \\
\hline
\end{tabular}

$\begin{array}{llll}\text { Pki } & \text { Camp-dependent protein kinase inhibitor } & \text { Growth regulation } & 514418\end{array}$

\begin{tabular}{lll}
\hline $\mathrm{Clu}$ & Clusterin & $\mathrm{OHh}$ \\
\hline $\mathrm{Crem}$ & CAMP responsive element modulator & $\mathrm{Gro}$
\end{tabular}

\begin{tabular}{ll} 
Crem & CAMP responsive element modulator \\
\hline Crem-like & CAMP responsive element modulator-like \\
\hline Cut3 & Cut3
\end{tabular} 514418

\begin{tabular}{ll} 
Cut3 & Cut3 \\
\hline Ccnf & Cyclin-F
\end{tabular}

Growth regulation 917298

Growth regulation 917671

Chromatin related

Cenf Cyclin-F

Ck17 Cytokeratin-17 $\quad$ Danage recognition, cell cycle, apoptosis 888861

$\begin{array}{llll}\text { Dapk1 DAP-kinase related protein 1 } & \text { Other } & 975849\end{array}$

\begin{tabular}{|c|c|c|c|c|c|c|c|c|c|c|c|c|}
\hline Dapk1 & DAP-kinase related protein 1 & Other & 403602 & 1.06 & 1.68 & 1.05 & 2.46 & 1.13 & 0.58 & 0.12 & 4.9 & 0.58 \\
\hline Dby & DEAD/H box polypeptide, $\mathrm{Y}$ chromosome & Meiosis/Spermatogenesis & 573643 & 1.04 & 1.51 & 1.43 & 1.33 & 1.69 & 0.14 & $* 0.01640$ & 3.0 & 0.83 \\
\hline Dnai & Dnaj & Stress response/ Stress inducible & 602316,602961 & 0.67 & 0.11 & 0.16 & 0.17 & 0.20 & 1.99 & $* 0.03350$ & 43.5 & 0.01 \\
\hline Dnaj-like & Dnaj-like & Stress response/ Stress inducible & 514436 & 0.93 & 0.25 & 0.47 & 0.61 & 0.57 & 0.94 & $* 0.01690$ & 20.7 & 0.12 \\
\hline E2f1 & E2f transcription factor 1 & Transcription/ Translation & 605037 & 0.87 & 0.94 & 2.24 & 0.93 & 1.17 & 0.64 & $* 0.00859$ & 13.9 & 0.12 \\
\hline E2f3 & E2f transcription factor 3 & Transcription/ Translation & 539249 & 1.02 & 0.46 & 0.48 & 0.54 & 0.78 & 0.49 & 0.08 & 6.2 & 0.38 \\
\hline Faf1 & Fas(TNFRSF6)-associated factor 1 & Damage recognition, cell cycle, apoptosis & 574610 & 0.91 & 0.55 & 0.81 & 0.85 & 0.77 & 0.16 & $* 0.01930$ & 3.4 & 0.75 \\
\hline Fbr-MuSV & Finkel-Biskis-Reilly murine sarcoma virus & Other & 805511 & 0.87 & 2.88 & 0.67 & 1.61 & 1.07 & 1.37 & 0.05 & 28.4 & 0.03 \\
\hline Figf & $\mathrm{C}$-fos induced growth factor & Transcription/ Translation & 614347 & 1.18 & 1.01 & 0.48 & 1.32 & 1.09 & 0.66 & 0.56 & 1.2 & 1.00 \\
\hline Gadd153 & Growth arrest and DNA damage inducible 153 & Stress response/ Stress inducible & 903718 & 1.07 & 0.59 & 5.44 & 1.88 & 1.77 & 2.79 & 0.10 & 28.6 & 0.03 \\
\hline Gap43 & Growth accentuating protein 43 & Damage recognition, cell cycle, apoptosis & 479228 & 1.06 & 1.02 & 1.02 & 1.26 & 2.52 & 0.62 & $* 0.01960$ & 13.7 & 0.12 \\
\hline Gas2 & Growth arrest specific 2 & Damage recognition, cell cycle, apoptosis & 520303 & 0.92 & 8.57 & 3.70 & 3.01 & 2.20 & 2.73 & 0.33 & 8.3 & 0.23 \\
\hline Gli & Glioma-associated oncogene homolog & Transcription/ Translation & 386514 & 1.08 & 1.09 & 0.73 & 0.60 & 0.65 & 0.33 & 0.14 & 2.5 & 0.91 \\
\hline Gpx1 & Glutathione peroxidase 1 & Stress response/ Stress induced & 861820 & 1.10 & 2.09 & 26.50 & 4.15 & 3.38 & 5.93 & 0.13 & 46.2 & 0.01 \\
\hline Grp78 & Glucose regulated protein, $78 \mathrm{kDa}$ & Stress response/ Stress inducible & 935093 & 0.89 & 0.96 & 1.17 & 1.88 & 0.82 & 0.46 & 0.12 & 3.8 & 0.70 \\
\hline Gstp2 & Glutathione S-transferase, pi 2 & Stress response/ Stress inducible & 864333 & 1.13 & 0.95 & 18.00 & 5.18 & 3.95 & 6.05 & 0.06 & 106.0 & 0.00 \\
\hline Hdacl & Histone deacetylase 1 & Chromatin related & 641105 & 1.02 & 0.94 & 0.53 & 0.63 & 0.80 & 0.32 & 0.05 & 6.0 & 0.41 \\
\hline Histone-1 & Histone-1 & Chromatin related & 493091 & 1.28 & 2.58 & 2.31 & 1.41 & 1.63 & 0.39 & 0.23 & 1.7 & 1.00 \\
\hline Histone-H1.1 & Histone-H1.1 & Chromatin related & 483515 & 0.84 & 2.63 & 0.74 & 1.34 & 1.00 & 1.06 & 0.12 & 8.9 & 0.22 \\
\hline
\end{tabular}

Histone-H1.

Chromatin related

483515

\begin{tabular}{lllllllll}
1.08 & 0.92 & 2.68 & 1.82 & 1.53 & 0.75 & $* 0.04070$ & 16.4 & 0.12 \\
\hline
\end{tabular}

\begin{tabular}{lllllllll}
1.33 & 0.58 & 6.52 & 12.30 & 2.13 & 6.23 & $* 0.03120$ & 137.0 & 0.00 \\
\hline
\end{tabular}

$\begin{array}{lllllllll}1.10 & 1.23 & 1.43 & 8.28 & 0.98 & 3.26 & 0.10 & 31.3 & 0.03\end{array}$

$\begin{array}{lllllllll}1.00 & 1.86 & 2.47 & 1.46 & 1.73 & 0.46 & 0.05 & 10.1 & 0.18 \\ 0.96 & 0.60 & 0.60 & 0.71 & 0.60 & 0.17 & 0.07 & 2.5 & 0.91\end{array}$

\begin{tabular}{lllllllll}
0.04 & 0.60 & 0.60 & 0.71 & 0.60 & 0.17 & 0.07 & 2.5 & 0.91 \\
1.04 & 0.64 & 0.54 & 0.59 & 0.69 & 0.27 & 0.05 & 5.4 & 0.52 \\
\hline
\end{tabular}

\begin{tabular}{lllllllll}
1.19 & 2.88 & 2.15 & 2.28 & 2.86 & 0.54 & 0.05 & 10.2 & 0.18 \\
\hline
\end{tabular}

$\begin{array}{lllllllll}0.93 & 0.19 & 0.20 & 0.46 & 0.33 & 1.81 & 0.12 & 15.4 & 0.12 \\ 0.66 & 0.18 & 0.19 & 0.25 & 0.28 & 1.11 & 0.06 & 18.2 & 0.12\end{array}$

$\begin{array}{lllllllll}0.87 & 1.44 & 0.87 & 2.04 & 1.09 & 0.55 & 0.11 & 4.8 & 0.58\end{array}$

$\begin{array}{lllllllll}0.76 & 0.25 & 0.33 & 0.50 & 0.57 & 0.80 & 0.36 & 2.2 & 0.96 \\ 0.85 & 0.18 & 0.26 & 0.30 & 0.38 & 1.39 & 0.13 & 10.6 & 0.17\end{array}$

$\begin{array}{lllllllll}0.85 & 0.18 & 0.26 & 0.30 & 0.38 & 1.39 & 0.13 & 10.6 & 0.17 \\ 0.79 & 0.23 & 0.22 & 0.87 & 0.50 & 1.83 & 0.18 & 9.9 & 0.19\end{array}$

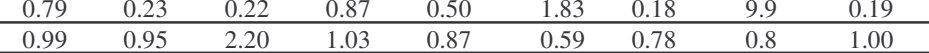

\begin{tabular}{lllllllll}
0.99 & 0.95 & 2.20 & 1.03 & 0.87 & 0.59 & 0.78 & 0.8 & 1.00 \\
\hline .86 & 1.25 & 2.42 & 1.16 & 1.20 & 0.60 & 0.34 & 1.8 & 1.00
\end{tabular} \begin{tabular}{lllllllll}
1.06 & 1.68 & 1.05 & 2.46 & 1.13 & 0.58 & 0.12 & 4.9 & 0.58 \\
1.04 & 1.51 & 1.43 & 1.33 & 1.69 & 0.14 & $* 0.01640$ & 3.0 & 0.83 \\
\hline
\end{tabular}

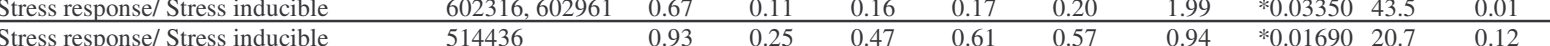




\begin{tabular}{|c|c|c|c|c|c|c|c|c|c|c|c|c|}
\hline \multirow[t]{2}{*}{ Gene Symbol } & \multirow[t]{2}{*}{ Gene Name } & \multirow[t]{2}{*}{ Pathways (General) } & \multirow[t]{2}{*}{ I.M.A.G.E. ID } & \multicolumn{5}{|c|}{ Ratio to Pooled Testis } & \multicolumn{3}{|c|}{ F Statistic ${ }^{b}$} & \multirow[t]{2}{*}{$\begin{array}{c}\mathbf{P} \\
\text { value }^{\mathrm{c}}\end{array}$} \\
\hline & & & & Testis & Spleen & Heart & Liver & Brain & Num. & Denom. & Ratio & \\
\hline Histone-H3.3A & Histone-H3.3A & Chromatin related & 961662 & 0.97 & 0.49 & 0.39 & 0.26 & 0.44 & 0.95 & 0.14 & 6.9 & 0.33 \\
\hline Histone-H4 & Histone-H4 & Chromatin related & 493223 & 0.97 & 1.73 & 14.80 & 4.43 & 9.97 & 5.47 & 0.09 & 60.6 & 0.01 \\
\hline Hk1 & Hexokinase 1 & Growth regulation & 973936 & 0.65 & 1.38 & 0.27 & 0.81 & 0.79 & 1.46 & 0.07 & 19.5 & 0.12 \\
\hline Hmox2 & Heme oxygenase 2 & Stress response/ Stress induced & 602116 & 0.82 & 0.33 & 0.28 & 0.54 & 0.63 & 0.82 & 0.05 & 15.1 & 0.12 \\
\hline hnRNP-A2 & heterogenous nuclear ribonucleoprotein $\mathrm{A} 2 / \mathrm{B} 1$ & Transcription/ Translation & 721779 & 1.52 & 1.71 & 1.18 & 1.21 & 1.51 & 0.11 & 0.11 & 1.0 & 1.00 \\
\hline hnRP-A1 & heterogenous nuclear ribonucleoprotein A1 & Transcription/ Translation & 386370 & 1.14 & 3.66 & 1.55 & 1.11 & 0.93 & 1.24 & 0.09 & 14.2 & 0.12 \\
\hline hTAFII18-like & PolII transcription factor TFIID chain hTAFIII 18 & Transcription/ Translation & 523974 & 0.78 & 0.42 & 0.70 & 0.76 & 0.89 & 0.36 & 0.07 & 4.9 & 0.58 \\
\hline Idb2 & Inhibitor of DNA binding 2 & Transcription/ Translation & 608134 & 0.88 & 1.19 & 1.95 & 1.39 & 1.46 & 0.36 & $* 0.02120$ & 7.8 & 0.24 \\
\hline Jun & $\mathrm{v}$-jun sarcoma virus 17 oncogene & Growth regulation & 975691 & 0.80 & 1.61 & 3.24 & 1.10 & 1.24 & 1.16 & 1.11 & 1.0 & 1.00 \\
\hline Keratin-like & Keratin-like & Housekeeping & $\begin{array}{l}975676,975855, \\
608390,608109\end{array}$ & 1.08 & 1.58 & 2.71 & 2.06 & 1.49 & 0.50 & $* 0.02260$ & 11.0 & 0.15 \\
\hline Kifla & Kinesin heavy chain member 1A & Growth regulation & 492514 & 1.12 & 15.90 & 4.84 & 2.76 & 1.95 & 4.26 & 0.45 & 9.5 & 0.19 \\
\hline Kif1b & Kinesin heavy chain member 1B & Growth regulation & 560049 & 1.08 & 1.83 & 1.51 & 1.49 & 1.03 & 0.25 & $* 0.00513$ & 5.5 & 0.50 \\
\hline Kif2 & Kinesin heavy chain member 2 & Growth regulation & 602145 & 0.94 & 0.34 & 0.90 & 1.08 & 1.06 & 0.97 & $* 0.03390$ & 21.2 & 0.11 \\
\hline Kif3b & Kinesin family member $3 \mathrm{~b}$ & Growth regulation & 1108812 & 1.08 & 0.76 & 0.48 & 0.52 & 0.75 & 0.44 & 0.06 & 7.8 & 0.24 \\
\hline Kinesin-2-related & Kinesin-2-related & Growth regulation & 990126 & 0.71 & 0.95 & 0.53 & 0.75 & 0.85 & 0.21 & 0.06 & 3.7 & 0.70 \\
\hline Krag & Kras oncogene-associated gene & Growth regulation & 484140 & 1.06 & 2.80 & 1.34 & 2.14 & 1.13 & 0.75 & 0.10 & 7.8 & 0.24 \\
\hline Kras2 & Kirsten rat sarcoma oncogene 2 & Growth regulation & 572995 & 1.04 & 1.17 & 3.84 & 1.24 & 1.31 & 1.18 & 2.31 & 0.5 & 1.00 \\
\hline Krt1-10 & Keratin complex 1 , acidic, gene 10 & Housekeeping & 976351 & 0.93 & 0.37 & 0.26 & 0.41 & 0.48 & 0.90 & 0.42 & 2.1 & 0.96 \\
\hline Krt1-13 & Keratin complex 1, acidic, gene 13 & Housekeeping & 521007 & 1.11 & 2.37 & 2.88 & 1.28 & 0.95 & 1.00 & $* 0.03720$ & 21.9 & 0.11 \\
\hline Lama2 & Laminin, alpha 2 & Other & 493133 & 1.45 & 8.51 & 5.90 & 2.14 & 1.89 & 2.49 & 0.07 & 37.2 & 0.01 \\
\hline Lama4 & Laminin, alpha 4 & Other & 584781 & 1.10 & 0.87 & 15.40 & 2.67 & 3.27 & 5.36 & $* 0.00823$ & 118.0 & 0.00 \\
\hline Mak & Male germ cell associated kinase & Growth regulation & 602281 & 0.94 & 0.16 & 0.19 & 0.24 & 0.27 & 2.06 & $* 0.02610$ & 45.2 & 0.01 \\
\hline Mapk2 & Mitogen activated protein kinase 2 & Growth regulation & $\begin{array}{l}749454,439956, \\
554209\end{array}$ & 1.07 & 0.91 & 0.79 & 2.05 & 0.90 & 0.59 & $* 0.02690$ & 12.9 & 0.13 \\
\hline Mcl1 & Myeloid cell leukemia sequence 1 & Damage recognition, cell cycle, apoptosis & 493170 & 1.20 & 2.38 & 9.42 & 4.32 & 2.46 & 2.47 & 0.15 & 16.5 & 0.12 \\
\hline Mea1-like & Male enhanced antigen 1-like & Other & 315756 & 0.64 & 0.40 & 0.40 & 0.56 & 0.82 & 0.40 & $* 0.01120$ & 8.8 & 0.22 \\
\hline Mea1 & Male enhanced antigen 1 & Other & 608800 & 1.01 & 0.11 & 0.18 & 0.20 & 0.21 & 2.89 & 0.18 & 16.1 & 0.12 \\
\hline Meg1 & Meiosis expressed gene 1 & Other & 514389 & 0.75 & 0.11 & 0.11 & 0.18 & 0.22 & 2.52 & $* 0.04480$ & 55.3 & 0.01 \\
\hline Map2k1 & Mitogen activated protein kinase kinase 1 & Meiosis/Spermatogenesis & 616850 & 1.17 & 2.03 & 1.50 & 1.24 & 1.37 & 0.19 & $* 0.03230$ & 4.2 & 0.58 \\
\hline Map3k1 & Mitogen activated protein kinase kinase kinase 1 & Growth regulation & 875311 & 0.90 & 0.25 & 0.49 & 0.44 & 0.43 & 0.89 & 0.16 & 5.5 & 0.51 \\
\hline Mgmt & 0-6-methylguanine-DNA methyltransferase & DNA repair (direct reversal) & 493108 & 1.12 & 1.11 & 2.83 & 1.56 & 1.38 & 0.61 & 0.13 & 4.9 & 0.58 \\
\hline Mig-2 & Mitogen inducible gene 2 & Meiosis/Spermatogenesis & 988186 & 1.24 & 1.07 & 5.50 & 18.40 & 3.14 & 5.67 & 0.88 & 6.4 & 0.38 \\
\hline Mkk7 & Mitogen-activated protein kinase kinase 7 & Growth regulation & 821017 & 0.96 & 1.87 & 1.60 & 1.63 & 4.90 & 1.48 & $* 0.00408$ & 32.4 & 0.02 \\
\hline Mlc2 & Myosin light chain 2 & Housekeeping & 556208,604573 & 1.04 & 0.96 & 2.91 & 0.94 & 1.11 & 0.95 & $* 0.04520$ & 20.8 & 0.12 \\
\hline Mns1 & Meiosis-specific nuclear structural protein 1 & Meiosis/Spermatogenesis & 538140 & 1.11 & 0.23 & 0.36 & 0.27 & 0.37 & 1.58 & 0.32 & 5.0 & 0.58 \\
\hline Kzf2 & Kruppel zinc finger protein 2 & Other & 789990 & 1.11 & 0.56 & 0.70 & 0.51 & 0.87 & 0.42 & $* 0.00970$ & 9.2 & 0.20 \\
\hline $\mathrm{RbAp} 48$ & Retinoblastoma-binding protein & Other & 660074 & 0.77 & 1.93 & 0.57 & 0.95 & 0.66 & 0.96 & 0.15 & 6.5 & 0.38 \\
\hline Mre11b & Meiotic recombination 11 homolog $\mathrm{b}$ & DNA Repair (RR-Non-Homologous end joi & 524361 & 0.96 & 0.46 & 0.74 & 0.62 & 0.77 & 0.32 & $* 0.02260$ & 7.0 & 0.32 \\
\hline Msk2 & Mitogen- and stress-activated protein kinase- 2 & Growth regulation & 873975 & 1.03 & 1.42 & 1.73 & 1.26 & 0.99 & 0.22 & 0.10 & 2.2 & 0.96 \\
\hline Mt2 & Metallothionein 2 & Other & 963382 & 0.80 & 0.26 & 0.24 & 0.34 & 1.11 & 1.99 & 0.07 & 27.9 & 0.03 \\
\hline Mybl2 & Myeloblastosis oncogene-like 2 & Growth regulation & 532188 & 1.02 & 0.54 & 0.69 & 0.84 & 0.69 & 0.24 & $* 0.03350$ & 5.3 & 0.54 \\
\hline Myla & Myosin light chain, alkali & Housekeeping & 586078 & 0.94 & 1.24 & 5.22 & 1.32 & 1.21 & 1.94 & 0.07 & 27.2 & 0.05 \\
\hline
\end{tabular}


I.M.A.G.E. ID

Ratio to Pooled Testis

F Statistic ${ }^{b}$

$\mathbf{P}$

\begin{tabular}{|c|c|c|c|c|c|c|c|c|c|c|c|c|}
\hline & & & & & & & & & & & & \\
\hline Naip1 & Neuronal apoptosis inhibitory protein 1 & Damage recognition, cell cycle, apoptosis & 864370 & 0.73 & 1.23 & 2.38 & 1.01 & 1.15 & 0.78 & 1.43 & 0.5 & 1.00 \\
\hline Naip2 & Neuronal apoptosis inhibitory protein 2 & Damage recognition, cell cycle, apoptosis & 737787 & 0.93 & 0.73 & 0.89 & 4.93 & 0.99 & 2.53 & 0.12 & 20.5 & 0.12 \\
\hline Odf1 & Outer dense fiber of sperm tails 1 & Other & 603127 & 0.86 & 0.40 & 0.50 & 0.63 & 0.51 & 0.35 & 0.23 & 1.5 & 1.00 \\
\hline $\mathrm{p} 18$ & p18 & Transcription/ Translation & 474080 & 0.90 & 0.31 & 0.50 & 0.49 & 0.65 & 0.65 & 0.14 & 4.6 & 0.58 \\
\hline $\mathrm{p} 40$ & $\mathrm{p} 40$ & DNA repair (NER) & 931450 & 0.90 & 0.38 & 0.53 & 0.54 & 0.62 & 0.40 & 0.11 & 3.8 & 0.70 \\
\hline p52 & p52 & DNA repair (NER) & 443359 & 1.15 & 0.82 & 0.60 & 0.92 & 0.80 & 0.24 & 0.05 & 5.0 & 0.58 \\
\hline Pabp & PolyA binding protein & Transcription/ Translation & 891504,977971 & 0.70 & 0.54 & 0.33 & 0.29 & 0.37 & 0.55 & $* 0.04060$ & 12.1 & 0.15 \\
\hline Pabp (testis) & PolyA binding protein (testis-enriched isoform) & Transcription/ Translation & 516680 & 0.67 & 0.29 & 0.15 & 0.26 & 0.21 & 1.32 & 0.20 & 6.5 & 0.38 \\
\hline Paga & Proliferation-associated gene A & Damage recognition, cell cycle, apoptosis & 617734 & 0.93 & 1.31 & 2.67 & 12.90 & 1.68 & 4.43 & $* 0.03300$ & 97.1 & 0.00 \\
\hline Pcna & Proliferating cell nuclear antigen & DNA repair (NER) & 907695 & 1.04 & 0.72 & 0.31 & 0.37 & 0.48 & 1.02 & 0.14 & 7.3 & 0.28 \\
\hline Pcsk2 & Proprotein convertase subtilisin/kexin type 2 & Other & 477515 & 0.91 & 1.18 & 0.56 & 0.83 & 0.59 & 0.41 & 0.05 & 8.1 & 0.23 \\
\hline Pctk3 & PCTAIRE-motif protein kinase 3 & Damage recognition, cell cycle, apoptosis & 579416 & 1.07 & 1.35 & 1.08 & 1.42 & 2.34 & 0.42 & 0.14 & 2.9 & 0.87 \\
\hline Pgk1 & Phosphoglycerate kinase 1 & Growth regulation & 822652 & 0.98 & 0.74 & 2.47 & 1.70 & 1.68 & 0.97 & 0.06 & 15.8 & 0.12 \\
\hline Phb & Prohibitin & Other & 584178 & 0.94 & 0.47 & 1.42 & 1.07 & 0.66 & 0.78 & 0.06 & 13.0 & 0.13 \\
\hline Pkcq & Protein kinase $\mathrm{C}$, theta & Growth regulation & 582973 & 0.86 & 0.59 & 0.99 & 0.83 & 1.06 & 0.21 & 0.07 & 3.0 & 0.84 \\
\hline Pla2g2c & Phospholipase A2, group IIC & Housekeeping & 513783 & 1.13 & 1.52 & 21.00 & 6.50 & 5.30 & 5.83 & $* 0.02490$ & 128.0 & 0.00 \\
\hline Pol- $\beta$ & DNA polymerase beta & DNA repair (BER) & 918389 & 1.00 & 0.17 & 0.18 & 0.26 & 0.46 & 2.32 & $* 0.04520$ & 50.8 & 0.01 \\
\hline Mapk1 & Mitogen activated protein kinase 1 & Growth regulation & 736825,634946 & 1.21 & 1.64 & 1.65 & 1.26 & 2.72 & 0.44 & 0.10 & 4.2 & 0.60 \\
\hline Prkmk1 & Prkmk1 & Growth regulation & 585802 & 0.87 & 1.67 & 1.22 & 1.76 & 2.23 & 0.55 & 0.06 & 8.8 & 0.22 \\
\hline Prm1 & Protamine 1 & Meiosis/Spermatogenesis & 918252 & 0.41 & 0.17 & 0.18 & 0.16 & 0.13 & 0.79 & 0.29 & 2.7 & 0.87 \\
\hline Prm2 & Protamine 2 & Meiosis/Spermatogenesis & 917852 & 0.94 & 0.36 & 0.33 & 0.61 & 0.53 & 0.75 & 0.06 & 12.1 & 0.15 \\
\hline Prm3 & Protamine 3 & Meiosis/Spermatogenesis & 907309 & 1.11 & 2.16 & 1.42 & 0.88 & 1.01 & 0.52 & 0.31 & 1.7 & 1.00 \\
\hline $\operatorname{Prp} 22$ & Pre-mRNA splicing factor RNA helicase & Transcription/ Translation & 604173 & 1.05 & 1.10 & 0.29 & 0.42 & 0.45 & 1.45 & 0.18 & 8.2 & 0.23 \\
\hline Ptgds & Prostaglandin D2 synthase & Other & 571621 & 1.46 & 1.31 & 16.70 & 5.93 & 4.98 & 4.68 & 0.09 & 54.4 & 0.01 \\
\hline Rad51-ap1 & Rad51 associated protein 1 & DNA repair related & 849369 & 1.13 & 0.80 & 2.23 & 1.06 & 0.96 & 0.64 & 0.86 & 0.7 & 1.00 \\
\hline & & & 1225890 & & & & & & & & & \\
\hline $\operatorname{Rad} 51 b$ & $\operatorname{Rad} 51 \mathrm{~b}$ & DNA repair (Recombinational repair-Homo & 1246004 & 1.33 & 1.13 & 1.04 & 1.97 & 1.11 & 0.28 & 0.08 & 3.3 & 0.77 \\
\hline Rara & Retinoic acid receptor, alpha & Other & 475996 & 1.02 & 0.74 & 0.74 & 0.61 & 0.48 & 0.32 & $* 0.02520$ & 7.1 & 0.31 \\
\hline $\mathrm{Rbm} 3$ & RNA binding motif protein 3 & Transcription/ Translation & 872105 & 1.16 & 1.78 & 14.40 & 6.90 & 3.07 & 4.30 & $* 0.04340$ & 94.2 & 0.00 \\
\hline $\operatorname{Rec} 2$ & RecA-like protein & Other & 1246004 & 0.87 & 1.45 & 0.91 & 2.94 & 1.44 & 1.00 & 0.06 & 17.6 & 0.12 \\
\hline Req & Requiem & Damage recognition, cell cycle, apoptosis & 573346 & 1.03 & 0.95 & 3.30 & 0.70 & 0.75 & 1.66 & 1.14 & 1.5 & 1.00 \\
\hline Rip1 & Ral-interacting protein 1 & Damage recognition, cell cycle, apoptosis & 849333 & 1.11 & 0.98 & 19.40 & 3.52 & 3.59 & 6.02 & 0.13 & 47.8 & 0.01 \\
\hline $\begin{array}{l}\text { RNA pol transcrip. } \\
\text { reg. med. }\end{array}$ & $\begin{array}{l}\text { RNA polymerase transcriptional regulation } \\
\text { mediator }\end{array}$ & Transcription/ Translation & 635118 & 0.95 & 0.68 & 0.53 & 0.67 & 0.98 & 0.28 & 0.07 & 4.2 & 0.58 \\
\hline Rxrb & Retinoid $\mathrm{X}$ receptor beta & Other & 493651 & 1.27 & 4.79 & 6.07 & 1.92 & 1.65 & 1.98 & 0.70 & 2.8 & 0.87 \\
\hline Rxrg & Retinoid X receptor gamma & Other & 479866 & 1.03 & 3.51 & 3.16 & 1.54 & 1.07 & 1.43 & $* 0.00852$ & 31.4 & 0.03 \\
\hline Smp30 & Senescence marker protein-30 & Damage recognition, cell cycle, apoptosis & 521164,747954 & 1.07 & 1.82 & 2.72 & 10.50 & 1.97 & 3.06 & 0.07 & 41.3 & 0.01 \\
\hline Snf21 & $\begin{array}{l}\text { SWI/SNF-related, matrix associated, actin } \\
\text { dependent regulator of chromatin, subfamily a, } \\
\text { member } 1\end{array}$ & Transcription/ Translation & 960224 & 0.98 & 0.73 & 3.64 & 0.92 & 1.15 & 1.65 & $* 0.02490$ & 36.3 & 0.01 \\
\hline Snf51 & $\begin{array}{l}\text { SWI/SNF-related, matrix associated, actin } \\
\text { dependent regulator of chromatin, subfamily b, } \\
\text { member } 1\end{array}$ & Transcription/ Translation & 580874 & 1.08 & 0.91 & 0.90 & 2.51 & 0.94 & 0.80 & $* 0.00704$ & 17.5 & 0.12 \\
\hline 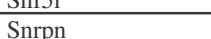 & Small nuclear ribonucleoprotein $\mathrm{N}$ & Transcription/ Translation & $\begin{array}{l}5808 / 4 \\
977306\end{array}$ & $\frac{1.08}{1.01}$ & 0.91 & 0.90 & 2.51 & $\frac{0.94}{2.36}$ & 0.80 & 0.05 & $1 / .5$ & $\frac{0.12}{0.12}$ \\
\hline Sod1 & Superoxide dismutase 1 & Stress response/ Stress induced & 762216 & 0.98 & 0.59 & 0.63 & 1.06 & 0.64 & 0.32 & 0.14 & 2.3 & 0.93 \\
\hline Sod3 & Superoxide dismutase 3 & Stress response/ Stress induced & 776821 & 1.16 & 0.78 & 8.78 & 2.57 & 2.58 & 3.59 & 0.06 & 62.4 & 0.01 \\
\hline
\end{tabular}




\section{Gene Symbol}

\begin{tabular}{|c|c|c|c|c|c|c|c|c|c|c|c|c|}
\hline & & & & Testis & Spleen & Heart & Liver & Brain & Num. & Denom. & Ratio & \\
\hline Sox6 & SRY-box containing gene 6 & Transcription/ Translation & 1068053 & 1.11 & 0.95 & 4.38 & 2.21 & 1.74 & 1.54 & 0.05 & 31.1 & 0.03 \\
\hline Srm & Spermidine-synthase & Other & 582569 & 0.89 & 1.09 & 0.88 & 0.90 & 2.04 & 0.54 & 0.13 & 4.3 & 0.58 \\
\hline Spnr & Spermatid perinuclear RNA-binding protein & Transcription/ Translation & 764543 & 0.87 & 0.34 & 0.30 & 0.40 & 0.78 & 0.99 & 0.07 & 14.8 & 0.12 \\
\hline Stat3 & Signal transducer and activator of transcription 3 & Growth regulation & 975718 & 0.97 & 0.76 & 1.85 & 0.66 & 0.58 & 0.88 & 0.64 & 1.4 & 1.00 \\
\hline Stat 4 & Signal transducer and activator of transcription 4 & Transcription/ Translation & 577343 & 0.77 & 0.19 & 0.18 & 0.98 & 0.34 & 2.55 & 0.19 & 13.5 & 0.12 \\
\hline Syср3 & Synaptonemal complex protein 3 & Chromatin related & $\begin{array}{l}874980, \\
1230236\end{array}$ & 0.92 & 0.19 & 0.18 & 0.26 & 0.27 & 1.81 & 0.07 & 25.8 & 0.06 \\
\hline Tak1 & TGF-beta-activated kinase & Growth regulation & 865301 & 0.96 & 0.92 & 2.24 & 0.91 & 0.81 & 0.71 & 0.86 & 0.8 & 1.00 \\
\hline $\mathrm{Tb} 4 \mathrm{y}$ & Thymosin, beta 4, Y chromosome & Meiosis/Spermatogenesis & 273224,325197 & 0.93 & 7.43 & 3.07 & 0.88 & 5.26 & 4.01 & 0.09 & 43.8 & 0.01 \\
\hline Tbp & TATA box binding protein & Transcription/ Translation & 573420 & 0.99 & 0.61 & 0.61 & 0.60 & 0.70 & 0.19 & 0.15 & 1.3 & 1.00 \\
\hline Tctex 2 & T-complex testis-expressed 2 & Meiosis/ Spermatogenesis & 514791,515753 & 0.65 & 0.34 & 0.20 & 0.15 & 0.22 & 1.36 & 0.27 & 5.0 & 0.58 \\
\hline Tdgb & $\begin{array}{l}\text { T:G mismatch-specific thymine-DNA } \\
\text { glycosylase }\end{array}$ & DNA repair (BER) & 990644 & 1.25 & 4.37 & 1.87 & 1.80 & 1.89 & 0.88 & $* 0.00642$ & 19.3 & 0.12 \\
\hline Tenr & Testis nuclear RNA-binding protein & Transcription/ Translation & 602129 & 0.93 & 0.39 & 0.86 & 1.14 & 1.09 & 0.80 & 0.14 & 5.8 & 0.46 \\
\hline Testin-2 & Testin-2 & Other & 917479 & 0.90 & 0.35 & 0.91 & 0.48 & 0.45 & 0.78 & 0.21 & 3.8 & 0.70 \\
\hline Pdcd 10 & Programmed cell death 10 & Damage recognition, cell cycle, apoptosis & 822588 & 0.90 & 0.71 & 0.54 & 0.88 & 1.11 & 0.32 & $* 0.01190$ & 7.0 & 0.32 \\
\hline TIFII-B & Transcription initiation factor IIB & Transcription/ Translation & 315324 & 0.98 & 0.77 & 0.55 & 0.61 & 0.87 & 0.24 & $* 0.04490$ & 5.2 & 0.55 \\
\hline Timp2 & Tissue inhibitor of metalloproteinase 2 & Adhesion/ Extracellular matrix & 535104 & 1.47 & 1.62 & 1.82 & 1.18 & 1.22 & 0.14 & 0.11 & 1.4 & 1.00 \\
\hline Tk1 & Thymidine kinase 1 & Other & 556061 & 0.97 & 0.99 & 3.93 & 0.90 & 1.14 & 1.60 & $* 0.01860$ & 35.0 & 0.01 \\
\hline Tnp1 & Transition protein 1 & Chromatin related & 602551 & 0.58 & 0.16 & 0.18 & 0.17 & 0.15 & 1.37 & 0.11 & 12.1 & 0.15 \\
\hline Top1 & Topoisomerase (DNA) I & Chromatin related & 873675 & 0.94 & 1.36 & 2.89 & 1.07 & 1.21 & 0.80 & 0.39 & 2.1 & 0.98 \\
\hline Top2b & Topoisomerase (DNA) II beta & Chromatin related & 652824 & 0.95 & 1.62 & 2.27 & 1.04 & 1.47 & 0.52 & 0.14 & 3.6 & 0.70 \\
\hline Tssk2 & Testis specific serine kinase 2 & Growth regulation & 602020 & 0.93 & 0.14 & 0.22 & 0.28 & 0.26 & 2.00 & 0.12 & 16.6 & 0.12 \\
\hline Tuba2 & Tubulin alpha 2 & Housekeeping & 919504 & 1.10 & 1.42 & 0.89 & 0.60 & 1.10 & 0.43 & $* 0.04300$ & 9.4 & 0.20 \\
\hline Ube $2 b$ & Ubiquitin-conjugating enzyme E2B & Other & 577631 & 0.98 & 0.50 & 1.22 & 0.73 & 0.64 & 0.52 & 0.09 & 6.0 & 0.40 \\
\hline Ube3a & Ubiquitin conjugating enzyme E3A & Other & 538653 & 0.93 & 0.38 & 0.52 & 0.60 & 0.91 & 0.59 & 0.13 & 4.5 & 0.58 \\
\hline Ung & Uracil-DNA glycosylase & DNA repair (BER) & $\begin{array}{l}355462,406824, \\
931428\end{array}$ & 0.92 & 0.50 & 0.33 & 0.49 & 0.53 & 0.56 & 0.29 & 2.0 & 0.99 \\
\hline Vegf & Vascular endothelial growth factor & Damage recognition, cell cycle, apoptosis & 988133 & 1.03 & 1.19 & 0.39 & 1.23 & 1.20 & 1.03 & 0.66 & 1.6 & 1.00 \\
\hline Wnt10b & Wingless related MMTV integration site $10 \mathrm{~b}$ & Growth regulation & 439485 & 1.10 & 0.33 & 0.23 & 0.23 & 1.47 & 3.28 & 0.07 & 47.5 & 0.01 \\
\hline Zfp105 & Zinc finger protein 105 & Damage recognition, cell cycle, apoptosis & 536078 & 1.23 & 1.06 & 2.38 & 1.04 & 1.45 & 0.48 & 0.20 & 2.4 & 0.92 \\
\hline
\end{tabular}

${ }^{a}$ Data for the 152 genes with expression ratios Š 0.60 or $\square 1.68$ in one or more tissues

benominators with an asterisk were replaced by the median of the denominators $(0.0456)$ before calculating the ratio

'Permuation $\mathrm{p}$ value

\section{I.M.A.G.E. ID Ratio to Pooled Testis} Rum Denom. Ratio

$\mathbf{P}$

alue ${ }^{c}$ 


\section{APPENDIX B}

All annotated genes showing significant differences in expression during the transition from mitosis to meiosis in the prepubertal mouse testis 


\section{All annotated genes showing significant differences in expression between spermatogonial mitosis and preleptotene}

\begin{tabular}{|c|c|c|c|c|c|c|c|}
\hline \multirow[t]{2}{*}{ Name } & \multirow[t]{2}{*}{ Symbol } & \multirow[t]{2}{*}{ Function } & \multirow{2}{*}{$\begin{array}{c}\text { GenBank } \\
\text { Accession } \\
\text { ID }\end{array}$} & \multicolumn{2}{|c|}{$\begin{array}{l}\text { Fold-difference in } \\
\text { expression }\end{array}$} & \multirow{2}{*}{\multicolumn{2}{|c|}{$\begin{array}{l}\text { Previously described role in } \\
\text { reproduction? }\end{array}$}} \\
\hline & & & & Ratio & P-value ${ }^{a}$ & & \\
\hline \multicolumn{8}{|c|}{ Genes with increased expression as germ cells progress from mitosis to the onset of meiosis } \\
\hline Seleno-protein & Sep & Misc. & M88463 & 9.8 & 0.04 & Yes & (Shih and Kleene, 1992) \\
\hline Ig germline $\mathrm{H}$-chain gene V-region & IgH (germline) & Immune response & M16724 & 6.8 & 0.001 & Yes & (Kerr and Burrows, 1991) \\
\hline Immunosuperfamily protein $\mathrm{B} 12$ & Igsf4 & Immune response & AF061260 & 4.0 & 0.04 & Yes & (Wakayama et al., 2001) \\
\hline Zinc finger protein $\mathrm{X}$-linked & Zfx & Cellular differentiation & M32309 & 2.7 & 0.05 & Yes & (Luoh et al., 1997) \\
\hline Adipocyte-specific protein adipoQ & AdipoQ & Unknown & $\mathrm{U} 49915$ & 37.0 & 0.02 & No & \\
\hline Glioblastoma amplified sequence & Gbas & Unknown & AJ001261 & 22.2 & 0.002 & No & \\
\hline Methylmalonyl coenzyme A mutase & Mut & Metabolism & $\mathrm{X} 51941$ & 11.9 & 0.04 & No & \\
\hline Sprouty-4 & Spry4 & Signal transduction & AB019280 & 5.6 & 0.02 & No & \\
\hline Short stature homeobox 2 & Shox 2 & Transcription & U66918 & 4.1 & 0.04 & No & \\
\hline Transactivating transcription factor 3 & Sp3 & Transcription & AF062567 & 3.8 & 0.01 & No & \\
\hline Histone $\mathrm{H} 2 \mathrm{a}(\mathrm{A}), \mathrm{H} 2 \mathrm{a}(\mathrm{B})$, and $\mathrm{H} 2 \mathrm{~b}$ & $\mathrm{H} 2 \mathrm{~A}-\mathrm{B}$ & Chromatin-related & U62673 & 2.8 & 0.03 & No & \\
\hline ADP-ribosyltransferase 5 & Art5 & Protein modification & U60881 & 2.3 & 0.03 & No & \\
\hline Cryptochrome 1 & Cry1 & Molecular clock & AB000777 & 2.1 & 0.01 & No & \\
\hline Intracisternal A-particle type IIB & Iap2 & Growth regulation & $\mathrm{X} 16672$ & 2.1 & 0.03 & No & \\
\hline
\end{tabular}

Genes with decreased expression as germ cells progress from mitosis to the onset of meiosis

\begin{tabular}{|c|c|c|c|c|c|c|c|}
\hline DiGeorge syndrome critical region 6 & Dgcr6 & Unknown & AF021031 & 143.8 & 0.02 & Yes & (Edelmann et al., 2001) \\
\hline Glutathione peroxidase 4 & Gpx4 & Stress response & D87896 & 44.1 & 0.03 & Yes & (Giannattasio et al., 1997) \\
\hline Budding inhibited by benzimidazoles 1 & Bub1 & Cell cycle & AF002823 & 22.6 & 0.02 & Yes & (Bernard et al., 2001) \\
\hline Hydroxysteroid (17-beta) dehydrogenase 10 & Hsd17b10 & Metabolism & U96116 & 20.4 & 0.002 & Yes & (Hansis et al., 1998) \\
\hline High mobility group 1 & Hmgb1 & Cellular differentiation & U00431 & 20.2 & 0.0003 & Yes & (Bucci et al., 1984) \\
\hline Hexosaminidase A & Hexa & Metabolism & U05837 & 20.1 & 0.02 & Yes & (Adamali et al., 1999a,b) \\
\hline Integrin linked kinase & Ilk & Signal transduction & U94479 & 15.7 & 0.05 & Yes & (Mulholland et al., 2001) \\
\hline Actin-related protein $2 / 31 \mathrm{~A}$ & Arpc1a & Cytoskeletal element & AB024984 & 13.2 & 0.01 & Yes & (Fouquet et al., 2000) \\
\hline Glutathione s-transferase, MU & Gstm5 & Cytoskeletal element & U24428 & 13.0 & 0.02 & Yes & (Fulcher et al., 1995) \\
\hline DEAD box polypeptide, Y chromosome & Dby & RNA helicase & AJ007376 & 11.4 & 0.03 & Yes & (Mazeyrat et al., 2001) \\
\hline Protein kinase, cAMP dependent, catalytic, alpha & Prkaca & Metabolism & M12303 & 11.1 & 0.005 & Yes & (Desseyn et al., 2000) \\
\hline
\end{tabular}

kinase, cAMP dependent, catalytic, alpha

Metabolism

M12303

11.1

0.005 
GenBank

Accession

ID
Fold-difference in

expression

Ratio P-value ${ }^{a}$
P-value

Genes with decreased expression as germ cells progress from mitosis to the onset of meiosis (continued)

Milk fat globule-EGF factor 8

Acrosomal vesicle protein 1

NIMA-related expressed kinase 2

Endothelin

Cystatin 3

Flap structure specific endonuclease 1

Triosephosphate isomerase

Bcl2-associated X protein

Catenin alpha 1

Phosphoglycerate mutase muscle-specific

Tubulin alpha 2

Mcm2

TIF1 beta

Breast cancer 2

ictrotubule-associated protein 7

Rab7

Polo-like kinase 1

RhoB

Preproenkephalin related

Heat shock cognate 70 (testis)

RNA binding motif 3

Actin, gamma 2

Peroxiredoxin protein 2

LIM protein-1

TPR-containing, SH2-binding phosphoprotein

Calponin 2

Isocitrate dehydrogenase 3 (NAD+)

Dynactin 3

Diacylglycerol acyltransferase

RNA binding protein regulatory subunit

Rab6/rab5-associated protein

SRY-box containing gene 18

Peptidylprolyl isomerase B

Chaperonin subunit 3

\begin{tabular}{|c|c|c|c|c|c|c|}
\hline Mfge8 & Cell adhesion & M38337 & 9.5 & 0.002 & Yes & (Kanai et al., 2000) \\
\hline Acvp1 & Fertilization & U31992 & 8.9 & 0.02 & Yes & (Kurth et al., 1991) \\
\hline Nek2 & Cell cycle & AF013166 & 8.8 & 0.004 & Yes & (Di Agostino et al., 2002) \\
\hline Edn1 & Signal transduction & U35233 & 7.7 & 0.01 & Yes & (Cai et al., 2000) \\
\hline Cst3 & Cellular differentiation & U10098 & 7.6 & 0.02 & Yes & (Tsuruta et al., 1993) \\
\hline Fen1 & DNA repair & L26320 & 7.0 & 0.04 & Yes & (Harrington and Lieber, 1994) \\
\hline Tpi & Metabolism & L31777 & 6.7 & 0.03 & Yes & (Russell and Kim, 1996) \\
\hline Bax & Apoptosis & L22472 & 6.4 & 0.01 & Yes & (Russell et al., 2002) \\
\hline Catna1 & Cell adhesion & X59990 & 4.8 & 0.01 & Yes & (Wine and Chapin, 1999) \\
\hline Pgam-m & Metabolism & AF029843 & 4.6 & 0.05 & Yes & (Broceno et al., 1995) \\
\hline Tuba2 & Cytoskeletal element & M28727 & 4.2 & 0.01 & Yes & (Bo and Wensink, 1989) \\
\hline Mcm2 & DNA replication & D86725 & 3.9 & 0.02 & Yes & (Lindner et al., 2002) \\
\hline Tif1b & Transcription & X99644 & 3.6 & 0.04 & Yes & (Le Douarin et al., 1996) \\
\hline Brca2 & DNA repair & U89652 & 3.5 & 0.02 & Yes & (Connor et al., 1997) \\
\hline Mtap7 & Cytoskeletal element & Y15197 & 3.0 & 0.02 & Yes & (Komada et al., 2000) \\
\hline Rab7 & Intracellular transport & Y13361 & 2.7 & 0.03 & Yes & (Ramalho-Santos and Moreno, 2001) \\
\hline Plk1 & Cell cycle & $\mathrm{U} 73170$ & 2.6 & 0.03 & Yes & (Matsubara et al., 1995) \\
\hline Arhb & Cytoskeletal element & X99963 & 2.4 & 0.002 & Yes & (Castellano et al., 1997) \\
\hline Penk-rs & Signal transduction & M55181 & 2.0 & 0.02 & Yes & (Kilpatrick et al., 1990) \\
\hline Hsc70t & Stress response & AF109905 & 2.0 & 0.02 & Yes & (Matsumoto et al., 1993) \\
\hline Rbm3 & Stress response & $\mathrm{AB} 016424$ & 1.9 & 0.04 & Yes & (Danno et al., 2000) \\
\hline $\operatorname{Actg} 2$ & Cytoskeletal element & U20365 & 1.8 & 0.05 & Yes & (Kim et al., 1989) \\
\hline Prdx2 & Stress response & AF093853 & 1752.9 & 0.03 & No & \\
\hline Lhx1 & Transcription & D88792 & 105.0 & 0.02 & No & \\
\hline Tsbp & Misc. & L49502 & 66.9 & 0.02 & No & \\
\hline Cnn2 & Cytoskeletal element & Z19543 & 43.1 & 0.01 & No & \\
\hline Idh3 & Metabolism & U68564 & 41.9 & 0.02 & No & \\
\hline Dctn3 & Cytoskeletal element & AF098508 & 39.0 & 0.01 & No & \\
\hline Dgat & Metabolism & AF078752 & 36.3 & 0.004 & No & \\
\hline Dj1 & Growth regulation & $\mathrm{AB} 015652$ & 34.7 & 0.05 & No & \\
\hline Rabac1 & Intracellular transport & L40934 & 33.2 & 0.002 & No & \\
\hline Sox 18 & Transcription & L35032 & 32.9 & 0.04 & No & \\
\hline Ppib & Protein modification & X58990 & 27.3 & 0.05 & No & \\
\hline Cct3 & Protein modification & L20509 & 24.5 & 0.01 & No & \\
\hline
\end{tabular}


GenBank

Accession

ID
Fold-difference in

expression

Ratio P-value ${ }^{a}$
Previously described role in reproduction? ${ }^{\text {b }}$

Genes with decreased expression as germ cells progress from mitosis to the onset of meiosis (continued)

Ubiquitin c-terminal hydrolase related

Uchrp Protein modification D84096

Viral envelope like protein (G7e)

RNA polymerase I associated factor

Centromere protein A

Thioredoxin reductase 1

Serine protease inhibitor 4

Alpha-actinin-2 associated LIM protein

Tuberous sclerosis 2

Baf53a

NIK-related kinase

Adaptor protein complex gamma

Cell surface antigen AA4

P35b

ClpP protease

$\mathrm{X}$ chromosome-

Elongation factor 2

cell leukemia sequence 1

Ribosomal protein L8

Dynactin 1

Mitogen activated protein kinase kinase 5

Anti-corynebacterium kutscheri

Solute carrier 20, member 1

Transaldolase

N-myristoyltransferase 1

Mini chromosome maintenance deficient 4

Seb4

Ferredoxin-NADP reductase

Annexin VI, p68

Rab24

Kryn

Histidyl-tRNA synthetase

SKD3

Retinal S-antigen

Thioredoxin

Sec22b

$\begin{array}{lll}\text { G7e } & \text { Unknown } & \text { U6948 } \\ \text { Paf53 } & \text { Transcription } & \text { D14336 }\end{array}$

Transcription

Cenp-a Chromatin-related

U69488

Stress response

Serpine2 $\quad$ Misc

\begin{tabular}{lll} 
Serpine2 & Misc. & X70296 \\
\hline
\end{tabular}

$\begin{array}{lll}\text { Alp } & \text { Cytoskeletal element } & \text { AF002283 }\end{array}$

AF012710

Growth regulation U39818

Baf53a $\quad$ Chromatin-related $\quad$ AF041476

Signal transduction

AB020741

Intracellular transport

X54424

Ap1g

Unknown

Immune response $\quad$ X53619 15.8

Protein modification $\quad$ AJ005253

ClpP Protein modification

Eef2 $\quad$ Biosynthesi

Mcl1

Apoptosis

Biosynthesis

M76131

$\mathrm{Rpl} 8$

Dctn1 Cytoskeletal element

Signal transduction

$\begin{array}{ll}\text { Map2k5 } & \text { Signal transduction } \\ \text { Ack } & \text { Immune response }\end{array}$

Slc20a1

Taldol

Intercellular transport

Metabolism

Nmt1 Protein modification

Cell cycle

Seb4l Post-transcriptional reg.

Metabolism

$\mathrm{Fdxr}$

Metabolism

Anx6

Rab24

Unknown

Kryn Unknown

Biosynthesis

Skd3

Intercellular transport

Sag

Misc.

Capping protein beta 1

Stress response

Intracellular transport

M76131

U67771

U60312

AB019374

24.3

0.03

$23.0 \quad 0.05-20$

$\begin{array}{lll}23.0 & 0.05 & \text { No } \\ 22.5 & 0.05 & \text { No } \\ 22.2 & 0.04 & \text { No }\end{array}$

$\begin{array}{lll}20.8 & 0.01 & \text { No }\end{array}$

$\begin{array}{lll}20.7 & 0.02 & \text { No } \\ 20.0 & 0.04 & \text { No }\end{array}$

$\begin{array}{lll}20.6 & 0.04 & \text { No } \\ 19.6 & 0.02 & \text { No }\end{array}$

$\begin{array}{lll}19.6 & 0.02 & \text { No } \\ 18.7 & 0.05 & \text { No }\end{array}$

$\begin{array}{lll}18.7 & 0.05 & \text { No } \\ 18.2 & 0.05 & \text { No }\end{array}$

$17.6 \quad 0.04$

$\begin{array}{ll}15.8 & 0.04 \\ 15.8 & 0.04\end{array}$

$\begin{array}{lll}15.8 & 0.04 & \text { No }\end{array}$

$\begin{array}{lll}15.0 & 0.03 & \text { No }\end{array}$

$\begin{array}{lll}14.9 & 0.01 & \text { No }\end{array}$

$\begin{array}{ll}14.9 & 0.04\end{array}$

$\begin{array}{ll}14.9 & 0.02 \\ 14.8 & 0.004\end{array}$

$\begin{array}{lll}14.8 & 0.004 & \text { No }\end{array}$

$\begin{array}{lll}14.4 & 0.04 & \text { No }\end{array}$

$\begin{array}{lll}14.2 & 0.01 \\ 0 & 13.5 & 0.04\end{array}$

\begin{tabular}{lll} 
& 14.2 & 0.01 \\
\hline & 13.5 & 0.04
\end{tabular}

M73696

13.3

U67611 13.3

AF043326

13.3

D26089

X75316

12.8

D49920 12.3

11.9

Z22819

D89677

U39473

U09874

M24086

Sec2211

Cytoskeletal element

$\mathrm{X} 77585$

U91538

U10407

$\begin{array}{ll}0.01 & \text { No } \\ 0.04 & \text { No } \\ 0.02 & \text { No }\end{array}$

$0.02 \quad$ No

$\begin{array}{ll}0.01 & \text { No } \\ 0.05 & \text { No }\end{array}$

$\begin{array}{ll}0.05 & \mathrm{No} \\ 0.01 & \mathrm{No}\end{array}$

$\begin{array}{ll}0.01 & \text { No } \\ 0.04 & \text { No }\end{array}$

$\begin{array}{ll}0.04 & \text { No } \\ 0.05 & \text { No } \\ 0.05 & \text { No }\end{array}$

$0.05 \quad$ No

$\begin{array}{lll}11.8 & 0.04 & \text { No }\end{array}$

$\begin{array}{lll}11.8 & 0.02 & \text { No }\end{array}$

$\begin{array}{lll}11.8 & 0.01 & \text { No }\end{array}$

$\begin{array}{ccc}11.0 & 0.003 & \text { No } \\ 11.0 & 0.05 & \text { No }\end{array}$

$\begin{array}{ccc}11.0 & 0.05 & \text { No } \\ 10.9 & 0.001 & \text { No }\end{array}$

$\begin{array}{ccc}10.9 & 0.001 & \text { No } \\ 10.3 & 0.02 & \text { No }\end{array}$

No 
GenBank

Accession

ID

Genes with decreased expression as germ cells progress from mitosis to the onset of miosis (continued)

Alcohol dehydrogenase-B2

Ubiquitin-like enzyme 1a

Transcription factor S-II

Histone 1-0

Cyclin F

Calcium/calmodulin serine protein kinase

Glutaredoxin

WSB-1

Neuropilin

Procollagen, type XVIII, alpha 1

Ribosomal protein L29

CMP-N-acetylneuraminic acid synthetase

Phosphatidylserine synthase-1

Chloride channel protein 3

NfiX1-protein

Lumican

Kinesin heavy chain member 2

Glycerol-3-phosphate dehydrogenase

Catechol-O-methyltransferase

S100 calcium-binding protein A13

Cleft lip and palate transmembrane 1

Hemoglobin, beta adult major chain

Cdc6-related protein

TFIIH, $62 \mathrm{kD}$ subunit

H2A histone, member $\mathrm{X}$

MHC class III region RD

Transcription factor 21

Golgi autoantigen subfamily a4

Wingless-related MMTV integration site 6

DNA polymerase alpha 1

Polyubiquitin TI-225

Ribosomal protein S16

ATP binding cassette D3

Unc-119

Acid beta glucosidase

Rp2

D3

3

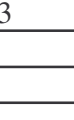

\begin{tabular}{|c|c|c|c|c|}
\hline & Adhb2 & Metabolism & M84147 & 9.5 \\
\hline & Uble1a & Protein modification & AB024303 & 9.5 \\
\hline & SII & Transcription & M18209 & 9.3 \\
\hline & H1fo & Chromatin-related & M29260 & 9.3 \\
\hline & Cenf & Cell cycle & Z47766 & 9.0 \\
\hline \multirow[t]{6}{*}{ kinase } & Cask & Signal transduction & Y17138 & 8.9 \\
\hline & Glrx1 & Metabolism & $\mathrm{AB} 013137$ & 8.8 \\
\hline & Wsb & Unknown & AF033186 & 8.1 \\
\hline & Nrp & Cell adhesion & D50086 & 8.0 \\
\hline & Col18a1 & Cell adhesion & L22545 & 7.8 \\
\hline & Rpl29 & Biosynthesis & X05021 & 7.6 \\
\hline \multirow[t]{6}{*}{ thetase } & Cmas & Biosynthesis & AJ006215 & 7.5 \\
\hline & Ptdss 1 & Biosynthesis & AF042731 & 7.4 \\
\hline & Clcn3 & Intracellular transport & AF029347 & 6.8 \\
\hline & Nfix & Transcription & Y07688 & 6.5 \\
\hline & Lum & Extracellular matrix & AF013262 & 6.4 \\
\hline & Kif2 & Intracellular transport & D12644 & 6.4 \\
\hline \multirow[t]{3}{*}{$\mathrm{se}$} & G3pd & Metabolism & D50430 & 6.3 \\
\hline & Comt & Metabolism & AF076156 & 6.3 \\
\hline & S100a13 & Misc. & X99921 & 6.2 \\
\hline 1 & Clptm1 & Intracellular transport & D67067 & 6.1 \\
\hline & $\mathrm{Hbb}$ & Misc. & J00413 & 6.1 \\
\hline & Cdc6p & Cell cycle & AJ223087 & 5.8 \\
\hline & Gtf2h1 & Transcription & AJ002366 & 5.7 \\
\hline & H2afx & Chromatin-related & Z35401 & 5.5 \\
\hline & $\mathrm{RD}$ & Unknown & AF109906 & 5.5 \\
\hline & Tf21 & Transcription factor & AF035717 & 5.4 \\
\hline & Golga4 & Growth regulation & AF051357 & 5.4 \\
\hline \multirow[t]{8}{*}{ n site 6} & Wnt6 & Signal transduction & M89800 & 5.3 \\
\hline & Pola1 & DNA replication & D13543 & 5.2 \\
\hline & Ti-225 & Protein modification & D50527 & 4.9 \\
\hline & Rps16 & Biosynthesis & M11408 & 4.9 \\
\hline & Abcd3 & Biosynthesis & L28836 & 4.8 \\
\hline & Unc119h & Misc. & AF030169 & 4.6 \\
\hline & Gba & Metabolism & M24119 & 4.5 \\
\hline & Rp2 & Misc. & X04097 & 4.5 \\
\hline
\end{tabular}

Fold-difference in
expression

P-value $^{\mathrm{a}}$

P-value

$\begin{array}{lll}0.01 & \text { No } \\ 9.5 & 0.01 & \text { No }\end{array}$

$\begin{array}{ll}0.01 & \text { No } \\ 0.02 & \text { No }\end{array}$

$\begin{array}{ll}0.04 & \text { No }\end{array}$

$\begin{array}{lll}8.9 & 0.04 & \text { No } \\ 8.8 & 0.01 & \text { No }\end{array}$

$0.05 \quad$ No

$\begin{array}{ll}0.02 & \text { No } \\ 0.01 & \text { No }\end{array}$

$0.03 \quad$ No

$0.04 \quad \mathrm{No}$

$\begin{array}{ll}0.04 & \text { No } \\ 0.03 & \text { No }\end{array}$

$0.05 \quad$ No

\begin{tabular}{lll}
0.05 & No \\
\hline & 0.04 & No
\end{tabular}

$\begin{array}{lll}6.3 & 0.02 & \text { No }\end{array}$

$0.02 \quad$ No

$\begin{array}{lll}0.01 & \text { No } \\ 0.003 & \text { No }\end{array}$

$0.01 \quad$ No

$0.03 \quad$ No

$\begin{array}{ll}0.03 & \text { No } \\ 0.01 & \text { No }\end{array}$

$0.02 \quad$ No

$0.01 \quad$ No

$\begin{array}{ll}0.01 & \text { No } \\ 0.01 & \text { No } \\ 0.04 & \text { No }\end{array}$

$0.02 \quad$ No

$0.03 \quad$ No

$\begin{array}{cc}0.03 & \text { No } \\ 0.004 & \text { No }\end{array}$

$\begin{array}{ll}0.002 & \text { No } \\ 0.02 & \text { No }\end{array}$

$0.02 \quad$ No

$\begin{array}{ll}0.02 & \text { No } \\ 0.02 & \text { No }\end{array}$

$0.05 \quad \mathrm{No}$
Previously described role in reproduction? ${ }^{\text {b }}$ 
GenBank

Accession
ID

-
Fold-difference in

expression

Ratio P-value $^{\text {a }}$
Previously described role in reproduction? ${ }^{\text {b }}$

Genes with decreased expression as germ cells progress from mitosis to the onset of meiosis (continued)

Programmed cell death 6

Pdcd6 Apoptosis

Discoidin domain receptor 1

Complement component 1 inhibitor

Defender against Apoptotic Death

Annexin 1

Tubulin, beta

Ribosomal protein S2

Lantibiotic synthetase component C

Sialyltransferase 10

Siva

Pur-alpha

Ddr1 Signal transduction $\quad$ L57509

Misc. $\quad$ AF010254

Dad1 Apoptosis

U81052

Anxa1 Growth regulation $\quad$ M69260

\begin{tabular}{lll} 
Tbb & Cytoskeletal element & X04663 \\
\hline
\end{tabular}

$\begin{array}{lll}\text { Rps2 } & \text { Biosynthesis } & \text { M20632 } \\ \text { Lanc11 } & \text { Signal transduction } & \text { Y16518 }\end{array}$

\begin{tabular}{lll} 
Sat10 & Signal transduction & Y16518 \\
Siva & Metabolism & D28941 \\
\hline Puraptosis & AF033115
\end{tabular}

Pura

Transcription

Phosphatidylinositol 4-phosphate 5-kinase I-beta

Activin receptor (ActR IIB)

Acidic ribosomal phosophoprotein PO

U02098

$\begin{array}{lll}\text { Pip5k1b } & \text { Signal transduction } & \text { D86177 }\end{array}$

Ndr1 related protein 3

Calpain small subunit

$\mathrm{G}$ protein beta 2

Cystatin B

CD1d1 antigen

Protein tyrosine phosphatase epsilon

Ribosomal protein L28

Trans-golgi network protein 1

Mitochondrial ribosomal protein S31

Poliovirus receptor homolog

Ndr1 related protein

Fibroblast growth factor inducible 13 $\quad$ Fgf13

Dia

Rab9

Rab9

Sara Sara

E46

Carnitine palmitoyltransferase 1

Sin3B

Signal peptidase complex 18

Ribosomal protein S3

Enoyl coenzyme A hydratase 1

Arbp $\quad$ Biosynthesis $\quad$ X15267

Biosynthesis

M84120

Cellular differentiation

$\mathrm{AB} 033922$

Capn4 $\quad$ Protein modification

Signal transduction

$\mathrm{AF} 058298$

\begin{tabular}{ll} 
Cstb & Apoptosis \\
\hline Cd1d1 & Immune response
\end{tabular}

Ptpe Signal transduction

Biosynthesis

Ttgn1 Intracellular transport

Biosynthesis

Signal transduction

U34960

U59807

M63695

D83484

$\mathrm{X} 74856$

D26107

Signal transduction

Intracellular transport

Intracellular transport

E46 Unknown

$\begin{array}{ll}\text { E46 } & \text { Unknown } \\ \text { Cpt1 } & \text { Metabolism }\end{array}$

Transcription

Sin3b

Rps3

Ech1

Intracellular transport

DNA polymerase zeta catalytic subunit

Rev31

Metabolism

DNA repair

$\mathrm{AB} 027290$

L20294

X61506

$4.4 \quad 0.01 \quad$ No

$\begin{array}{lll}4.4 & 0.004 & \text { No } \\ 4.4 & 0.01 & \text { No } \\ 4.3 & 0.01 & \text { No }\end{array}$

$\begin{array}{lll}4.2 & 0.001 & \text { No }\end{array}$

$\begin{array}{lll}0.02 & \text { No }\end{array}$

$4.2 \quad 0.01 \quad$ No

$4.2 \quad 0.04 \quad$ No

$\begin{array}{lcl}4.1 & 0.003 & \text { No } \\ 4.1 & 0.01 & \text { No }\end{array}$

$\begin{array}{lll}4.1 & 0.01 & \text { No } \\ 3.8 & 0.03 & \text { No }\end{array}$

$\begin{array}{lll}3.8 & 0.03 & \text { No } \\ 3.8 & 0.02 & \text { No } \\ 3.8 & 0.01 & \text { No }\end{array}$

$\begin{array}{lll}3.8 & 0.02 & \text { No } \\ 3.8 & 0.01 & \text { No } \\ 3.8 & 0.03 & \text { No } \\ 3.7 & 0.03 & \text { No }\end{array}$

$\begin{array}{lll}3.7 & 0.03 & \text { No } \\ 3.7 & 0.04 & \text { No }\end{array}$

$\begin{array}{lll}3.7 & 0.04 & \text { No } \\ 3.6 & 0.01 & \text { No } \\ 3.5 & 0.05 & \text { No }\end{array}$

$\begin{array}{lll}3.4 & 0.02 & \text { No }\end{array}$

$\begin{array}{lll}3.4 & 0.03 & \text { No } \\ 3.4 & 0.001 & \text { No }\end{array}$

$\begin{array}{lll}3.4 & 0.001 & \text { No }\end{array}$

$\begin{array}{lll}3.3 & 0.05 & \text { No } \\ 3.2 & 0.02 & \text { No }\end{array}$

$\begin{array}{lll}3.2 & 0.02 & \text { No } \\ 3.2 & 0.04 & \text { No }\end{array}$

$\begin{array}{lll}3.2 & 0.04 & \text { No } \\ 3.1 & 0.05 & \text { No }\end{array}$

\begin{tabular}{lll}
3.1 & 0.05 & No \\
3.1 & 0.05 & No \\
3.1 & 0.05 & No \\
\hline 3.1 & 0.05 & No
\end{tabular}

$\begin{array}{lll}3.1 & 0.05 & \text { No } \\ 3.1 & 0.05 & \text { No } \\ 3.0 & 0.01 & \text { No }\end{array}$

\begin{tabular}{llll}
\hline AF017175 & 2.9 & 0.02 & No \\
\hline AF 038848 & 2.9 & 0.01 & No
\end{tabular}

$\begin{array}{llll}\mathrm{AF} 038848 & 2.9 & 0.03 & \text { No }\end{array}$

$\begin{array}{llll}\mathrm{AF} 038848 & 2.9 & 0.03 & \text { No } \\ \mathrm{AB} 025405 & 2.9 & 0.02 & \text { No }\end{array}$

$\begin{array}{llll}\mathrm{AB} 025405 & 2.9 & 0.02 & \text { No }\end{array}$

$\begin{array}{llll}\mathrm{X} 76772 & 2.9 & 0.01 & \text { No } \\ \text { AF030343 } & 2.8 & 0.01 & \text { No }\end{array}$

$\begin{array}{llll}\text { AF083464 } & 2.8 & 0.01 & \text { No } \\ \end{array}$ 
Name
Function
GenBank

Accession
Fold-difference in
expression

P-value ${ }^{\text {a }}$
Previously described role in reproduction? ${ }^{\text {b }}$

Genes with decreased expression as germ cells progress from mitosis to the onset of meiosis (continued)

\begin{tabular}{|c|c|c|c|c|c|c|}
\hline DEAD box polypeptide 6 & Ddx6 & RNA helicase & AF038995 & 2.7 & 0.01 & No \\
\hline Nucleolin & $\mathrm{Ncl}$ & Transcription & X07699 & 2.7 & 0.001 & No \\
\hline Ribosomal protein S8 & Rps8 & Biosynthesis & X73829 & 2.6 & 0.001 & No \\
\hline Metallothionein 1 & Mt1 & Stress response & V00835 & 2.6 & 0.05 & No \\
\hline CD98 antigen & $\mathrm{Cd} 98$ & Immune response & $\mathrm{AB} 017189$ & 2.6 & 0.02 & No \\
\hline Actin, alpha 2, smooth muscle & Acta2 & Cytoskeletal element & X13297 & 2.5 & 0.004 & No \\
\hline Calnexin & Canx & Protein modification & L18888 & 2.5 & 0.04 & No \\
\hline Ribosomal protein S6 kinase 3 & Rps6ka2 & Biosynthesis & AJ131021 & 2.4 & 0.03 & No \\
\hline JTB & $\mathrm{Jtb}$ & Misc. & $\mathrm{AB} 016490$ & 2.4 & 0.03 & No \\
\hline Bat-4 & Bat4 & Unknown & L76155 & 2.4 & 0.02 & No \\
\hline Ribosomal protein S4, X-linked & Rps4x & Biosynthesis & M73436 & 2.3 & 0.001 & No \\
\hline Cyclin T1 & Cent1 & Cell cycle & AF095640 & 2.1 & 0.02 & No \\
\hline Ribosomal protein L19 & Rpl19 & Biosynthesis & M62952 & 2.1 & 0.03 & No \\
\hline Procollagen, type VI, alpha 1 & Col6a1 & Cell adhesion & X66405 & 2.1 & 0.03 & No \\
\hline Lymphocyte antigen 6 locus $\mathrm{E}$ & Ly6e & Immune response & U47737 & 2.1 & 0.03 & No \\
\hline Golgi autoantigen a5 & Golga5 & Growth regulation & $\mathrm{AB} 016784$ & 2.0 & 0.03 & No \\
\hline Ornithine decarboxylase antizyme & Oaz1 & Metabolism & U52823 & 2.0 & 0.005 & No \\
\hline Dystroglycan 1 & Dag1 & Cytoskeletal element & U43512 & 1.9 & 0.04 & No \\
\hline Antigen identified by monoclonal antibodies 4F2 & $4 \mathrm{~F} 2$ & Unknown & X14309 & 1.9 & 0.01 & No \\
\hline CD-1 cardiac troponin I & Tnni3 & Cytoskeletal element & U09181 & 1.8 & 0.03 & No \\
\hline
\end{tabular}

a Student's t-test p-values Ś 0.05 indicate significant differences in expression across time points (see Materials and Methods in Chapter 4)

${ }^{\mathrm{b}} \mathrm{Genes}$ with described roles in germ cell development or differentiation, meiosis, spermatogenesis, or fertilization 


\section{APPENDIX C}

Unannotated sequences with significant expression differences during the first wave of spermatogenesis in the prepubertal mouse 


\title{
Complete list of unnannotated sequences with differential expression during spermatogenesis in the prepubertal mouse
}

\author{
Unannotated sequences showing differential expression between spermatogonial mitosis and \\ preleptotene
}

\begin{tabular}{|c|c|c|c|c|c|}
\hline \multirow{2}{*}{$\begin{array}{c}\text { GenBank } \\
\text { Accession } \\
\text { ID }\end{array}$} & \multicolumn{2}{|c|}{$\begin{array}{c}\text { Preleptotene / Spermatogonial } \\
\text { Mitosis }\end{array}$} & \multirow{2}{*}{$\begin{array}{c}\text { GenBank } \\
\text { Accession } \\
\text { ID }\end{array}$} & \multicolumn{2}{|c|}{$\begin{array}{c}\text { Preleptotene / } \\
\text { Spermatogonial Mitosis }\end{array}$} \\
\hline & Ratio $^{a}$ & P-value ${ }^{b}$ & & Ratio $^{a}$ & P-value ${ }^{b}$ \\
\hline C81612 & 185.0 & 0.04 & AW125224 & -1.9 & 0.05 \\
\hline AW123801 & 63.1 & 0.03 & AI835883 & -2.0 & 0.03 \\
\hline AI451558 & 45.4 & 0.05 & AI847904 & -2.0 & 0.01 \\
\hline C79052 & 36.6 & 0.04 & AW124711 & -2.0 & 0.05 \\
\hline AI451008 & 34.5 & 0.04 & AI839770 & -2.1 & 0.05 \\
\hline AI853703 & 26.8 & 0.02 & AI463490 & -2.1 & 0.03 \\
\hline AI837621 & 18.3 & 0.02 & AI552528 & -2.1 & 0.05 \\
\hline AW048038 & 18.1 & 0.001 & AI854432 & -2.2 & 0.05 \\
\hline AI324972 & 14.1 & 0.02 & AW122284 & -2.3 & 0.003 \\
\hline C80919 & 11.0 & 0.02 & AA388099 & -2.3 & 0.02 \\
\hline AI197161 & 10.3 & 0.01 & AI842095 & -2.3 & 0.01 \\
\hline AI183202 & 7.7 & 0.03 & AI841629 & -2.4 & 0.05 \\
\hline AW121930 & 5.6 & 0.04 & AW061222 & -2.4 & 0.02 \\
\hline AI843895 & 5.3 & 0.03 & AI847269 & -2.5 & 0.03 \\
\hline AF045953 & 5.1 & 0.02 & AI854771 & -2.5 & 0.03 \\
\hline AI846484 & 4.7 & 0.01 & AW123032 & -2.5 & 0.05 \\
\hline AW046194 & 3.9 & 0.01 & AI854624 & -2.5 & 0.05 \\
\hline AA986782 & 3.6 & 0.02 & AI255450 & -2.5 & 0.01 \\
\hline AA266298 & 3.0 & 0.0004 & AA822413 & -2.6 & 0.01 \\
\hline AI842066 & 2.8 & 0.04 & AW049194 & -2.6 & 0.03 \\
\hline AW125669 & 2.6 & 0.02 & AI843895 & -2.6 & 0.04 \\
\hline AI842066 & 2.6 & 0.05 & AA760073 & -2.6 & 0.04 \\
\hline C76063 & 2.5 & 0.004 & AI843655 & -2.7 & 0.04 \\
\hline AW048944 & 2.5 & 0.05 & AA879764 & -2.7 & 0.04 \\
\hline AI892206 & 2.4 & 0.01 & AW123953 & -2.7 & 0.04 \\
\hline AW047476 & 2.4 & 0.04 & AW050353 & -2.8 & 0.03 \\
\hline AA684456 & 2.4 & 0.01 & AW122615 & -2.8 & 0.04 \\
\hline AW124681 & 2.3 & 0.04 & AI843655 & -2.8 & 0.05 \\
\hline AW124735 & 2.1 & 0.02 & AI852808 & -2.8 & 0.04 \\
\hline C77386 & 2.0 & 0.04 & AI851539 & -2.9 & 0.04 \\
\hline AI842259 & 1.9 & 0.01 & AI843682 & -3.0 & 0.02 \\
\hline AI843417 & -1.8 & 0.05 & AI844853 & -3.0 & 0.05 \\
\hline AW125739 & -1.8 & 0.03 & AI847904 & -3.0 & 0.02 \\
\hline L29441 & -1.8 & 0.03 & AA895984 & -3.1 & 0.02 \\
\hline AI647612 & -1.8 & 0.05 & AI851218 & -3.1 & 0.05 \\
\hline AW121892 & -1.8 & 0.02 & AI851046 & -3.1 & 0.03 \\
\hline AI462105 & -1.9 & 0.02 & AA919208 & -3.2 & 0.01 \\
\hline
\end{tabular}


Unannotated sequences showing differential expression between spermatogonial mitosis and preleptotene (continued)

\begin{tabular}{|c|c|c|c|c|c|}
\hline \multirow{2}{*}{$\begin{array}{c}\text { GenBank } \\
\text { Accession } \\
\text { ID }\end{array}$} & \multicolumn{2}{|c|}{$\begin{array}{c}\text { Preleptotene / Spermatogonial } \\
\text { Mitosis }\end{array}$} & \multirow{2}{*}{$\begin{array}{c}\text { GenBank } \\
\text { Accession } \\
\text { ID }\end{array}$} & \multicolumn{2}{|c|}{$\begin{array}{c}\text { Preleptotene / } \\
\text { Spermatogonial Mitosis }\end{array}$} \\
\hline & Ratio $^{\mathrm{a}}$ & P-value $^{\mathrm{b}}$ & & Ratio $^{a}$ & P-value \\
\hline AI845182 & -3.2 & 0.03 & AA655199 & -4.7 & 0.02 \\
\hline AW050086 & -3.2 & 0.03 & AA675468 & -4.8 & 0.02 \\
\hline AA688938 & -3.3 & 0.02 & AW046443 & -4.8 & 0.01 \\
\hline AI846628 & -3.3 & 0.03 & AI836686 & -4.9 & 0.03 \\
\hline AW048038 & -3.3 & 0.05 & AA612483 & -4.9 & 0.004 \\
\hline AW045665 & -3.3 & 0.04 & AI844011 & -4.9 & 0.01 \\
\hline AI851237 & -3.3 & 0.02 & AW050305 & -4.9 & 0.01 \\
\hline AI839988 & -3.3 & 0.05 & AI845882 & -5.0 & 0.02 \\
\hline AI852340 & -3.4 & 0.04 & AA596710 & -5.0 & 0.05 \\
\hline AW124044 & -3.4 & 0.04 & AI846127 & -5.0 & 0.03 \\
\hline AI854043 & -3.4 & 0.02 & AA165759 & -5.1 & 0.05 \\
\hline AW048272 & -3.5 & 0.01 & AI845580 & -5.1 & 0.01 \\
\hline AW124187 & -3.5 & 0.03 & AW045481 & -5.3 & 0.03 \\
\hline C88243 & -3.7 & 0.01 & AI842524 & -5.4 & 0.02 \\
\hline AI852457 & -3.7 & 0.04 & AI851356 & -5.5 & 0.001 \\
\hline AA967263 & -3.8 & 0.02 & AI853331 & -5.5 & 0.04 \\
\hline AW227778 & -3.8 & 0.03 & AI843586 & -5.6 & 0.02 \\
\hline AI840579 & -3.8 & 0.01 & AW125634 & -5.6 & 0.004 \\
\hline AI843679 & -3.9 & 0.02 & AW121930 & -5.7 & 0.04 \\
\hline AW046793 & -3.9 & 0.01 & AW122551 & -5.7 & 0.004 \\
\hline AI840267 & -3.9 & 0.04 & AI850356 & -5.7 & 0.05 \\
\hline AI843709 & -3.9 & 0.002 & AI851160 & -5.9 & 0.01 \\
\hline AW061255 & -3.9 & 0.05 & AW050133 & -5.9 & 0.01 \\
\hline AA709672 & -4.0 & 0.01 & AI846078 & -5.9 & 0.02 \\
\hline AI843335 & -4.0 & 0.01 & AC002397 & -6.2 & 0.002 \\
\hline AA122714 & -4.1 & 0.03 & AI838398 & -6.4 & 0.05 \\
\hline AI853269 & -4.1 & 0.02 & AI854771 & -6.4 & 0.01 \\
\hline AW047926 & -4.1 & 0.02 & AI849180 & -6.4 & 0.05 \\
\hline AW122935 & -4.2 & 0.01 & AW124933 & -6.4 & 0.01 \\
\hline AI851542 & -4.2 & 0.05 & AW046273 & -6.4 & 0.002 \\
\hline AI848471 & -4.3 & 0.04 & AA615161 & -6.5 & 0.05 \\
\hline AI851441 & -4.3 & 0.01 & AW210320 & -6.6 & 0.02 \\
\hline AI841629 & -4.4 & 0.02 & AW121162 & -6.6 & 0.03 \\
\hline AW 124778 & -4.4 & 0.02 & AI853331 & -6.9 & 0.04 \\
\hline AI846396 & -4.4 & 0.02 & AI414051 & -7.2 & 0.001 \\
\hline AW123802 & -4.4 & 0.04 & AA823653 & -7.3 & 0.03 \\
\hline AA693125 & -4.4 & 0.03 & AW124920 & -7.4 & 0.01 \\
\hline AW048347 & -4.4 & 0.04 & AW 125420 & -7.4 & 0.04 \\
\hline AI849271 & -4.4 & 0.004 & AI846078 & -7.5 & 0.05 \\
\hline AI153693 & -4.5 & 0.01 & AW124582 & -7.5 & 0.02 \\
\hline AA285446 & -4.5 & 0.05 & AA879709 & -8.0 & 0.01 \\
\hline AA755260 & -4.6 & 0.04 & AW045481 & -8.0 & 0.03 \\
\hline AA690091 & -4.6 & 0.02 & AW045710 & -8.1 & 0.01 \\
\hline AW124194 & -4.6 & 0.01 & AI847926 & -8.1 & 0.05 \\
\hline
\end{tabular}

${ }^{a}$ Fold difference in expression for preleptotene vs. spermatogonial mitosis; Negative numbers indicate decreased expression as germ cells differentiate

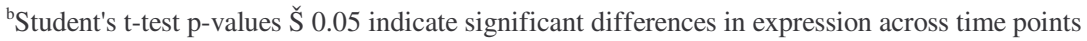


Unannotated sequences showing differential expression between spermatogonial mitosis and preleptotene (continued)

\begin{tabular}{|c|c|c|c|c|c|}
\hline \multirow{2}{*}{$\begin{array}{c}\text { GenBank } \\
\text { Accession } \\
\text { ID }\end{array}$} & \multicolumn{2}{|c|}{$\begin{array}{c}\text { Preleptotene / Spermatogonial } \\
\text { Mitosis }\end{array}$} & \multirow{2}{*}{$\begin{array}{c}\text { GenBank } \\
\text { Accession } \\
\text { ID }\end{array}$} & \multicolumn{2}{|c|}{$\begin{array}{l}\text { Preleptotene / } \\
\text { Spermatogonial Mitosis }\end{array}$} \\
\hline & Ratio $^{a}$ & P-value ${ }^{b}$ & & Ratio $^{a}$ & P-value ${ }^{b}$ \\
\hline AW060819 & -8.3 & 0.001 & C80836 & -16.6 & 0.02 \\
\hline AI844089 & -8.6 & 0.03 & AI152779 & -16.6 & 0.04 \\
\hline AI839286 & -8.7 & 0.001 & AW212479 & -16.8 & 0.01 \\
\hline AA796831 & -8.8 & 0.05 & AI839681 & -18.1 & 0.03 \\
\hline AW121136 & -8.8 & 0.02 & AW122530 & -18.1 & 0.03 \\
\hline AI838398 & -8.9 & 0.01 & AI845581 & -18.2 & 0.002 \\
\hline L29441 & -8.9 & 0.04 & AW124401 & -19.6 & 0.01 \\
\hline AI838053 & -9.0 & 0.01 & AA866668 & -19.9 & 0.01 \\
\hline AW259199 & -9.1 & 0.04 & AW050287 & -21.3 & 0.04 \\
\hline AI838915 & -9.2 & 0.01 & AI647493 & -22.6 & 0.05 \\
\hline AW121767 & -9.2 & 0.01 & AW125224 & -24.1 & 0.04 \\
\hline AI788543 & -9.4 & 0.02 & U38981 & -24.6 & 0.01 \\
\hline AI845593 & -9.6 & 0.05 & AI835592 & -27.2 & 0.02 \\
\hline AI847314 & -10.0 & 0.003 & AA615100 & -27.2 & 0.002 \\
\hline AI847564 & -10.2 & 0.05 & AW120691 & -30.6 & 0.04 \\
\hline AV380793 & -10.3 & 0.04 & AI853173 & -31.9 & 0.04 \\
\hline AA517835 & -10.8 & 0.02 & AI115399 & -34.0 & 0.01 \\
\hline AI843709 & -10.8 & 0.05 & AW125649 & -34.4 & 0.04 \\
\hline AA657164 & -11.1 & 0.04 & AW227345 & -34.8 & 0.01 \\
\hline AI845165 & -11.3 & 0.02 & AI843884 & -35.7 & 0.01 \\
\hline AI006319 & -11.5 & 0.04 & AW060257 & -37.1 & 0.04 \\
\hline AW123952 & -11.6 & 0.01 & AA285446 & -37.7 & 0.05 \\
\hline AW123801 & -11.7 & 0.05 & AW060324 & -38.3 & 0.02 \\
\hline AA388099 & -12.5 & 0.05 & AA693246 & -39.3 & 0.01 \\
\hline AW123880 & -12.6 & 0.04 & AI846708 & -41.3 & 0.04 \\
\hline AI644179 & -12.8 & 0.02 & AW046496 & -43.5 & 0.03 \\
\hline AI747444 & -12.8 & 0.05 & AW049122 & -44.0 & 0.003 \\
\hline AA624336 & -13.1 & 0.01 & AW120683 & -46.1 & 0.0004 \\
\hline AI849620 & -13.3 & 0.03 & AW046038 & -59.5 & 0.05 \\
\hline AA657164 & -13.4 & 0.04 & AW120986 & -60.0 & 0.05 \\
\hline AA940430 & -13.5 & 0.03 & AI843074 & -67.7 & 0.02 \\
\hline AW120557 & -13.6 & 0.001 & AW061222 & -75.1 & 0.003 \\
\hline AW047012 & -14.2 & 0.01 & AI846773 & -82.4 & 0.03 \\
\hline AW213777 & -14.6 & 0.05 & AW124874 & -104.4 & 0.05 \\
\hline AW124735 & -14.7 & 0.01 & AI847972 & -107.3 & 0.02 \\
\hline AI849280 & -14.7 & 0.03 & AI844737 & -108.8 & 0.04 \\
\hline AI842095 & -15.4 & 0.01 & AI843401 & -132.2 & 0.02 \\
\hline AI060709 & -15.7 & 0.03 & AW120739 & -132.9 & 0.04 \\
\hline AW125880 & -16.1 & 0.05 & AI843417 & -146.5 & 0.004 \\
\hline AI847056 & -16.2 & 0.03 & & & \\
\hline
\end{tabular}

${ }^{a}$ Fold difference in expression for preleptotene vs. spermatogonial mitosis; Negative numbers indicate decreased expression a: germ cells differentiate

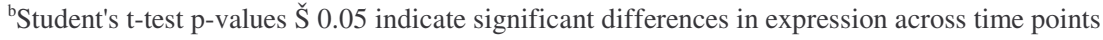


Unannotated sequences showing differential expression between preleptotene and pachytene

\begin{tabular}{|c|c|c|c|c|c|}
\hline \multirow{2}{*}{$\begin{array}{c}\text { GenBank } \\
\text { Accession } \\
\text { ID }\end{array}$} & \multicolumn{2}{|c|}{ Pachytene / Preleptotene } & \multirow{2}{*}{$\begin{array}{c}\text { GenBank } \\
\text { Accession } \\
\text { ID }\end{array}$} & \multicolumn{2}{|c|}{ Pachytene / Preleptotene } \\
\hline & Ratio $^{a}$ & P-value ${ }^{b}$ & & Ratio $^{\mathrm{a}}$ & P-value ${ }^{b}$ \\
\hline AI852571 & 34.8 & 0.04 & AW125043 & -5.4 & 0.03 \\
\hline AW124239 & 7.0 & 0.04 & AI006228 & -6.7 & 0.05 \\
\hline AW060971 & 6.5 & 0.04 & AI850793 & -8.7 & 0.04 \\
\hline AI842544 & 6.2 & 0.04 & AW046661 & -11.4 & 0.05 \\
\hline AI120844 & 5.9 & 0.04 & AI851220 & -12.1 & 0.01 \\
\hline AA921481 & 5.0 & 0.01 & AI195392 & -14.8 & 0.05 \\
\hline AW120890 & 4.5 & 0.002 & AA763918 & -24.5 & 0.03 \\
\hline AW049598 & 3.3 & 0.05 & AI891475 & -30.7 & 0.05 \\
\hline AW049513 & 2.5 & 0.01 & & & \\
\hline AI847766 & 2.5 & 0.02 & & & \\
\hline AA989957 & 2.5 & 0.03 & & & \\
\hline AI594427 & 2.4 & 0.002 & & & \\
\hline AW124128 & 2.2 & 0.02 & & & \\
\hline AA839465 & 2.1 & 0.04 & & & \\
\hline AI413179 & 1.9 & 0.004 & & & \\
\hline AI842603 & 1.9 & 0.05 & & & \\
\hline AW124656 & -1.8 & 0.03 & & & \\
\hline AI843396 & -1.8 & 0.02 & & & \\
\hline AI851081 & -1.9 & 0.01 & & & \\
\hline AW120746 & -2.0 & 0.03 & & & \\
\hline AI839690 & -2.0 & 0.05 & & & \\
\hline AI843802 & -2.1 & 0.01 & & & \\
\hline AI838859 & -2.2 & 0.04 & & & \\
\hline AI837107 & -2.3 & 0.01 & & & \\
\hline AA981154 & -2.3 & 0.02 & & & \\
\hline AI226368 & -2.3 & 0.04 & & & \\
\hline AI836182 & -2.4 & 0.01 & & & \\
\hline AI844939 & -2.5 & 0.04 & & & \\
\hline AU044050 & -2.5 & 0.001 & & & \\
\hline AA266467 & -2.6 & 0.01 & & & \\
\hline AI848623 & -2.9 & 0.01 & & & \\
\hline AW 125218 & -2.9 & 0.005 & & & \\
\hline AA866768 & -2.9 & 0.01 & & & \\
\hline AI848671 & -3.6 & 0.002 & & & \\
\hline AW124926 & -4.2 & 0.04 & & & \\
\hline AI852665 & -5.0 & 0.03 & & & \\
\hline AA409481 & -5.2 & 0.04 & & & \\
\hline
\end{tabular}


Unannotated sequences with differential expression between spermatogonial mitosis and preleptotene and also between preleptotene and pachytene

\begin{tabular}{|c|c|c|c|c|c|}
\hline \multirow[t]{2}{*}{$\begin{array}{c}\text { GenBank } \\
\text { Accession ID }\end{array}$} & \multicolumn{2}{|c|}{$\begin{array}{c}\text { Preleptotene / } \\
\text { Spermatogonial } \\
\text { Mitosis }\end{array}$} & \multicolumn{2}{|c|}{$\begin{array}{l}\text { Pachytene / } \\
\text { Preleptotene }\end{array}$} & \multirow[t]{2}{*}{$\begin{array}{c}\text { Expression } \\
\text { Pattern }^{c}\end{array}$} \\
\hline & Ratio $^{a}$ & P-value ${ }^{b}$ & Ratio $^{a}$ & P-value ${ }^{\mathrm{b}}$ & \\
\hline AI848888 & 6.4 & 0.02 & -5.0 & 0.02 & ID \\
\hline AW047237 & 3.7 & 0.04 & -8.5 & 0.04 & ID \\
\hline AI854214 & -1.8 & 0.05 & -2.6 & 0.05 & DD \\
\hline AI854144 & -2.4 & 0.04 & -1.8 & 0.01 & DD \\
\hline AI837369 & -2.4 & 0.02 & 2.1 & 0.03 & DI \\
\hline AI836082 & -2.9 & 0.03 & -2.2 & 0.02 & DD \\
\hline AI849082 & -3.0 & 0.02 & 3.0 & 0.01 & DI \\
\hline AW124044 & -3.0 & 0.02 & 2.5 & 0.03 & DI \\
\hline AI848968 & -3.1 & 0.005 & 2.3 & 0.01 & DI \\
\hline AW122609 & -3.4 & 0.01 & -3.2 & 0.04 & DD \\
\hline AW049326 & -3.4 & 0.001 & 2.2 & 0.05 & DI \\
\hline AI847054 & -3.7 & 0.04 & -4.2 & 0.02 & DD \\
\hline AW125431 & -4.1 & 0.03 & -1.8 & 0.03 & DD \\
\hline AW049897 & -4.5 & 0.02 & 4.8 & 0.01 & DI \\
\hline AI415065 & -4.8 & 0.001 & 1.8 & 0.01 & DI \\
\hline AI840458 & -5.2 & 0.03 & 2.3 & 0.05 & DI \\
\hline AI850953 & -5.5 & 0.03 & 1.9 & 0.02 & DI \\
\hline AW060843 & -6.2 & 0.04 & 1.7 & 0.05 & DI \\
\hline AI843650 & -6.7 & 0.01 & -2.8 & 0.02 & DD \\
\hline AI844549 & -6.8 & 0.04 & 2.2 & 0.05 & DI \\
\hline AI837302 & -13.3 & 0.04 & -3.0 & 0.01 & DD \\
\hline AW047625 & -20.60 & 0.01 & 3.2 & 0.04 & DI \\
\hline AI467390 & -23.50 & 0.02 & -3.8 & 0.03 & DD \\
\hline AW213883 & -28.40 & 0.002 & -2.2 & 0.05 & DD \\
\hline AA794350 & -39.60 & 0.02 & 9.6 & 0.001 & DI \\
\hline AW046708 & -46.50 & 0.002 & 5.8 & 0.01 & DI \\
\hline AI836446 & -81.20 & 0.001 & 2.4 & 0.03 & DI \\
\hline
\end{tabular}

${ }^{\text {a }}$ Fold difference in expression for preleptotene vs. spermatogonial mitosis and pachytene vs. preleptotene; Negative numbers indicate decreased expression as germ cells differentiate

${ }^{\text {b} S t u d e n t ' s ~ t-t e s t ~ p-v a l u e s ~} \breve{S} 0.05$ indicate significant differences in expression across time points

${ }^{c} \mathrm{DD}=$ Decreasesd expression from spermatogonial mitosis to preleptotene and decreased expression from preleptotene to pachytene; DI = Decreasesd expression from spermatogonial mitosis to preleptotene and increased expression from preleptotene to pachytene; ID = Increasesd expression fron spermatogonial mitosis to preleptotene and decreased expression from preleptotene to pachytene 


\section{APPENDIX D}

Functional genomics-related websites 
Websites utilized for functional genomics-related research

\section{Website Name}

National Center for Biotechnology Information (NCBI) PubMed

Entrez Nucleotide Query

UniGene

Basic Local Alignment Search Tool (BLAST)

CloneRanger

I.M.A.G.E. Consortium at LLNL

Large-Scale Gene Expression \& Microarray Resources

Affymetrix

Mouse Genome Informatics: Gene Expression

Human Gene Nomenclature Database

Spidey

BLAST 2 Sequences

CLUSFAVOR

MicroArray Explore

Gene Microarray Pathway Profiler (GenMAPP)

Gene Ontology Project

Genomatix PromoterInspector

Methods for Affymetrix Oligonucleotide Arrays

National Library of Medicine Gateway Search
URL

http://www.ncbi.nlm.nih.gov/

http://www.ncbi.nlm.nih.gov/entrez/query.fcgi

http://www.ncbi.nlm.nih.gov/Entrez/nucleotide.html

http://www.ncbi.nlm.nih.gov/UniGene/

http://www.ncbi.nlm.nih.gov/BLAST/

https://www.resgen.com/resources/apps/cloneranger/index.php3

http://image.llnl.gov/

http://industry.ebi.ac.uk/ alan/MicroArray/

http://www.affymetrix.com/index.affx

http://www.informatics.jax.org/menus/expression_menu.shtml

http://www.gene.ucl.ac.uk/cgi-bin/nomenclature/searchgenes.pl http://www.ncbi.nlm.nih.gov/IEB/Research/Ostell/Spidey/

http://www.ncbi.nlm.nih.gov/gorf/bl2.html

http://mbcr.bcm.tmc.edu/genepi/home.html

http://www.lecb.ncifcrf.gov/MAExplorer/

http://www.genMAPP.org/

http://www.geneontology.org

http://www.genomatix.de/cgi-bin/promoterinspector/promoterinspector.pl http://biosun01.biostat.jhsph.edu/ ririzarr/Raffy

http://gateway.nlm.nih.gov/gw/Cmd

\section{Website Description}

Public databases for biological research

Searchable scientific publication database

Searchable nucleotide sequence database

Searchable non-redundant gene cluster database

Compares DNA and/or protein sequences

Searchable cDNA clone database

Searchable cDNA clone database

Non-commercial microarray-related resources

Commercial GeneChip resource

Searchable gene expression databases

Searchable database for obtaining gene symbols

Aligns mRNA and genomic sequences

Aligns 2 user-selected nucleotide sequences against each other

Unsupervised hierarchial cluster and principal component analyses

Analyzes the expression of individual genes and gene families; Compares expression patterns; Provides access to other genomic databases

Maps gene expression data to biological pathways

Searchable database of molecular functions, biological processes, and cellular components that are similar across organisms

Predicts promoter regions in mammalian genomic sequences Interactive Affymetrix oligonucleotide array data analysis Simultaneously searches multiple databases at the U.S. National Library of Medicine 


\title{
APPENDIX E
}

\author{
Curriculum Vitae
}




\section{Lisa Tomascik-Cheeseman \\ 5381 Moonflower Way \\ Livermore, CA 94550 \\ (925)456-5354}

\section{Education}

\section{West Virginia University, Morgantown, WV}

Graduate student in the interdisciplinary program of Genetics and Developmental Biology (Aug. 1995 - Present)

Passed written and oral comprehensive qualifying examinations for Ph.D. degree candidacy (Sept. 1997)

Ph.D. dissertation research in the Biology and Biotechnology Research Program at LLNL in the laboratory of Dr. A.J. Wyrobek (Dec. 1997 - Present)

\section{Delaware Valley College of Science and Agriculture, Doylestown, PA}

B.S. in Biology with Chemistry minor (May 1995)

\section{Work Experience}

7/98-Present: Life Sciences Scholar, Genetic Damage and Disease Team, Biology and Biotechnology Research Program, Lawrence Livermore National Laboratory, Livermore, CA.

Characterize the baseline expression of genes essential for DNA repair, stress response, cell cycle regulation, apoptosis, signal transduction and chromosome segregation in various mouse and human tissues using cDNA microarrays.

Develop a mouse model to investigate the molecular mechanisms of meiosis and the genetic causes of male infertility.

Determine the temporal expression of DNA repair, chromosome segregation and recombination-associated genes during the first wave of mouse spermatogenesis.

Develop and optimize cDNA microarray protocols for RNA isolation, probe labeling and hybridization in order to maximize hybridization specificity and sensitivity.

Optimize microarray slide chemistries to maximize binding of target cDNA and to minimize background fluorescence during image analysis. 
12/97-7/98: Participating Guest, Biology and Biotechnology Research Program, Genetic Damage and Disease Team, Lawrence Livermore National Laboratory, Livermore, CA.

Conducted research on the molecular mechanisms of paternally transmitted genetic disease.

Investigated the role of centromere protein B (CENP-B) in male meiotic chromosome segregation using multicolor fluorescence in situ hybridization (FISH).

Developed and applied several multicolor FISH assays to assess the frequency of autosomal and sex-chromosomal non-disjunction in sperm from a father of multiple aneuploid pregnancies.

Used immunochemistry to identify protamine expression in specific cell types in the mouse testis.

Performed small animal surgery.

8/95-5/97: Graduate Teaching Assistant, Department of Biology, West Virginia University, Morgantown, WV.

Taught 4-5 undergraduate general biology laboratory classes per semester.

Developed lectures to complement every laboratory exercise.

Supervised independent student research projects.

Promoted critical thinking in a cooperative learning environment.

Evaluated student performance based on independent research and examinations.

\section{Research Articles}

Tomascik-Cheeseman LM, Coleman MA, Nelson DO, Kegelmeyer LM, Marchetti F, Nath J and AJ Wyrobek. 2002. Differential basal expression of genes associated with stress response, damage control and DNA repair among mouse tissues. Molecular Biology of the Cell. Submitted.

Tomascik-Cheeseman LM, Marchetti F, Lowe X, Shamanski F, Nath J and AJ Wyrobek. 2002. CENP-B is not critical for meiotic chromosome segregation in male mice. Mutation Research (513):197-203.

Kegelmeyer LM, Tomascik-Cheeseman L, Burnett MS, VanHummelen P and AJ Wyrobek. 2001. A groundtruth approach to accurate quantitation of fluorescence microarrays. Microarrays: Optical Technologies and Informatics, Proceedings of SPIE (4266):35-45. 


\section{Meeting Presentations and Published Abstracts}

Tomascik-Cheeseman LM, Marchetti F, Coleman MA, Yin E, Nath J and AJ Wyrobek. 2002. Stage-dependent transcriptional profiling of male germ cells. Environmental and Molecular Mutagenesis (39)A203.

Velazquez-Wong AC, Sloter E, Tomascik-Cheeseman LM, Araujo-Solis MA, Wyrobek AJ and F Salamanca-Gomez. 2002. Structural and numerical chromosomal abnormalities in sperm following accidental occupational exposure to ${ }^{192}$ Iridium. Environmental and Molecular Mutagenesis (39)A210.

Tomascik-Cheeseman LM, Marchetti F, Coleman MA, Yin E, Rankin K, Nath J and AJ Wyrobek. 2001. Microarray transcriptional profiling of mammalian male meiosis. American Journal of Human Genetics, 69 (4):953.

Tomascik-Cheeseman LM, Coleman MA, Marchetti F, Mascio-Kegelmyer L, Nelson D, Nath J and AJ Wyrobek. 2001. Baseline expression of DNA repair-related genes differs among healthy mouse tissues. Environmental and Molecular Mutagenesis (37)A225.

Yin E, Coleman MA, Tomascik-Cheeseman L, Mascio-Kegelmeyer L, Wyrobek AJ. 2001. Radiation-induced changes in the expression of stress response and DNA repair genes in human and mouse cells. Proceedings of the American Association for Cancer Research (42)A713.

Tomascik-Cheeseman LM, Coleman MA, Kegelmeyer LM, Marchetti F, Raja R, Nath J and AJ Wyrobek. 2000. cDNA microarray analyses reveal differential expression of DNA-repair related genes among normal tissues. American Journal of Human Genetics, 67 (4):1466.

Coleman MA, Yin E, Sorensen K, Marsh BJ, Mabery S, Tomascik-Cheeseman LM, Liu S, Gregg J, Kegelmeyer LM, Attix T, Tucker J and AJ Wyrobek. 2000. Radiation-induced changes in the expression of

stress response and DNA repair genes in human and mouse cells. American Journal of Human Genetics, 67 (4):1019.

Tomascik-Cheeseman LM, Raja R, Mabery S, Marsh B, Marchetti F, Nath J and AJ Wyrobek. 2000. Parallel expression analyses of DNA repair genes in adult mouse tissues using cDNA microarrays. Environmental and Molecular Mutagenesis, 35 (31):212.

Raja RG, Tomascik-Cheeseman LM, Pera RR and AJ Wyrobek. 2000. Representational Difference Analysis (RDA) of DNA repair genes using cDNA microarrays. Cambridge Healthtech Institute's Fourth Annual Genome 2000 Tri-Conference: Gene Functional Analysis, San Francisco, CA.

Raja RG, Kegelmeyer LM, Tomascik-Cheeseman LM, VanHummelen P, Marchetti F and AJ Wyrobek. 1999. Quantitation of cDNA expression microarrays for DNA repair and damage response genes. Proceedings of The Microarray Meeting: Technology, Application and Analysis, Nature Genetics, 70.

Tomascik-Cheeseman LM, Raja RG, Lowe X, Wilson D, Nath J and AJ Wyrobek. 1999. Parallel expression analyses of DNA repair genes in adult mouse brain and testis using cDNA microarrays. American Journal of Human Genetics, 65 (4):421. 
Tomascik-Cheeseman LM, Lowe X, Kidd S, Eskenazi B, Nath J and AJ Wyrobek. 1999. Persistence of autosomal and sex-chromosomal disomy in a father of four aneuploid pregnancies. Environmental and Molecular Mutagenesis, 33 (30):216.

\section{Honors}

Young Investigator Achievement Award, Environmental Mutagen Society, 2002

Best Student/New Investigator Presentation, $32^{\text {nd }}$ Annual Meeting of the Environmental Mutagen Society, 2001

Achievement Award, Biology \& Biotechnology Research Program at Lawrence Livermore

National Laboratory, 2001

Young Investigator Achievement Award, Environmental Mutagen Society, 2001

Student Travel Award, Environmental Mutagen Society, 2000

Student Travel Award, Environmental Mutagen Society, 1999

Cum laude graduate, Delaware Valley College of Science and Agriculture, 1995

Outstanding Senior Student in Biology, Delaware Valley College of Science and Agriculture, 1995

National Dean's List, 1994

Who's Who Among Students in American Colleges and Universities, 1994

National Student Government, 1994

Full Tuition Scholarship, Delaware Valley College of Science and Agriculture, 1991

William C. Dougherty National Scholarship, 1991

\section{Activities}

Student Committee, Environmental Mutagen Society

Education Award Subcommittee Chair, Environmental Mutagen Society

Special Interest Group on Animal Genetics/Aneuploidy/Germ Cells, Environmental Mutagen

Society

Tri-Valley Animal Rescue Foster Parent

Lawrence Livermore National Laboratory S.T.O.M.P. (Scientists of Tomorrow: Oakland

Mentoring Project) Mentor

Granada High School Supporters Club Scholarship Judge

Mervyn's Child Spree Volunteer

\section{Professional Society Memberships}

The American Society of Human Genetics

Environmental Mutagen Society

Genetic and Environmental Toxicology Association of Northern California 


\title{
APPENDIX F
}

\author{
Published research articles
}

